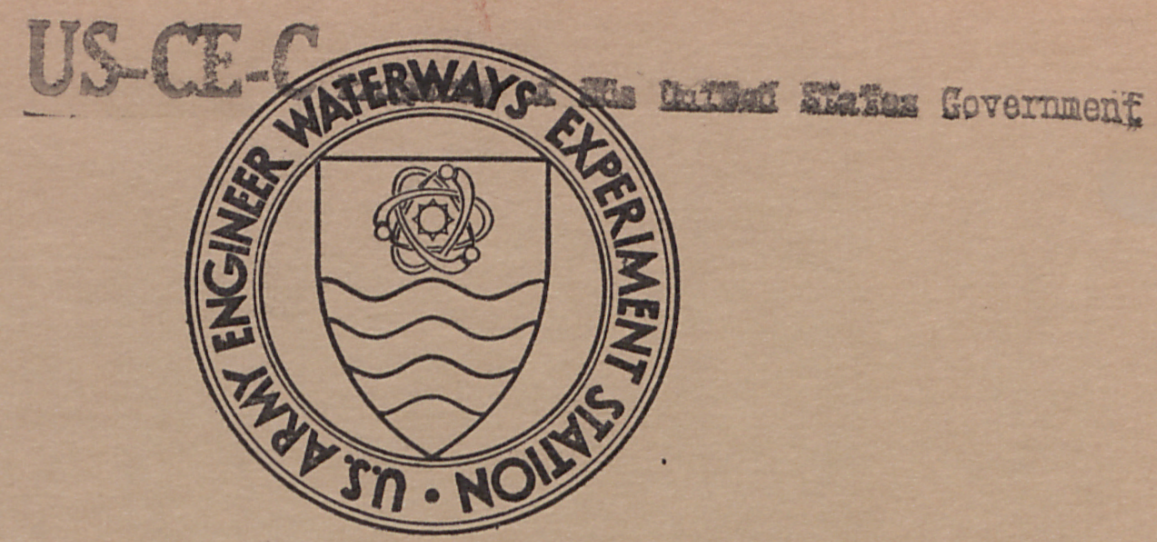

MISCELLANEOUS PAPER S-74-18

\title{
A SIMPLE ELASTIC CONSTITUTIVE EQUATION FOR GRANULAR MATERIAL
}

by

M. M. Al-Hussaini
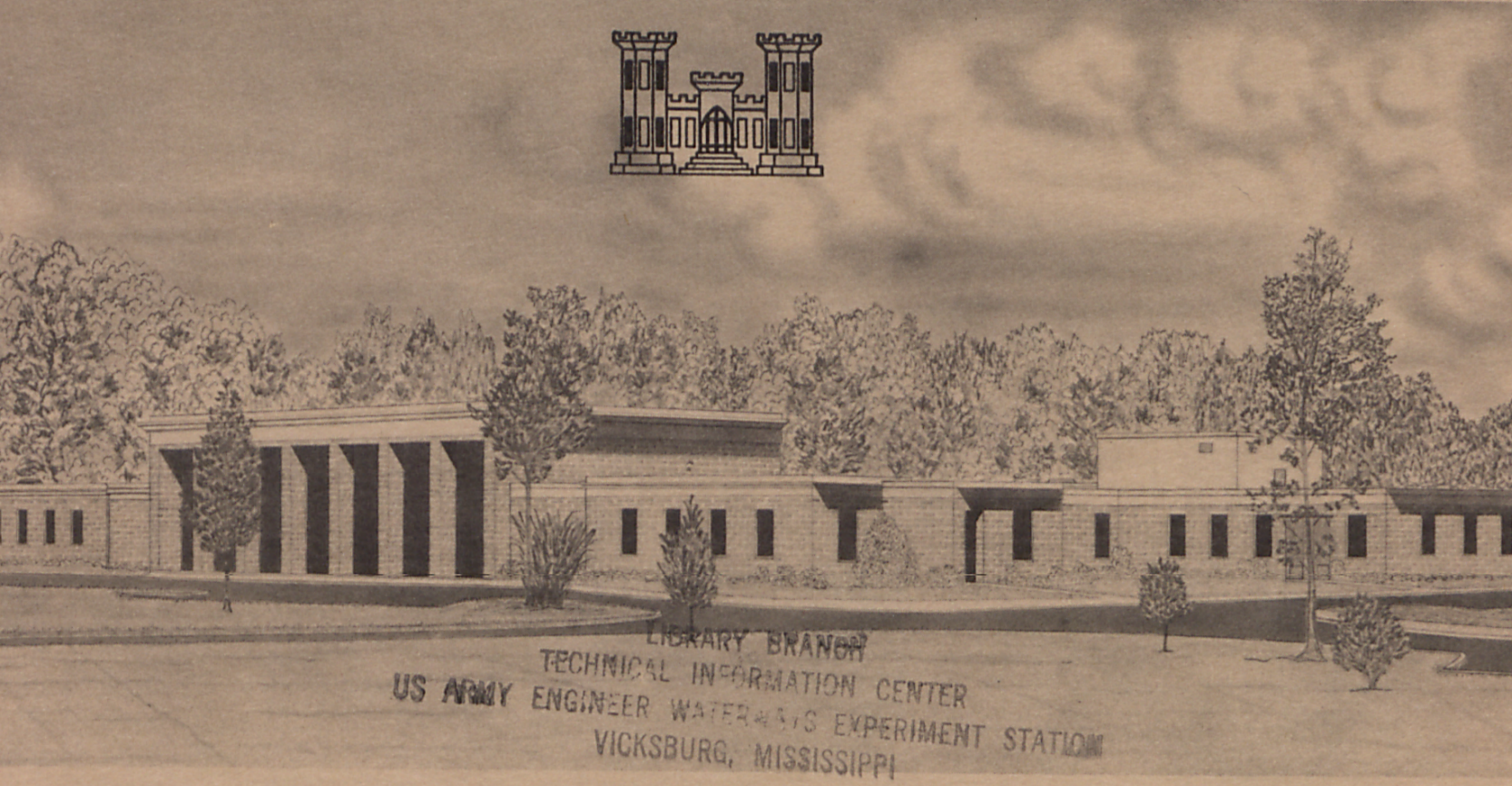

June 1974

Sponsored by Assistant Secretary of the Army (R\&D), Department of the Army

Conducted by U. S. Army Engineer Waterways Experiment Station

Soils and Pavements Laboratory

Vicksburg, Mississippi 


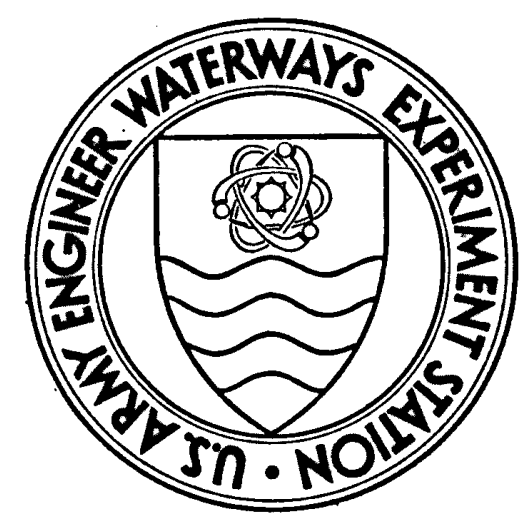

MISCELLANEOUS PAPER S-74-18

\section{A SIMPLE ELASTIC CONSTITUTIVE EQUATION FOR GRANULAR MATERIAL \\ by}

M. M. Al-Hussaini

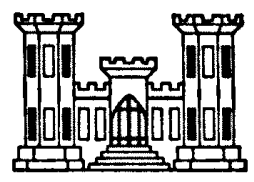

June 1974

Sponsored by Assistant Secretary of the Army (R\&D), Department of the Army Project No. 4A06IIOIA9ID

Conducted by U. S. Army Engineer Waterways Experiment Station

Soils and Pavements Laboratory

Vicksburg, Mississippi 
FOREWORD

The study reported herein was initiated by the U. S. Army Engineer Waterways Experiment Station (WES), Vicksburg, Mississippi, and was funded under Department of the Army Project No. 4A061101A9ID, "In-House Laboratory Independent Research Program (ILIR)," sponsored by the Assistant Secretary of the Army (R\&D).

This work was accomplished during the period March 1972-December 1973 under the general supervision of Dr. F. C. Townsend, Chief, Soils . Research Facility; Mr. C. L. McAnear, Chief, Soil Mechanics Division; and Mr. J. P. Sale, Chief, Soils and Pavements Laboratory, WES. This report was prepared by Dr. M. M. Al-Hussaini and was reviewed by Mr. W. C. Sherman, Jr., Chief, Earthquake Engineering and Vibrations Division, and Dr. B. Rohani of the Soll Dynamics Division prior to its publication. Useful suggestions and comments by Dr. Rohani are greatly appreciated.

Directors of WES during the conduct of the study and the preparation and publication of this report were BG E. D. Peixotto, CE, and COL G. H. Hilt, CE. Technical Director was Mr. F. R. Brown. 
FOREWORD . . . . . . . . . . . . . . . . . . . . . iil

CONVERSION FACTORS, BRITISH TO METRIC UNITS OF MEASUREMENT . • . VII SUMMARY . • . . . . . . . . . . . . . . . . . . . . ix

PART I: INTRODUCTION ...................... . . . . I

Background .. . . . . . . . . . . . . . . 1

Purpose of the Study ................... . 2

Scope of the Study . . . . . . . . . . . . . . 3

PART II: REVIEW OF ELASTIC CONSTITUTIVE MODELS . • • • . • . 4

Linear Models . . . . . . . . . . . . . . . 5

Nonlinear Models Using Functional Forms ......... . 11

Constitutive Models with Shear and Bulk Moduli . . . . . . 17

Higher Order Elastic Material Models . . . . . . . . . . 20

PART III: DEVELOPMENT OF THE CONSTITUTIVE MODEL . . . • . • • . 27

Total Strain Deformation . . . . . . . . . . . 27

The Constitutive Model . . . . . . . . . . . . . 29

PART IV: EXPERIMENTAL DETERMINATION OF MATERIAL CONSTANTS . . 38

Material Parameters $\sigma_{0}$ and $\beta$. . . . . . . 38

Material Parameters $\alpha$ and $\gamma$........... 38

Material Constant $\lambda^{\prime}$................... 39

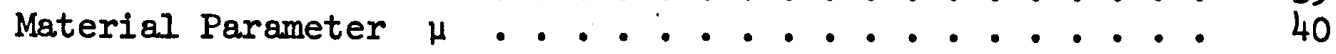

PART V: APPLICATION OF THE CONSTITUTIVE EQUATION . . . . • . 43

Hydrostatic State of Stress . . . . . . . . . . 43

Uniaxial State of Strain................ 44

Interpretation of Volumetric Deformation of Granular

Material .. . . . . . . . . . . . . 45

Cylindrical State of Strain . . . . . . . . . . . 46

Predicted and Experimental Correlation for the Cylindrical

State of Strain ................ 47

Plane Strain State.................... 48

PART VI: CONCLUSIONS AND RECOMMENDATIONS . . . . . . . . . . 49

LITERATURE CITED !. . . . . . . . . . . . . . . . . 51

TABLES 1-6

PLATES $1-35$ 
CONVERSION FACTORS, BRITISH TO METRIC UNITS OF MEASUREMENT

British units of measurement used in this report can be converted to metric' units as follows:

Multiply

pounds per square inch
By

0.6894757
To Obtain

newtons per square centimeter 
In the past or until recently the majority of stress-deformation and stability analyses have been restricted to ideal material behavior. Such idealizations in material properties and geometrical conditions may lead to divergence between observed and predicted behavior. Realistic stress and deformation analyses of homogeneous earth masses or soil-structure interaction problems using numerical techniques such as the finite element and finite difference methods require the formulation of a constitutive model for the soil and structural materials.

A literature review made in this study indicated that most procedures used in modeling soils are based on the theory of elasticity and curve fitting. (This study is limited to constitutive models which are based on theory of elasticity.) Linear, bilinear, trilinear, and hyperbolic models provide, under special conditions, good agreement between observed and predicted soil behavior. Unfortunately, these models lack sufficient experimental and theoretical verification to be qualified as constitutive models. A general constitutive model should predict or reproduce soil behavior under any state of stress and not be restricted to the state of stress from which it is derived. Constitutive models based on higher order elastic continuum are probably the only hope for generating truly representative material models. However, the procedure used in obtaining the needed parameters for such models is very difficult if not impossible unless some simplified assumptions are made.

A nonlinear elastic constitutive relationship was developed for two granular materials: crushed Napa basalt and Painted Rock Dam material. The behavior of the material was assumed to conform with Cauchy elastic material (i.e., the state of stress is only a function of the state of strain); also, the tensorial dilatancy, which contributes to volume expansion of the material, was ignored. Previous laboratory data obtained from hydrostatic compression, triaxial compression, and plane strain shear tests on both crushed Napa basalt and Painted Rock Dam material were used to obtain the needed parameters. The resulting constitutive model was used to predict the stress-strain relations for the uniaxial state of strain (i.e., $K_{0}$ tests), and the predicted curves were compared with laboratory $\mathrm{K}_{0}$ data. The results showed that there is a qualitative agreement between the data predicted by the model and those observed in the laboratory. However, the quantitative agreement between the predicted and observed data needs to be improved. 
The proposed constitutive relationship accounts for nonlinear pressure-volumetric strain behavior, nonlinear shearing stress-strain behavior, and the effect of superimposed hydrostatic pressure on the behavior of soils. The constitutive relationship, however, does not account for shear-dilatancy phenomena often observed during laboratory testing of soils. Therefore, this constitutive model should not be expected to predict the exact behavior of the material. A more complicated constitutive equation which includes tensorial nonlinearity might significantly improve the accuracy of the model. In such a case, however, more experimental work is required to evaluate the additional unknown parameters which are needed to develop the constitutive model. 
FOR GRANULAR MATERIAL

\section{PART I: INTRODUCTION}

\section{Background}

1. In the past, it has been almost impossible to perform an exact analysis for any realistic field problem in soil engineering due to the lack of high-speed computers and powerful numerical techniques. As a result, stress and deformation analyses in soil media have been restricted to ideal material properties, which are only a gross representation of actual material behavior. This idealization has not only been restricted to material behavior but also to geometric and boundary conditions. The idealization of material properties and geometrical conditions may simplify the mathematical complexity of the problem, but generally it leads to a divergence between observed and predicted soil behavior.

2. In recent years, considerable advancement to a very mature stage of development has been made in numerical stress analysis techniques such as the finite element and the finite difference methods. This advancement, plus larger and faster computers which can handle the most complex computations in soll mechanics problems, has provided research and designing engineers with powerful tools. However, no stress or deformation analysis, regardless of how intricate and theoretically exact it may be, can be useful unless a correct constitutive equation which describes the actual behavior of the material has been used in the analysis.

3. The selection of a constitutive model is somewhat easier for structural materials such as steel and concrete than for soils. In most cases, steel and concrete are assumed to be linear elastic, and the application of Iinear theories of elasticity for such materials yieldis reasonable answers for all practical purposes. However, the behavioral characteristics of soils dictate that a linear elastic assumption will 
only provide approximate solutions in representing actual material behavior. In cases in which solutions based upon theories of plasticity are used, the soil is usually assumed to be rigid plastic and its behavior is governed by a failure criterion such as Mohr's failure theory. Actually, the behavior of soils is neither linear elastic nor compatible with rigid plastic or even elastic plastic classification. The nonlinear properties of soils stem from the fact that soils are a three-phase system: solids, liquids, and gases. Their stress-strain behavior depends on many factors such as mineral composition, stress level, drainage condition, density, strain condition, etc. Therefore, any correct modeling of soil by a constitutive relation should consider most if not all the variables which affect the stress and deformation behavior of soil.

4. Modeling soil behavior in the form of a constitutive equation has been the subject of many soil mechanics publications, and the concept of a constitutive relation in its broadest sense is still in a state of flux. To date, more than 20 different models have been proposed in soil mechanics literature for soils not subjected to creep or temperature effects. These proposed models involve various forms of nonlinearity to be used for a particular problem. Review and discussion of these models are two of the objectives of this report.

\section{Purpose of the Study}

5. The initial motivation of this study was the necessity to understand the nonlinear response of solls under different stress states when subjected to monotonically increasing loads. Consequently, a comprehensive review of existing procedures published in soil mechanics literature was made with emphasis on the following three classes of constitutive models:

$$
\begin{aligned}
& \text { a. Models derived from theories of elasticity. } \\
& \text { b. Models derived from theories of plasticity. } \\
& \text { c. Hybrid models. }
\end{aligned}
$$

The ability of each model to approximate the actual stress-strain 
behavior of soil was considered; the theory and assumptions used in deriving the model were examined; and the procedures used in obtaining soil parameters from experimental data needed to formulate the model were summarized.

6. The ultimate objective of this study was to develop a constitutive relation for granular soils which would be able to predict the nonlinear soil behavior under states of stress or deformation different from those conditions from which it was derived. The model was to be based on actual laboratory tests such as plane strain, triaxial compression, and other types of tests for evaluating the needed soil parameters. The constitutive model was to be general enough to be adopted in finite element and finite difference methods of stress or deformation analyses.

\section{Scope of the Study}

7. The aforementioned objectives were achieved by using laboratory plane strain and triaxial compression test data for two granular materials, crushed Napa basalt and Painted Rock Dam material. These soils.were prepared at two relative densities: 70 and 100 percent. The description of these materials and other testing variables are presented in reports of previous studies. ${ }^{1,2}$ The testing equipment and procedures used also have been presented previously. 3,4 
8. Although the nonlinear behavior of soil has been recognized since the birth of experimental soil mechanics, the concept of linear elastic analysis has proved to be useful in the solution of many problems, particularly those involving very small deformations. The adoption of the theory of elasticity for solutions of certain classes of problems has been based primarily on practical experience in which reasonable agreement between theory and actual phenomena has been observed.

9. The simplest elastic model assumes that the soil material is linear, elastic, and isotropic, i.e., Hooke's law is valid. In this context, the stress-strain relationship for soll may be expressed by two elastic constants

$$
\begin{gathered}
\sigma_{i j}=\lambda \varepsilon_{k k} \delta_{i j}+2 G \varepsilon_{i j}, i, j, k=1,2,3 \\
\sigma_{i j}=K \varepsilon_{k k} \delta_{i j}+2 G\left(\varepsilon_{i j}-\frac{1}{3} \varepsilon_{k k} \delta_{i j}\right)
\end{gathered}
$$

where

$$
\begin{aligned}
\sigma_{i j} & =\text { components of stress tensor } \\
\lambda & =\text { Lame's constant } \\
\varepsilon_{k k} & =\text { dilatation } \\
\delta_{i j} & =\text { Kronecker's delta } \\
G & =\text { shear modulus } \\
\varepsilon_{i j} & =\text { components of strain tensor } \\
I_{2, j}, k & =\text { indices } \\
K & =\text { bulk modulus }
\end{aligned}
$$

Equation 1 can be written in other forms in which the elastic constants $\lambda$ and $G$ are expressed by other known elastic constants such as the modulus of elasticity $E$, the bulk modulus $K$, and Poisson's ratio $\nu$. The relationships between these different elastic constants for isotropic soils are shown in table 1 . 


\section{Linear Models}

Linear elastic model

10. The linear elastic model (fig. 1) has been used in conjunction with the theory of elasticity for the solution of many practical problems such as beams on elastic foundations, 5 stresses and deformations

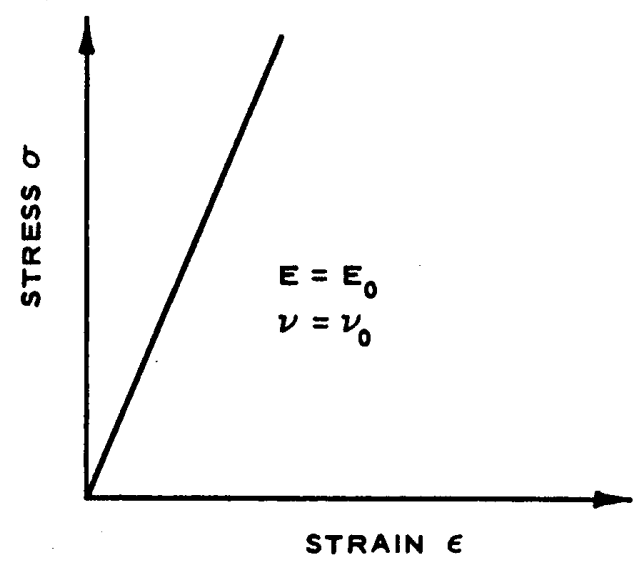

Fig. 1. The linear elastic model

beneath pavements, 6 and many other applications which can be found in any standard soll mechanics textbook. 7 Although the linear elastic model usually has been applied to thick homogeneous layers of soil, it has also been used in stress and deformation analyses in which more than one homogeneous layer of soil is encountered. Burmister used the linear elastic model to derive expressions for stresses and displacements in a two-layered airport pavement for which he obtained good agreement between actual and predicted pavement behavior under load. 7

1I. In general, the elastic parameters required for formulating a linear elastic model can be obtained from one or more of the following experimental tests: triaxial compression, plane strain, one-dimensional compression (i.e., $K_{0}$ test), and sonic tests. Girijavallabhan and Reese ${ }^{7}$ used a linear elastic model for the solution of stresses and deformations beneath a circular footing and obtained good agreement between the observed and predicted surface settlements. In a similar study by 
Duncan et al., 8 the deformation beneath a uniformly loaded circular area placed on the surface of a homogeneous subgrade was analyzed using finite element techniques by assigning constant $E$ and $\nu$ values to each of three layers. The resulting stresses and deformations compared very well with those obtained from the elastic layer system developed by the California Research Corporation. 9 A linear elastic model was also incorporated in the finite element program for plane strain problems developed by Duncan and Dunlop ${ }^{10}$ to study the stability of slopes in homogeneous stiff fissured clay and shale.

12. In general, it appears that the linear elastic model is most useful in the analysis of stresses and deformations in homogeneous soils at low stress levels. However, for higher deviatoric stress levels in which the stress-strain curve deviates significantly from the linear form, the linear elastic model becomes of little or no value for analysis. Bilinear elastic isotropic model

13. The stress-strain behavior of soil in this model is assumed to be bilinear and can be defined by five soil parameters, as shown in fig. 2. These parameters are the initial elastic modulus (i.e., before yield) $E_{o}$, elastic modulus after yield $E_{y}$, initial Poisson's

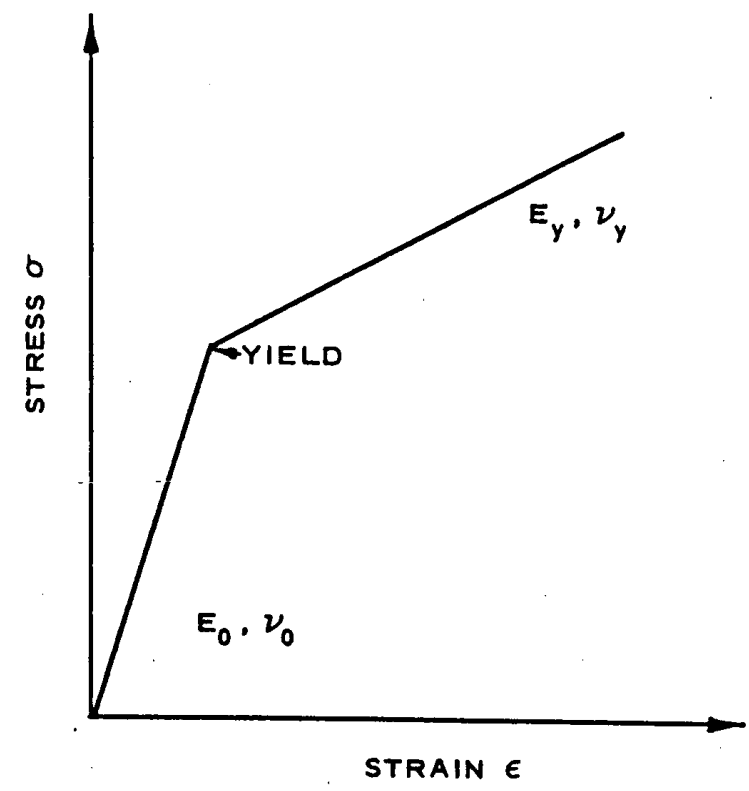

Fig. 2. The bilinear elastic model 
ratio $v_{0}$, Poisson's ratio after yield $v_{y}$, and the yield stress. This model was used by $D^{\prime A p p o l o n i a ~ a n d ~ L a m b e ~}{ }^{11}$ in the finite element analysis of a footing resting on Boston blue clay under an anisotropic state of stress. In their analysis, the initial elastic modulus was taken as the average modulus for extension and compression at a shear stress equal to half the shear stress at failure; $E_{y}$ was assumed to equal $0.001 \mathrm{E}_{0}$, and the yield stress was taken as 90 and 75 percent of the shear stress at failure for compression and extension, respectively.

14. A bilinear constitutive model was also used by Dunlop and Duncan $^{12}$ and incorporated in their finite element program for plane strain problems to study the development of the failure zone around excavated slopes in homogeneous stiff fissured clay shales. They used a normalized stress-strain curve for evaluating the elastic parameters in the same manner as that used by D'Appolonia and Lambe. ${ }^{11}$ However, they assumed $\mathrm{E}_{\mathrm{y}}$ to be on the order of $0.0001 \mathrm{E}_{0}$.

15. Because the conventional finite element program cannot be used with values of Poisson's ratio $v$ greater than 0.5 without numerical difficulties, * $v$ must be assigned a value less than 0.5 . D'Appolonia and Lambe ${ }^{11}$ assumed $v$ to equal 0.499 before yielding and 0.4999995 after yielding, while Dunlop and Duncan ${ }^{12}$ assumed values ranging from 0.475 to 0.4999 . In general, the bilinear model has demonstrated reasonable agreement between predicted behavior obtained by finite element analysis and field observations. Trilinear elastic isotropic model

16. In this model, the actual stress-strain relationship for soll is assumed to be approximated by three linear segments. The first segment represents the initial part of the stress-strain curve; the second segment represents transient behavior between the initial and yield conditions; and the third segment represents the stress-strain behavior

* The numerical difficulties arise from the fact that the matrix of the elastic parameter which relates the stress to the strain matrix contains terms in the denominator equal to $1-2 v$. Hence, a value of $\nu=0.5$ causes the denominator to equal zero. 
after yield. This model was used in the finite element analysis by Ellison et al. 13 to predict the load-deformation behavior of bored piles in London clay. The stress-strain curve was idealized by three segments, as shown in fig. 3, and the elastic modulus of each segment was related to the average undrained shear strength of soil $s_{u}$ as

$$
\begin{aligned}
& E_{0}=\beta S_{u} \\
& E_{1}=\lambda_{1} \beta S_{u} \\
& E_{2}=\lambda_{2} \beta S_{u}
\end{aligned}
$$

where

$$
\begin{aligned}
& \mathrm{E}_{0}=\text { initial elastic modulus } \\
& \mathrm{E}_{1}=\text { intermediate elastic modulus } \\
& \mathrm{E}_{2}= \text { elastic modulus after yield } \\
& \beta, \lambda_{1}, \lambda_{2}= \text { constant parameters used to define the shape of the } \\
& \text { stress-strain curve }
\end{aligned}
$$

The value of $\nu$ in the analysis was assumed to be constant at all times and equal to 0.48 . Ellison et al. ${ }^{13}$ showed that a trilinear model can

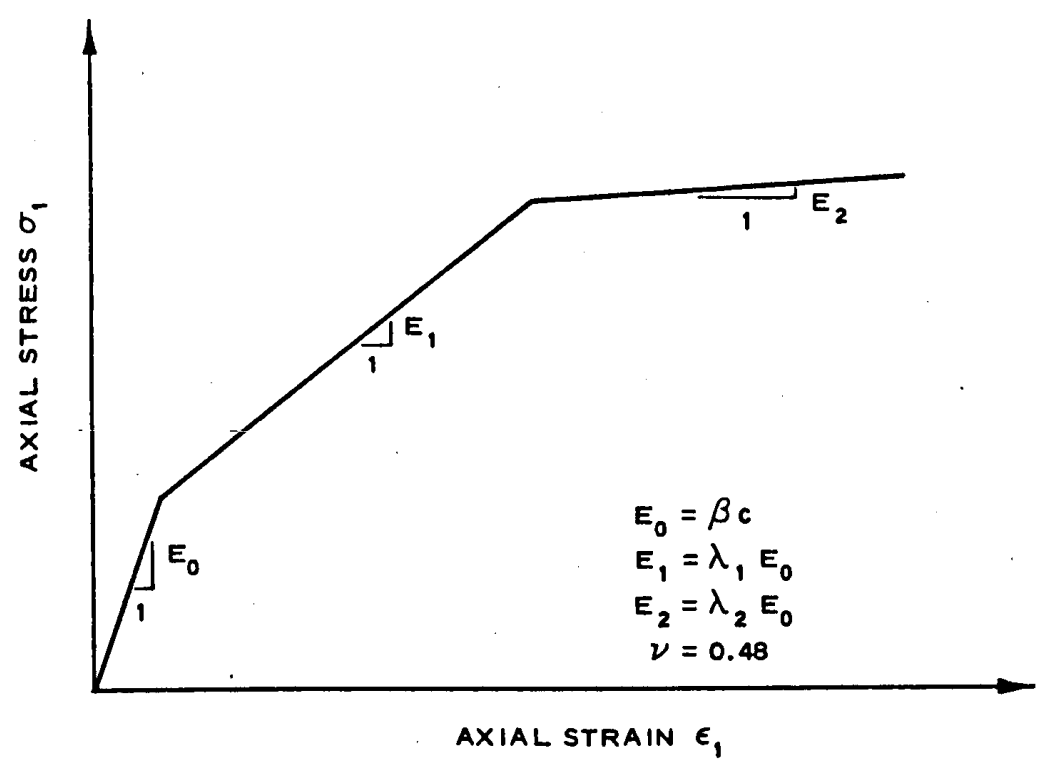

Fig. 3. Trilinear elastic model (after Ellison et al. ${ }^{13}$ ) 
accurately predict the load capacity and load-deformation behavior of bored piles in clay.

Multilinear stress-strain model

17. While some interesting and useful results have been obtained using the linear, bilinear, and trilinear models, the multilinear model generally is the most useful since it is more representative of the actual geometry of the stress-strain curve for soils. A number of procedures have been used to incorporate this model in finite element analyses to represent the nonlinear material behavior of soils. 14 In modeling nonlinear soil behavior by multilinear or piecewise approximations, two procedures have been widely accepted: the iterative and incremental procedures.

a. Iterative procedure. This procedure consists of first selecting an initial value of the elastic modulus $E$ for each element in the finite element mesh. A certain change in the external load is applied and the resulting stresses and strains are compared with the stress-strain relation of the material as shown in fig. 4a. If the calculated stresses and strains are not compatible, then another value of $E$ is chosen for the next anaiysis. The process is repeated until the difference in $\mathrm{E}$ calculated from one increment and $E$ calculated from the previous increment is within an accepted tolerance. The iterative procedure is easy to program and use in the finite element analysis and can be applied to both loading and unloading situations. However, the procedure cannot be used in problems with an initial stress of zero without some modification.

b. Incremental procedure. The incremental procedure consists of subdividing the external load into many small and equal increments which are applied incrementally. The stressstrain curve between each successive increment is assumed to be linear as shown in fig. 4b. The displacement increments which are related to strain are accumulated to give the total displacement at any stage- of loading. At thebeginning of this procedure, an initial value for $E$ is assigned and the stresses and strains in each element are calculated. A new increment of load is added and another appropriate $E$ value is selected based upon the stressstrain curve of the material at that particular increment. The process is repeated and the nonlinear stress-strain behavior of the material is approximated by a series of straight lines. This procedure is slightly more difficult than the iterative procedure to program; however, it is 


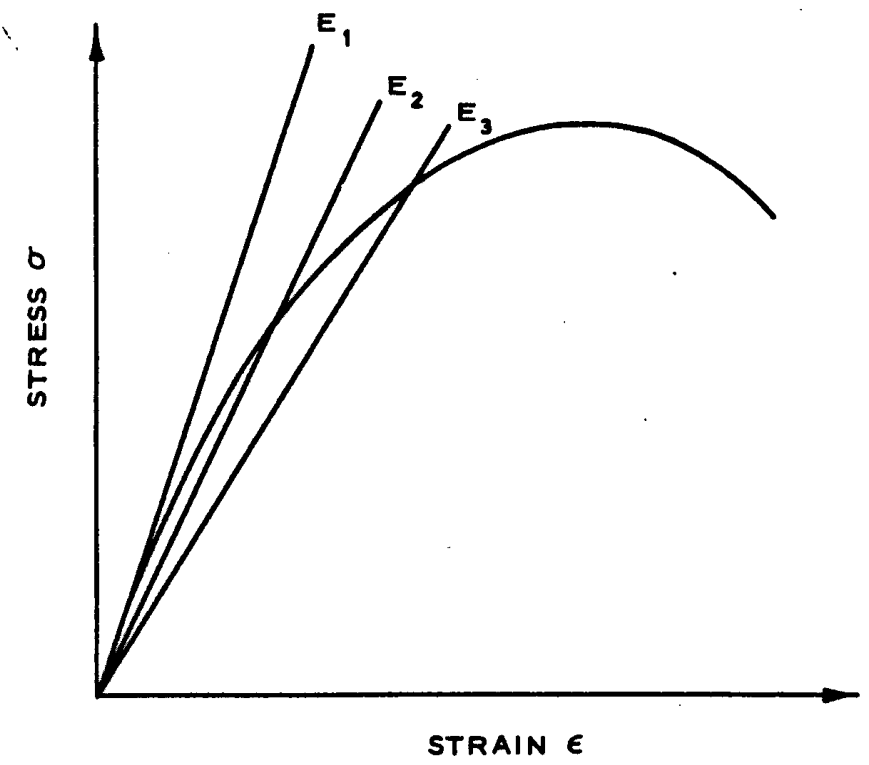

a. The iterative procedure

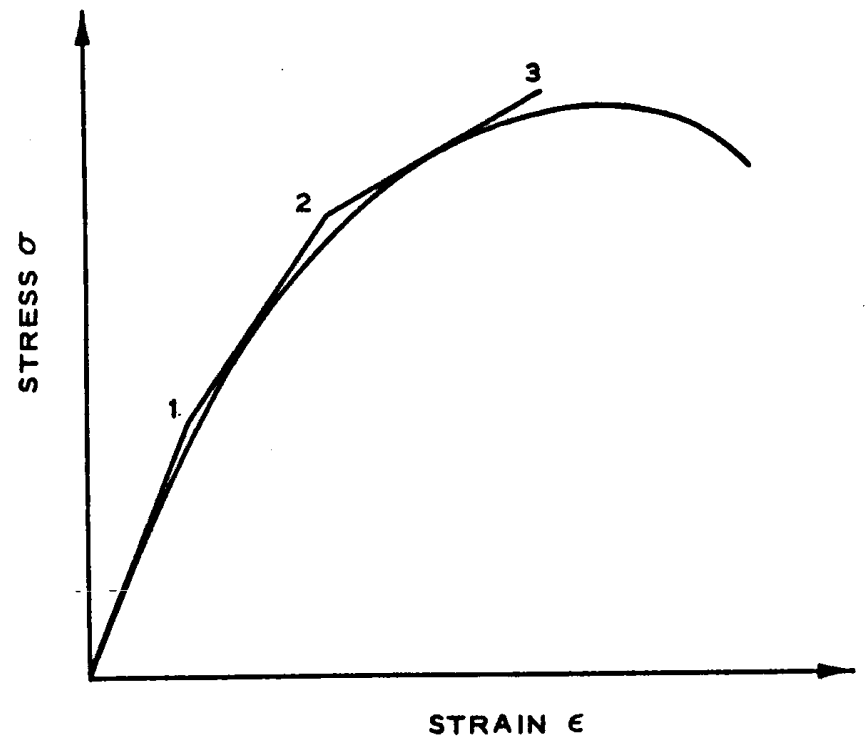

b. The incremental procedure

Fig. 4. Techniques for approximating nonlinearity of material 
much more general since it provides a complete description of the stress-strain behavior of the material. It can be applied for zero as well as nonzero initial stresses, but it cannot be applied for materials exhibiting strainsoftening behavior, $i . e .$, a reduction in stress with additional postpeak straining.

In many cases, a mixed procedure which employs a combination of incremental and iterative procedures is used. In such cases, the load is applied by increments; however, after each increment, an iterative procedure is performed to increase the accuracy of the nonlinear approximation.

18. To summarize, the nonlinear analysis in both iterative and incremental schemes consists of a sequence of linear approximations in which the modulus of elasticity $E$ and Poisson's ratio $v$ are the only parameters needed to describe the behavior of soll material. Thus, both procedures implicitly assumed that the material in each element is linear, elastic, isotropic, and independent of the stress level. However, if the effect of the stress level must be considered, then a family of stress-strain curves under different confining pressures is needed to reflect the realistic material behavior. Such a procedure is not economical because it requires a large computer space and it is tedious to obtain closure using iterative or incremental techniques. These disadvantages are responsible for the development of constitutive models in the form of analytical functions.

Nonlinear Models Using Functional Forms

19. Because of the large computer space required to consider the effect of the stress level by the iterative or incremental procedure, a number of functional forms and curve-fitting techniques have been devised in an effort to approximate a family of stress-strain curves by one general expression. Two functional forms have been widely used in finite element analysis to achieve this purpose: the hyperbolic function and the spline function. 
Hyperbolic function

20. The hyperbolic approximation for idealizing the entire triaxial compression stress-strain curve was developed by Kondner ${ }^{15}$ and Kondner and zelasko. ${ }^{16}$ They showed that the stress-strain relationship for sand sheared under a constant mean normal stress can be approximated by a rectangular hyperbola whose shape is controlled by the initial slope and asymptotic value of the stress difference. The proposed hyperbola was used to express the principal stress difference $\left(\sigma_{1}-\sigma_{3}\right)$ and the axial strain $\varepsilon_{1}$ as

$$
\left(\sigma_{1}-\sigma_{3}\right)=\frac{\varepsilon_{1}}{a+b \varepsilon_{1}}
$$

where

$$
\begin{aligned}
\sigma_{1} & =\text { major principal stress } \\
\sigma_{3} & =\text { minor principal stress } \\
\varepsilon_{1} & =\text { axial strain } \\
a, b= & \text { parameters whose values depend on the sand tested and the } \\
& \text { octahedral normal stress applied }
\end{aligned}
$$

The physical meaning of $a$ and $b$ can be seen in fig. $5 a$, in which $a$ is equal to the reciprocal of the initial tangent modulus $E_{i}$, and $b$ is equal to the asymptotic value of the ultimate stress difference $\left(\sigma_{1}-\sigma_{3}\right) u l t$. Equation 3 car be simplified by expressing $\varepsilon_{1} /\left(\sigma_{1}-\sigma_{3}\right)$ as a linear function of $\varepsilon_{1}$, which would enable direct evaluation of the parameters $a$ and $b$ as depicted in fig. 5b. The linear form of equation 3 may be written as

$$
\frac{\varepsilon_{1}}{\left(\sigma_{1}-\sigma_{3}\right)}=a+b \varepsilon_{1}
$$

where $a$ is the intercept and $b$ is the slope of the line. Thus, by plotting the experimental data in the transformed form, the corresponding values of $a$ and $b$ can be easily obtained.

21. More complicated forms of Kondner and Zelasko's hyperbolic functions have been suggested by Hansen ${ }^{17}$ as 


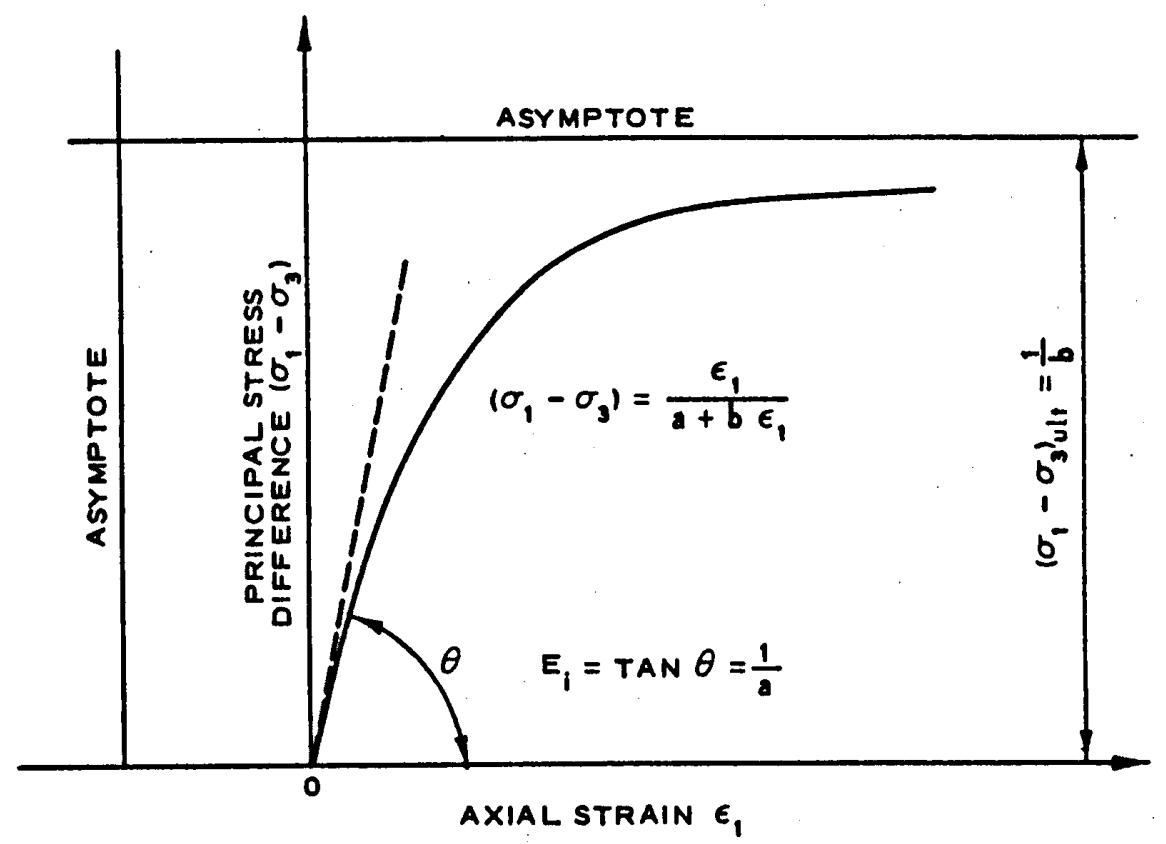

a. Kondner's 15

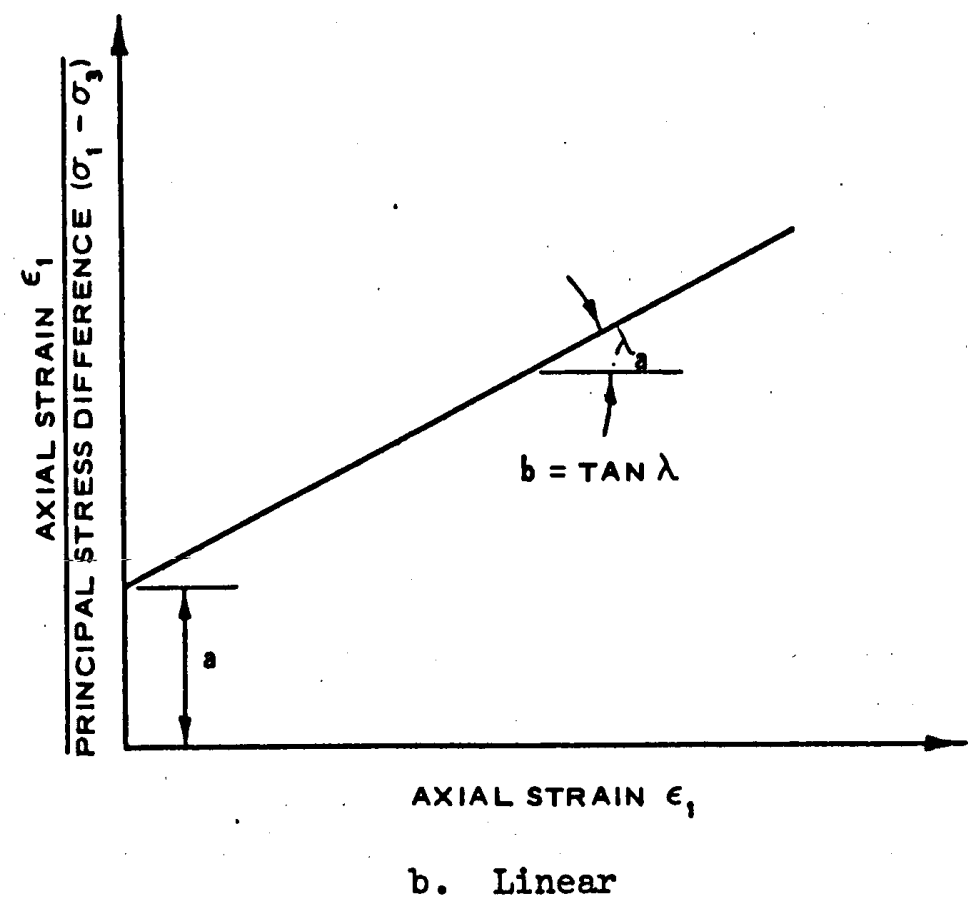

Fig. 5. Representations of the hyperbolic stress-strain function

13 


$$
\begin{aligned}
& \left(\sigma_{1}-\sigma_{3}\right)=\sqrt{\frac{\varepsilon_{1}}{a+b \varepsilon_{1}}} \\
& \left(\sigma_{1}-\sigma_{3}\right)=\frac{\sqrt{\varepsilon_{1}}}{a+b \varepsilon_{1}}
\end{aligned}
$$

Although in some cases Hansen's equation was found to give a slightly better fit to the experimental data than Kondner's equation, equation 3 has been favored by many researchers due to its simplicity.

22. Duncan and Chang ${ }^{18}$ expanded Kondner's hyperbolic stressstrain function and used it very conveniently in an incremental finite element analysis by expressing the tangent modulus $E_{t}$ as a function of $\left(\sigma_{1}-\sigma_{3}\right)$, the initial tangent modulus $E_{i}$, and the Mohr-Coulomb soil shear strength parameters $c$ and $\varnothing$ as

$$
E_{t}=\left[1-\frac{R_{f}(1-\sin \phi)\left(\sigma_{1}-\sigma_{3}\right)}{2 c \cos \phi+2 \sigma_{3} \sin \phi}\right]^{2} E_{i}
$$

in which $R_{f}$ is the ratio of $\left(\sigma_{1}-\sigma_{3}\right)$ at failure to the asymptotic value of $\left(\sigma_{1}-\sigma_{3}\right)$ ult . The dependency of the initial tangent modulus on the stress level was expressed by

$$
E_{i}=K_{a} P_{a}\left(\frac{\sigma_{3}}{P_{a}}\right)^{n}
$$

in which $K_{a}$ and $n$ are experimentally determined parameters and $P_{a}$ is the atmospheric pressure. Substituting equation 8 in equation 7 yields

$$
E_{t}=\left[1-\frac{R_{f}(1-\sin \phi)\left(\sigma_{1}-\sigma_{3}\right)}{2 c \cos \phi+2 \sigma_{3} \sin \phi}\right]^{2} K_{a} P_{a}\left(\frac{\sigma_{3}}{P_{a}}\right)^{n}
$$

The five parometers $c, \emptyset, R_{f}, K_{a}$, and $n$ may be determined conveniently from the results of a series of triaxial compression tests. 23. The Duncan and Chang model was used primarily to predict the stress-strain behavior of the material, and no serious attention was 
given to predicting volume changes during shear (1.e., Poisson's ratio in this model was assumed to be constant). This model was used by Chang and Duncan ${ }^{19}$ to predict soil movement around a deep excavation, and close agreement was obtained between actual and predicted behavior. 24. A study made by Kulhawy et al. ${ }^{20}$ on a number of soils showed that the variation of radial strain with respect to axial strain as obtained from triaxial compression tests is nonlinear and can be approximated by a hyperbolic function similar to that shown in fig. 5. The slope at any point of this hyperbola was designated as the tangent Poisson's ratio $\nu_{t}$ which is expressed as

$$
\nu_{t}=-\frac{d \varepsilon_{r}}{d \varepsilon_{a}}
$$

where $\varepsilon_{r}$ and $\varepsilon_{a}$ are the radial and axial strains, respectively. The value of $v_{t}$, which reflects the nonlinear volume change characteristics of the soil during primary loading, was found to be dependent on the stress level in a manner similar to that of $E_{t}$. Using the same procedure adopted by Duncan and Chang ${ }^{18}$ in deriving $E_{t}$, Kulhawy et al. ${ }^{20}$ derived an expression for $\nu_{t}$ in terms of stress only as

$$
\nu_{t}=\frac{G-F \log \left(\frac{\sigma_{3}}{P_{a}}\right)}{\left[1-\frac{D\left(\sigma_{1}-\sigma_{3}\right)}{K_{a} P_{a}\left(\frac{\sigma_{3}}{P_{a}}\right)^{n}\left[1-\frac{R_{f}\left(\sigma_{1}-\sigma_{3}\right)(1-\sin \phi)}{2 c \cos \phi+2 \sigma_{3} \sin \phi}\right]}\right]^{2}}
$$

where $K_{a}, n, c, \emptyset$, and $R_{f}$ are again experimentally determined and the three additional parameters $G, F$, and $D$ may be obtained from volume change and axial strain measurements from the triaxial compression tests.

25. The hyperbolic function model which incorporates the nonlinearity of the stress-strain curve as well as Poisson's ratio has also been used in a three-dimension finite element program by 
Palmerton 21 to study flexible pavement behavior. He was able to; obtain close agreement between the predicted deformations and the fielid data. Because the parameters used in the hyperbolic function were obtained from triaxial compression tests, their application to problems which are not axially symmetric generally is not valid. For example in problems not categorized as axially symmetrical, the ratio of lateral strain to axial strain does not represent Poisson's ratio, nor does the slope of stress difference versus axial strain represent the modulus of elasticity of the material.

\section{Spline function}

26. The mathematical expression used to span a given set of experimental points by several polynomials of different degrees in a manner similar to the one obtained by employing a mechanical spline or French curve is referred to as the spline function. In general, the spline function is not defined as a single expression over the entire range of data as is the hyperbolic function. Detailed derivations of spline functions and their mathematical properties have been presented by Ahlberg et al. 22 and will not be discussed herein. Spline functions have been used as a valuable tool in curve fitting and have been applied to practical problems in science and engineering. 23,24

27. A cubical spline was used by $\operatorname{Desai}^{25}$ to approximate the nonlinear stress-strain relationship of a cohesionless soil. He incorporated a spline function in a finite element analysis for predicting the load-deformation curve of footings. The application of spline functions for steady state seepage problems has been discussed by Cheek et al. 23 28. The advantage of the spline function is that the actual experimental data can be represented to any degree of accuracy. Also, the intermediate points and their derivatives at any instance can be readily obtained. However, spline functions require larger computer storage than hyperbolic functions. If the effect of confining pressure must be accounted for, then splines are required for a number of stressstrain curves under various confining pressures, which requires considerably more computer storage. 
29. Nonlinear stress-strain models with a variable modulus of elasticity $E$ and constant Poisson's ratio $v$ lead in most cases to erroneous estimates of volume changes that occur in soils during shear. To accurately predict volume changes, $\nu$ should also be varied in a manner compatible with the variation of strains at any increment of stress. If a constitutive model is to be incorporated in a finite element program, then any variation in the value of $v$ should not exceed 0.5 ; otherwise, the mathematical formulations of the finite element analysis become unstable. This condition places a restriction on the nonlinear procedure used in accounting for the actual deformation of the material. Therefore, it appears that $E$ and $v$ are not necessarIly the most convenient material property parameters, and another pair of independent parameters such as the shear modulus $G$ and the bulk modulus $K$ are more appropriate to use in many cases. Constant bulk modulus model

30. As an alternative to using $E$ and $v$ for describing the nonlinear behavior of soil, Clough and Woodward 26 formulated a constitutive matrix in terms of the shear modulus $G$, and the bulk modulus $K$, and used it in finite element analyses to predict the deformation and stresses in embankments. Their analysis was based on the assumption that soil is homogeneous and isotropic. Based on these assumptions, the stress-strain relationship for plane strain deformation may be expressed as

$$
\left[\begin{array}{c}
\sigma_{1} \\
\sigma_{3} \\
\tau_{m}
\end{array}\right]=\frac{E}{(1+v)(1-2 v)}\left[\begin{array}{ccc}
(1-v) & v & 0 \\
v & (1-v) & 0 \\
0 & 0 & \left(\frac{1-2 v}{2}\right)
\end{array}\right]\left[\begin{array}{c}
\varepsilon_{1} \\
\varepsilon_{3} \\
r_{m}
\end{array}\right]
$$

where

$$
\begin{aligned}
& \sigma_{1}=\text { major principal stress } \\
& \sigma_{3}=\text { minor principal stress }
\end{aligned}
$$


$\tau_{m}=$ maximum shear stress

$\varepsilon_{1}=$ major principal strain

$\varepsilon_{3}=$ minor principal strain

$\gamma_{m}=$ maximum shear strain

They also defined the values of $G$ and $K$ in terms of $E$ and $\nu$ as

$$
\begin{gathered}
G=\frac{E}{2(1+v)} \\
K=\frac{E}{2(1+v)(1-2 v)}
\end{gathered}
$$

By introducing the above definitions of $G$ and $K$ into equation 12 , the stress-strain matrix may be written as

$$
\left[\begin{array}{c}
\sigma_{1} \\
\sigma_{3} \\
\tau_{m}
\end{array}\right]=\left[\begin{array}{ccc}
(K+G) & (K-G) & 0 \\
(K-G) & (K+G) & 0 \\
0 & 0 & G
\end{array}\right]\left[\begin{array}{c}
\varepsilon_{1} \\
\varepsilon_{3} \\
\gamma_{m}
\end{array}\right]
$$

31. The values of $G$ and $K$ in the above analysis were obtained from triaxial compression tests such that

$$
G=\frac{1}{2}\left(\frac{\sigma_{1}-\sigma_{3}}{\varepsilon_{1}-\varepsilon_{3}}\right)
$$

and

$$
K=\frac{1}{2}\left(\frac{\sigma_{1}+\sigma_{3}}{\varepsilon_{1}+\varepsilon_{3}}\right)
$$

Clough and Woodward ${ }^{26}$ assumed $K$ to be constant and handled the stressstrain-nonlinearity by incrementing the shear modulus $G$ in equation 15. The model was used to study the deformation of Otter Brook Dam during construction, and reasonable agreements were found between the predicted and actual deformations of the dam.

Variable bulk and

shear modulus model

$$
\text { 32. Many investigators } 27,28,29 \text { have shown that the bulk modulus }
$$


of soil is not constant but rather is a function of the density and confining pressure. Domaschuk and Wade ${ }^{29}$ conducted two series of tests on Chattahoochee River sand over a wide range of relative densities. In the first test series, the sand was subjected to hydrostatic pressure only, and they expressed the bulk modulus by

$$
\mathrm{K}=\mathrm{K}_{\mathrm{i}}+\mathrm{m} \sigma_{\mathrm{m}}
$$

where $K_{i}$ and $m$ are parameters whose values depend on the relative density and the applied confining pressure, respectively, and $\sigma_{m}$ is the mean normal stress.

33. The second test series conducted by Domaschuk and Wade 29 consisted of triaxial compression tests using a constant $\sigma_{m}$ in a manner similar to that in tests conducted by Kondner and Zelasko. 16 They showed that, when the stress-strain curves are plotted in terms of the octahedral shear stress $\tau_{\text {oct }}$ and the octahedral shear strain $\gamma_{\text {oct }}$, the general shape of each curve is a rectangular hyperbola which can be expressed as

$$
\tau_{\text {oct }}=\frac{\gamma_{\text {oct }}}{\alpha+\beta \gamma_{\text {oct }}}
$$

where $\alpha$ is the reciprocal of the initial shear modulus $G_{1}$ and $\beta$ is the reciprocal of the ultimal octahedral shear stress $\tau_{u l t}$. The parameters $\alpha$ and $\beta$ are analogous but not identical with $a$ and $b$ in equation 3.

34. An expression for the tangent shear modulus $G_{t}$ was derived by taking the derivative of $\tau_{\text {oct }}$ with respect to $\gamma_{\text {oct }}$ to yield

$$
G_{t}=\left(1-B \tau_{\text {oct }}\right)^{2} G_{i}
$$

Equations 18 and 20 combined define the nonlinear behavior of soil under primary loading. The validity of this model was checked by comparing the predicted and experimental stress-strain curves obtained from triaxial compression tests under a constant $\sigma_{m}$. Good agreement was 
obtained for each stress-strain curve.

35. Domaschuk and Wade 29 indicated that $G_{i}$ increased with increasing $\sigma_{m}$; however, no attempt was made to relate the variables in a mathematical form. Later, Al-Hussaini and Radhakrishnan 30 expanded Domaschuk and Wade's model and derived three empirical equations to express $G_{i}, G_{t}$, and $\nu$ as

and

$$
\begin{aligned}
& G_{i}=K_{b} P_{a}\left(\frac{\sigma_{3}}{P_{a}}\right)^{n} \\
& G_{t}=\left(1-\frac{S_{f}{ }^{\tau} o c t}{d+e \sigma_{3}}\right)^{2} G_{i}
\end{aligned}
$$

where

$$
v=v_{0}+\left(\frac{K_{d} \tau_{o c t}}{\sqrt{G_{i} G_{t}}}\right)
$$

$$
\begin{aligned}
& S_{f}=\text { ratio of the octahedral shear stress at failure } \tau_{f} \text { to } \tau_{u l t} \\
& v_{0}=\text { initial Poisson's ratio }
\end{aligned}
$$

The constants $d, e, K_{b}, K_{d}, n$, and $\nu_{0}$ can be determined from laboratory test results. The equations were incorporated in a finite element analysis to predict stresses and deformations in soil specimens sheared under plane strain conditions. Comparisons with the experimental data showed good agreement between the predicted and observed results. A variable shear modulus model with constant $\nu$ was used in conjunction with a finite element analysis by Clough and Duncan $^{31}$ and also by Girijavallabhan and Mehta. 32

Higher Order Elastic Material Models

36. Although there is no complete theory of constitutive equations that encompasses all known physical phenomena, there have been a few successful attempts to develop theoretically sound constitutive models on the basis of their gross material behavior rather than their atomistic behavior. Such constitutive models are based on the assumption that matter can be replaced by a mathematical model whose kinematic 
or dynamic variables are piecewise continuous functions of the spatial coordinates. For an ideal material to represent physical behavior adequately, it should satisfy the principles of invariance, determinism, isotropy, and consistency. 33 Higher order elastic material behavior has been divided into three major categories: hyperelastic, Cauchy elastic, and hypoelastic. The major differences between these categories are that the behavior of a hypoelastic material is path-independent while both hyperelastic and Cauchy elastic materials are path-dependent. Hyperelastic material model

37. Elastic bodies that possess an energy density function are referred to as hyperelastic materials. The constitutive equation for hyperelastic materials is derived from laws of thermodynamics. 33 For adiabatic behavior, the conservation of energy requires that

$$
\sigma_{i j}=\frac{\partial U}{\partial \varepsilon_{i j}}
$$

where $\sigma_{\text {If }}$ is the stress tensor, $U$ is the internal energy density function, and $\varepsilon_{i j}$ is strain tensor.

38. For isotropic materials whose strain energy density function satisfies the invariance principles, $U$ can be expressed in terms of three strain invariants as

$$
U=U\left(I_{1}, I_{2}, I_{3}\right)
$$

where $I_{1}, I_{2}$, and $I_{3}$ are the first, second, and third strain invariants, respectively, which may be defined as

$$
\begin{aligned}
& I_{1}=\varepsilon_{\mathrm{kk}} \\
& I_{2}=\frac{1}{2} \varepsilon_{\mathrm{mn}} \varepsilon_{\mathrm{mn}} \\
& I_{3}=\frac{1}{3} \varepsilon_{i m} \varepsilon_{\mathrm{mn}} \varepsilon_{\mathrm{in}}
\end{aligned}
$$


Employing equation 23 in a chain rule differentiation of equation 22 leads to the expression

$$
\sigma_{i j}=\frac{\partial U}{\partial I_{1}} \frac{\partial I_{1}}{\partial \varepsilon_{i j}}+\frac{\partial U}{\partial I_{2}} \frac{\partial I_{2}}{\partial \varepsilon_{i j}}+\frac{\partial U}{\partial I_{3}} \frac{\partial I_{3}}{\partial \varepsilon_{i j}}
$$

Employing equation 24 , the variation of the strain invariants with respect to $\varepsilon_{i j}$ may be obtained as

$$
\begin{aligned}
& \frac{\partial I_{1}}{\partial \varepsilon_{i j}}=\delta_{i j} \\
& \frac{\partial I_{2}}{\partial \varepsilon_{i j}}=\varepsilon_{i j} \\
& \frac{\partial I_{3}}{\partial \varepsilon_{i j}}=\varepsilon_{i m} \varepsilon_{m j}
\end{aligned}
$$

where $\delta_{i j}$ is Kronecker's delta. Substituting equation 26 into equation 25 yields

$$
\sigma_{i j}=\frac{\partial U}{\partial I_{1}} \delta_{i j}+\frac{\partial U}{\partial I_{2}} \varepsilon_{i j}+\frac{\partial U}{\partial I_{3}} \varepsilon_{i m} \varepsilon_{m j}
$$

which can be simplified to

$$
\sigma_{i j}=\alpha_{1} \delta_{i j}+\alpha_{2} \varepsilon_{i j}+\alpha_{3} \varepsilon_{i m} \varepsilon_{m j}
$$

where $a_{i}(i=1,2,3)$ is a response function that satisfies the following condition:

Cauchy elastic material model

$$
\frac{\partial \alpha_{i}}{\partial I_{j}}=\frac{\partial \alpha_{j}}{\partial I_{i}}
$$

39. Cauchy material refers to elastic materials which do not possess elastic potential. For these materials it is not possible to apply Green's theorem; therefore, an alternative method by Cauchy may be applied to obtain a constitutive equation. ${ }^{34}$ Cauchy's method is based on the assumption that the state of stress is only a function of the current state of strain; thus, 


$$
\sigma_{i j}=f_{i j}\left(\varepsilon_{m n}\right)
$$

where $f_{i j}$ is an unknown function which must be determined. 40. The most direct approach for evaluating $f_{1 j}$ is to expand equation 30 as a polynomial such as

$$
\sigma_{i j}=a_{0}+a_{1} \varepsilon_{i j}+a_{2} \varepsilon_{i m} \varepsilon_{m j}+a_{3} \varepsilon_{i m} \varepsilon_{m n} \varepsilon_{n j}+a_{4} \varepsilon_{i m} \varepsilon_{m n} \varepsilon_{n s} \varepsilon_{s j}+\ldots
$$

where $a_{0}, a_{1}, a_{2}, \ldots a_{n}$ are real coefficients. Since the strain tensor $\varepsilon_{i j}$ is symmetric, then using the Cayley-Hamilton theorem of matrix analysis, which implies that $\varepsilon_{i j}$ should satisfy its own characteristic equation, it is possible to show that

$$
\sigma_{i j}=\emptyset_{1} \delta_{i j}+\emptyset_{2} \varepsilon_{i j}+\emptyset_{3} \varepsilon_{i m} \varepsilon_{m j}
$$

where $\emptyset_{1}, \emptyset_{2}$, and $\emptyset_{3}$ are scaler polynomials that can be expressed in terms of the strain invariants $I_{1}, I_{2}$, and $I_{3} \cdot$

41. Comparing equations 32 and 28 , it can be seen that the general form of the Cauchy elastic model for infinitesimal deformation is similar to that of a hyperelastic material even though the hyperelastic is derived from thermodynamic consideration while Cauchy elastic material is based on matrix algebra. Because of the thermodynamic restriction imposed on the hyperelastic material, the Cauchy elastic material is considered more general. Hypoelastic material model

42. In both hyperelastic and Cauchy elastic material models, it is assumed that the stress tensor $\sigma_{i j}$ is a function of the strain tensor $\varepsilon_{i j}$ and that their relationship does not depend on the loading path. However, the stress-strain relationship for many engineering materials is a function of the stress path followed during shear. For such materials, Truesdell ${ }^{35}$ proposed a constitutive equation in which the rate of stress is expressed as a function of stress and the rate of deformation. 


$$
\frac{\partial \sigma_{i j}}{\partial t}=f_{i j}\left(\sigma_{m n}, \frac{\partial \varepsilon_{k \ell}}{\partial t}\right)
$$

Equation 33 can be expanded into a general constitutive equation by employing the Rivlin-Ericksen ${ }^{36}$ equation. Following procedures outlined by Rohani, 37 a constitutive equation for rate-independent hypoelastic material can be obtained as

$$
\begin{aligned}
\sigma_{i j}=d \varepsilon_{n n} \beta_{0} \delta_{i j} & +\sigma_{m n} d \varepsilon_{m n} \beta_{1} \delta_{i j}+\sigma_{m n} \sigma_{n p} d \varepsilon_{p m} \beta_{2} \delta_{i j}+d \varepsilon_{n n} \beta_{3} \sigma_{i j} \\
& +\sigma_{m n} d \varepsilon_{m n} \beta_{4} \sigma_{i j}+\sigma_{m n} \sigma_{n p} d \varepsilon_{p m} \beta_{5} \sigma_{i j}+d \varepsilon_{n n}{ }^{\sigma} \sigma_{i m} \sigma_{m j} \\
& +\sigma_{m n} d \varepsilon_{m n} \beta_{7} \sigma_{i s} \sigma_{s j}+\sigma_{m n} \sigma_{n p} d \varepsilon_{p m} \beta_{8}{ }_{i s} \sigma_{s j} \\
& +n_{5}\left(\sigma_{i m} d \varepsilon_{m j}+d \varepsilon_{i m} \sigma_{m j}\right)+n_{6}\left(\sigma_{i m} \sigma_{m n} d \varepsilon_{n j}\right. \\
& \left.+d \varepsilon_{i m} \sigma_{m j}\right)+n_{3} d \varepsilon_{i j}
\end{aligned}
$$

where $d$ is an increment and the $\beta^{\prime} s$ and $\eta^{\prime} s$ are response functions that can be expressed as polynomial functions of the stress invariants $\mathrm{J}_{1}, \mathrm{~J}_{2}$, and $\mathrm{J}_{3}$, where

$$
\begin{aligned}
& \mathrm{J}_{1}=\sigma_{\mathrm{kk}} \\
& \mathrm{J}_{2}=\frac{1}{2} \sigma_{\mathrm{mn}} \sigma_{\mathrm{mn}} \\
& \mathrm{J}_{3}=\frac{1}{3} \sigma_{i m} \sigma_{\mathrm{mn}} \sigma_{\mathrm{in}}
\end{aligned}
$$

The solution of equation 34 for any stress path may be obtained by integration when the initial conditions are specified.

43. The degree of $\sigma_{i j}$ on the right-hand side of equation 34 dictates the grade of the hypoelastic material. For example, in hypoelastic materials of grade zero, all terms containing $\sigma_{i j}$ vanish and consequently equation 34 reduces to 


$$
d \sigma_{i j}=\beta_{0} d \varepsilon_{n n} \delta{ }_{i j}+n_{3} d \varepsilon_{i j}
$$

By substituting for $B_{0}=\lambda=\frac{3 K-2 G}{3}$ and $\eta_{3}=2 G$ and after arranging terms, equation 36 may be reduced further to

$$
d \sigma_{i j}=K d \varepsilon_{n n} \delta_{i j}+2 G\left(d \varepsilon_{i j}-\frac{1}{3} d \varepsilon_{n n} \delta_{i j}\right)
$$

Equation 37 has the same form of incremental Hooke's law. If only terms up to first power of $\sigma_{1 j}$ are retained, then equation 34 reduces to a hypoelastic material of grade one and so on.

44. The formulation of higher order elastic models which model experimental test results presents a complicated problem, especially when dealing with soils. Such difficulties are reflected by the limited amount of research published to date on this subject. Rohani ${ }^{38}$ derived a nonlinear elastic constitutive equation for earth materials, and he obtained reasonable agreements with experimental results. Chang et al. 39 used a second order hyperelastic equation in an incremental form to develop a constitutive equation for ottawa sand, which was then incorporated in a finite element program to predict sand behavior. Their predicted results agreed only qualitatively with the experimental data. Nelson and Baron ${ }^{40}$ used an incremental constitutive equation of the hyperbolic type to investigate ground shock effect in nonlinear hysteretic media. Two separate models were used in their study. In the first model, both the bulk and the shear modulus were taken to be functions of the strain invariants alone; in the second model, they assumed that the bulk modulus was a function of combined invariance. However, they did not attempt to match results from the derived model with actual data. A first order hypoelastic constitutive equation was also used. by Coon and Evans ${ }^{41}$ to interpret the behavior of granular material as tested under triaxial compression. They obtained reasonable agreements between the predicted and actual stress-strain behavior. Concluding remarks

45. In the preceding discussion, it has been shown that the majority of elastic models which are based on curve-fitting techniques 
(i.e., linear, bilinear, trilinear, and hyperbolic) provide good agreement between the observed and predicted soil behavior. However, these models lack sufficient experimental and theoretical verification to be qualified as constitutive models. A general constitutive model should be able to predict or define the behavior of soil media under any posible state of stress and deformation. None of the previously discussed elastic models possess such qualities. In addition, the majority of the elastic models were derived from triaxial compression test data, a situation which implies axisymmetric stress and strain conditions, and, inappropriately, these models have been applied to design problems which might be better approximated as plane stress or plane strain problems. Such inconsistency between the developed model and actual field conditions may lead to erroneous estimates of soil behavior. A further restriction of incorporating elastic models in finite element programs is that Poisson's ratio must be kept below 0.5 because of instability problems. This limitation places a restriction on accounting for actual soil behavior.

46. Higher order elastic material models are very difficult to derive since experimental data under various stress states are required to evaluate the needed parameters. In some cases, these parameters are extremely difficult if not impossible to obtain. This drawback probably is the major reason why higher order elastic models have not been fully investigated or applied. Nevertheless, higher order elastic material models may prove to be useful in handling soil behavior associated with work softening and dilatancy and in predicting soil behavior under conditions different than those from which the parameters were derived. These higher order elastic material models may also provide finite element formulation free from the instability associated when $v=0.5$ since the classical definition of Poisson's ratio is no longer required. 
47. In the previous part of this report it was concluded that a constitutive equation based on higher order elastic continuum is probably the only way to generate a truly representative material model. However, the procedure used to obtain the various parameters needed for such a model is very difficult if not impossible. In this portion of the report, special forms of the general constitutive equation will be used to generate a simple but practical constitutive model for granular materials. Procedures for obtaining material constants from various tests are discussed and presented, and the proposed constitutive equation is evaluated by comparing the derived stress-strain relationship with observed material behavior.

\section{Total Strain Deformation}

48. The basic assumption of total deformation theory is that the state of stress is a function of the current state of strain and is independent of the stress path. The hyperelastic and Cauchy elastic materials, which were described in Part II, fall in this category. The response coefficient $\emptyset_{i}$ in equation 32 (Cauchy elastic material), which may take various forms for different materials, must be determined from experimental data. However, there is no reason (unless one is dictated by experimental observation) for requiring all the response coefficients in the constitutive equation. For reasons of practicability and mathematical simplicity, the response coefficient $\emptyset_{3}$ has been assumed to be zero in using equation 32 for describing the stress-strain behavior of soil. For this material, the-tensorial dilatancy which contributes to volume expansion of material under shear is ignored; however, the scaler dllatancy may be accounted for by making $\emptyset_{1}$ and $\emptyset_{2}$ functions of $I_{1}$ and $I_{2}$. Thus, equation 32 becomes

$$
\sigma_{i j}=\emptyset_{1} \delta_{i j}+\emptyset_{2} \varepsilon_{i j}
$$

The unknown $\emptyset_{1}$ and $\emptyset_{2}$ may be obtained by first replacing 
$i$ with $j$ and reducing equation 38 to

$$
J_{1}=3 \phi_{1}+\phi_{2} I_{1}
$$

By definition, the stress deviatoric tensor $S_{i f}$ and the strain deviatoric tensor $E_{i j}$ may be expressed as

$$
\begin{aligned}
& S_{i j}=\sigma_{i j}-\frac{J_{1}}{3} \delta_{i j} \\
& E_{i j}=\varepsilon_{i j}-\frac{I_{1}}{3} \delta_{i j}
\end{aligned}
$$

Using equation 40 in conjunction with equation 38 and equating $i$ to $\mathrm{j}$, the following invariant equation can be obtained:

$$
\sqrt{J_{2}^{\prime}}=\emptyset_{2} \sqrt{I_{2}^{\prime}}
$$

where $J_{2}^{\prime}$ and $I_{2}^{\prime}$ are, respectively, the second invariants of the stress and strain deviatoric tensor and are defined as

$$
\begin{aligned}
& J_{2}^{\prime}=\frac{I}{2} S_{i j} S_{i j} \\
& I_{2}^{\prime}=\frac{I}{2} E_{i j} E_{i j},
\end{aligned}
$$

From equations 39 and 41 , the values of $\phi_{1}$ and $\phi_{2}$ can be defined as

$$
\begin{aligned}
& \emptyset_{1}=\frac{I}{3}\left(J_{1}-I_{1} \sqrt{\frac{J_{2}^{\prime}}{I_{2}^{\prime}}}\right) \\
& \emptyset_{2}=\sqrt{\frac{J_{2}^{\prime}}{I_{2}^{\prime}}}
\end{aligned}
$$

Since $\phi_{1}$ and $\phi_{2}$ are known in terms of the invariants, the stressstrain relationship expressed in equation 38 may be written, after rearranging terms, as 


$$
\sigma_{i j}=\frac{J_{1}}{3} \delta_{i j}+\sqrt{\frac{J_{2}^{\prime}}{I_{2}^{\prime}}}\left(\varepsilon_{i j}-\frac{I_{1}}{3} \delta_{i j}\right)
$$

In equation 44 it is only necessary to determine the functional forms of the invariants $J_{1}$ and $J_{2}^{\prime}$ in terms of strain invariants $I_{1}$ and $I_{2}^{\prime} \cdot$

The Constitutive Model

49. The invariants $J_{1}$ and $J_{2}^{\prime}$ in equation 44 can be expressed by two parameters

$$
\begin{aligned}
& J_{1}=f_{1}\left(I_{1}\right) \\
& J_{2}^{\prime}=f_{2}\left(I_{2}^{\prime}, J_{1}\right)
\end{aligned}
$$

where $f_{1}$ expresses the nonlinear pressure-volume change relationship and $f_{2}$ expresses the nonlinear shear stress-strain relationship.

50. The relationship between $J_{1}$ and $I_{1}$ may be determined from tests in which deviatoric stresses are not permitted, 1.e., a spherical state of stress. A common example of this is the case of isotropic consolidation. The relationship between $J_{2}^{\prime}$ and $I_{2}^{\prime}$ can be obtained from tests in which only a deviatoric state of stress is applied; however, such a condition is difficult to impose by conventional means although an approximate relationship can be obtained using triaxial compression or plane strain shear devices.

Isotropic compression test

51. This test is characterized by three principal stresses and three principal strains such that

$$
\begin{array}{ll}
\sigma_{11}=\sigma_{22}=\sigma_{33}=p ; & \sigma_{1 j}=0, \\
\varepsilon_{11}=\varepsilon_{22}=\varepsilon_{33}=\frac{\varepsilon}{3} ; & \varepsilon_{1 j}=0,
\end{array}
$$

where $\sigma_{11}, \sigma_{22}$, and $\sigma_{33}$ are principal stresses, $\varepsilon_{11}, \varepsilon_{22}$, and 
$\varepsilon_{33}$ are principal strains, $\mathrm{p}$ is the hydrostatic pressure, and $\varepsilon$ is the volumetric strain.

52. A typical stress-strain curve for granular material under isotropic compression is shown in fig. 6. Attempts have been made to

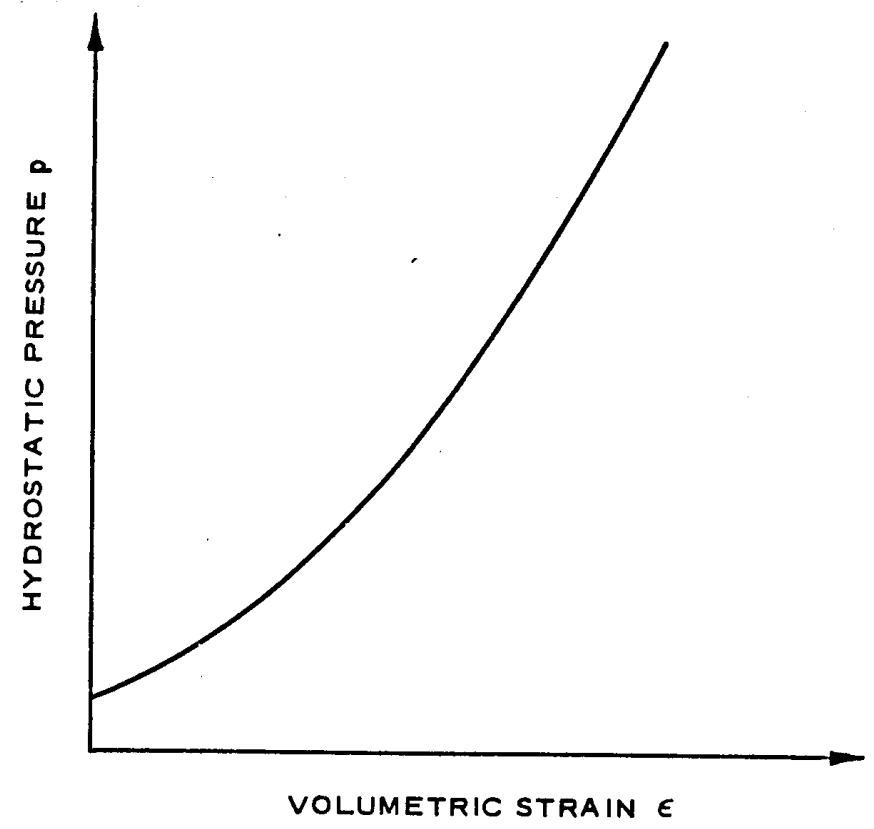

Fig. 6. Typical hydrostatic compression test

relate the elastic behavior of individual particles to the overall elastic behavior of the mass of granular material using Hertz ${ }^{42}$ contact theory. Such an approach was used by Ko and $\operatorname{scott}^{27}$ who showed that the volumetric strain $\varepsilon$ for a simple cubical element of spheres can be expressed in terms of hydrostatic pressure $p$ as

$$
\varepsilon=3(16 \mathrm{wp})^{2 / 3}
$$

where $w=3\left(1-\nu^{2}\right) / 4 E$. Actual data on sand showed that $\varepsilon$ does not vary with the two-thirds power of external pressure as predicted by Hertz' contact theory. Another empirical expression which is modified from Hertz' contact theory was used by El-Sohby ${ }^{28}$ as

$$
\varepsilon=\mathrm{Sp}^{\mathrm{m}}
$$


where $S$ and $m$ are constants that can be determined from experimental data.

53. Other expressions used were strictly based on curve fittings. Rohani ${ }^{38}$ suggested the following:

$$
p=\sigma_{0} e^{\beta \varepsilon}
$$

where $\sigma_{0}$ is the initial state of stress of the material that defines the state of ease* and $\beta$ is a parameter. Both $\sigma_{0}$ and $\beta$ can be obtained experimentally. A similar expression was suggested by Domaschuk and Wade 29 as

$$
\varepsilon=\frac{1}{m}\left[\ln \left(K_{1}+m p\right)\right]
$$

where $K_{i}$ is the initial bulk modulus and $m$ is a constant.

54. For reasons of simplicity, an expression similar to equation 49 was adopted for describing the nonlinear stress-strain behavior under isotropic compression as

$$
\frac{J_{1}}{3}=\sigma_{0}\left(e^{\beta I_{1}}-1\right)
$$

where $J_{1}$ and $I_{1}$ are the first stress and strain invariants, respectively.

Triaxial compression test

55. This test is characterized by the symmetry of stresses and strains around one of the principal axes (i.e., major principal axis). Conditions under which the conventional triaxial test is performed may be defined as.

$$
\begin{array}{ll}
\sigma_{11}>\sigma_{22}=\sigma_{33} ; & \sigma_{i j}=0, \\
\varepsilon_{11}>\varepsilon_{22}=\varepsilon_{33} ; & \varepsilon_{i j}=0,
\end{array}
$$

It should be noted that $\sigma_{0}$ is not a material constant but rather a parameter which defines the initial state of stress of the soil tested. 
In this test, it is customary to plot the stress difference $\left(\sigma_{11}-\sigma_{33}\right)$ as a function of axial strain $\varepsilon_{1}$ (see fig. 5), and the resulting curve can be approximated by a hyperbola. $15,16,18$ For granular material, the shape and size of such a hyperbola depend upon many factors such as relative density, drainage conditions, confining pressure, size and shape of particles, etc. A study by Domaschuk and Wade ${ }^{29}$ showed that the hyperbolic shape of the stress-strain curve will be maintained in triaxial compression tests if the data are represented by the deviatoric stress. $S_{d}$ and the deviatoric strain $\varepsilon_{\mathrm{d}}$ where

$$
\begin{aligned}
& S_{d}=\frac{\sqrt{2}}{\sqrt{3}}\left(\sigma_{11}-\sigma_{33}\right) \\
& \varepsilon_{d}=\frac{2 \sqrt{2}}{\sqrt{3}}\left(\varepsilon_{11}-\varepsilon_{33}\right)
\end{aligned}
$$

However, because $S_{d}$ and $\varepsilon_{d}$ are directly related to $J_{2}^{\prime}$ and $I_{2}^{\prime}$, respectively,

$$
\begin{aligned}
& \sqrt{J_{2}^{\prime}}=\frac{1}{\sqrt{2}} S_{d}=\frac{1}{\sqrt{3}}\left(\sigma_{11}-\sigma_{33}\right) \\
& \sqrt{I_{2}^{\prime}}=\frac{1}{2 \sqrt{2}} \varepsilon_{d}=\frac{1}{\sqrt{3}}\left(\varepsilon_{11}-\varepsilon_{33}\right)
\end{aligned}
$$

Therefore, if $\sqrt{J_{2}^{1}}$ is to be plotted as a function of $\sqrt{I_{2}^{1}}$ for triaxial compression tests, the resulting stress-strain curve should also be a hyperbola.

Formulation of the hyperbolic function:

56. For a given value of relative density and confining pressure the value of $\sqrt{J_{2}^{r}}$ versus $\sqrt{I_{2}^{T}}$ may be characterized by a rectangular hyperbolic function in a manner similar to that used by Kondner and Zelasko. ${ }^{16}$ The parameters are illustrated in fig. 7 , and the resulting equation for the stress-strain curve can be expressed as

$$
\sqrt{J_{2}^{\prime}}=\frac{\sqrt{I_{2}^{\prime}}}{\alpha+\gamma \sqrt{I_{2}^{\prime}}}
$$




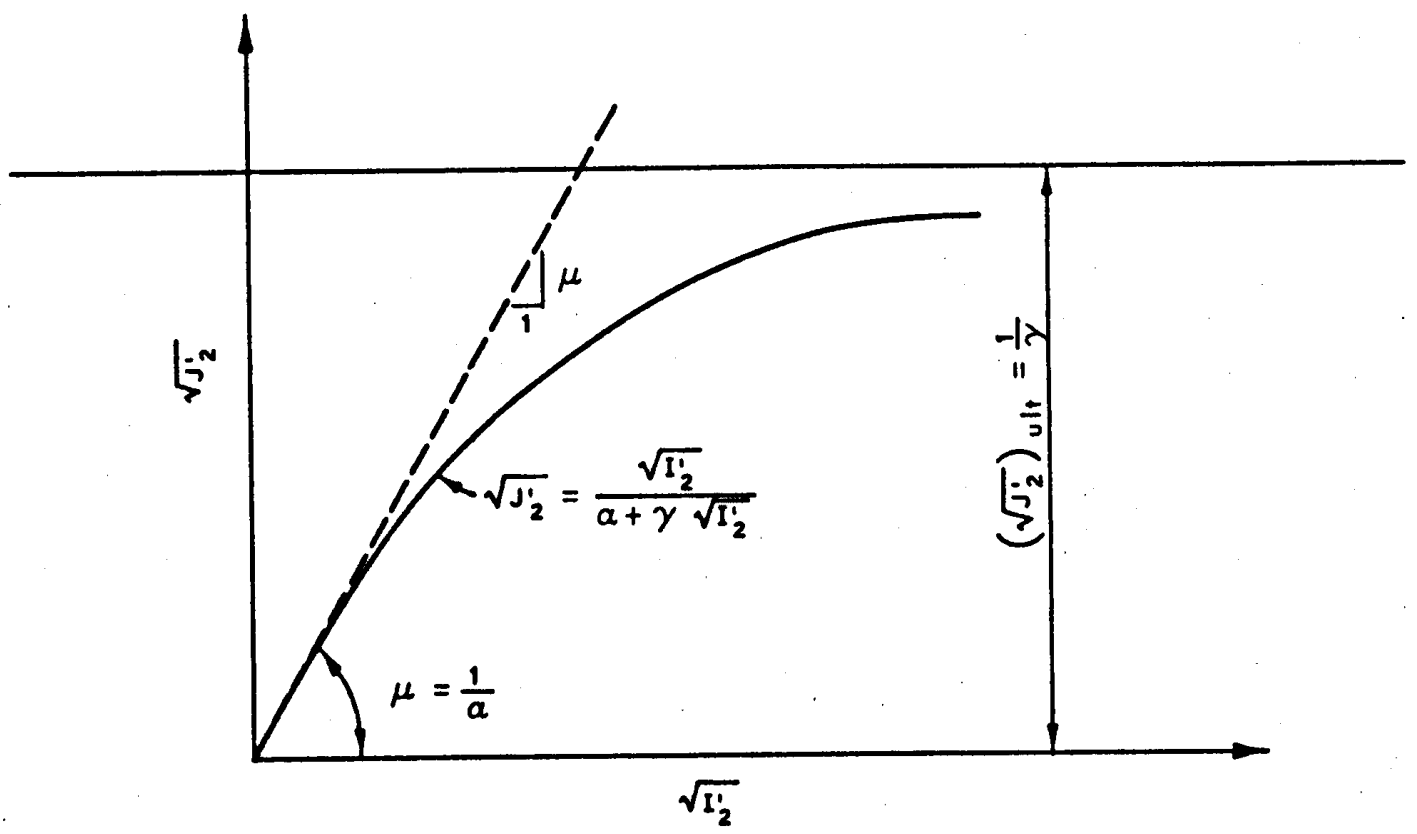

Fig. 7. Typical triaxial compression test

where $\alpha$ and $\gamma$ are parameters whose values depend on the material properties and testing conditions. The physical meaning attached to $\alpha$ and $\gamma$ can be seen in fig. 7, in which $\gamma$ is equal to the inverse of the asymptotic value of $\sqrt{J_{2}^{\prime}}$ (called the ultimate value of $\sqrt{J_{2}^{\prime}}$ and $\alpha$ is equal to the reciprocal of the initial slope of the stress-strain curve $\mu$. Thus,

$$
\begin{aligned}
& \gamma=\frac{1}{\left(\sqrt{J_{2}^{\prime}}\right)_{\text {ult }}} \\
& \alpha=\frac{1}{\mu}
\end{aligned}
$$

For linear elastic material, $\mu=2 G$.

\section{Yield criteria}

57. Mohr-Coulomb criteria have been generally accepted as useful and practical failure criteria in theoretical and applied soil mechanics. In simplest form, these criteria may be stated as 


$$
\tau=c^{\prime}+\sigma^{\prime} \tan \phi^{\prime}
$$

where

$$
\begin{aligned}
\tau & =\text { shear stress on the failure plane } \\
c^{\prime} & =\text { cohesion } \\
\sigma^{\prime} & =\text { normal stress on the failure plane } \\
\emptyset^{\prime} & =\text { angle of internal friction }
\end{aligned}
$$

Despite its wide application and popularity, the Mohr-Coulomb theory has been the subject of controversy among soils engineers regarding the experimental determination of $c^{\prime}$ and $\phi^{\prime}$. Probably the most severe criticism is due to the fact that the Mohr-Coulomb theory does not account for the effect of the intermediate principal stress on material strength. Drucker and Prager ${ }^{43}$ postulated a generalization of the Mohr-Coulomb failure criteria which includes the effect of the intermediate principal stress on the behavior of soil. The yield surface derived by them is conical in the principal stress space (fig. 8) and can be expressed as

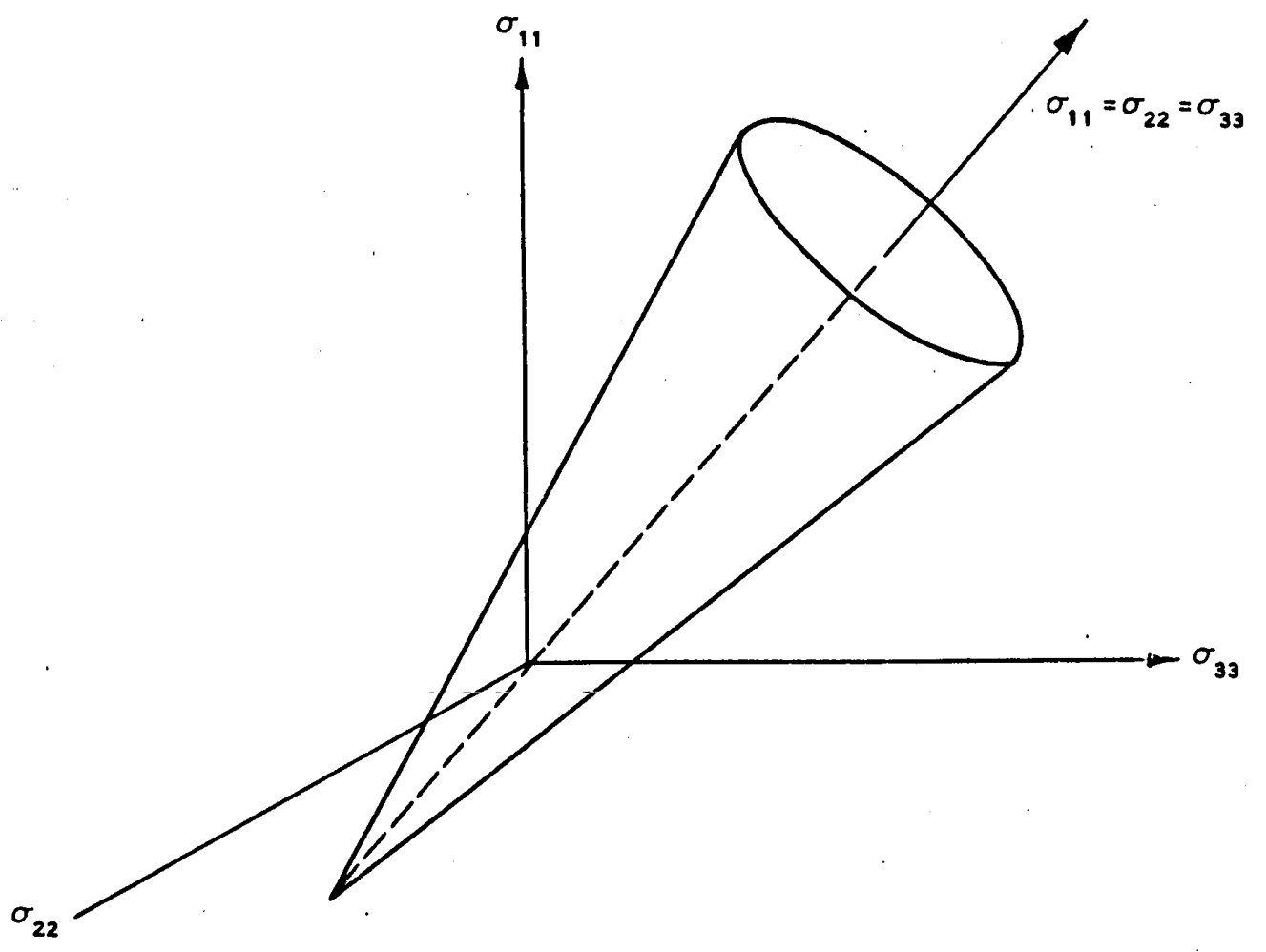

Fig. 8. Three-dimensional representation of Drucker-Prager 43 yield surface 


$$
\sqrt{J_{2}^{\prime}}=K_{c}+\lambda \cdot \frac{J_{1}}{3}
$$

where $\lambda^{\prime}$ and $K_{c}$ are physical constants as shown in fig. 9.

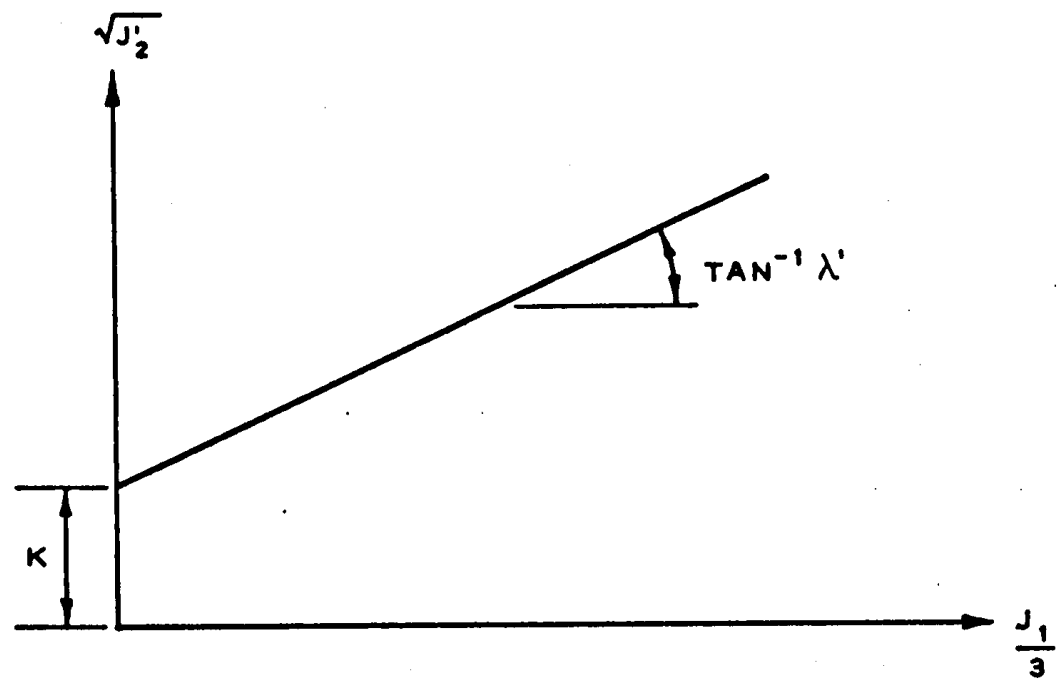

Fig. 9. Drucker-Prager 43 yield envelope

58. Material constants $\lambda$ and $K$ can be related to $c^{\prime}$ and $\emptyset^{\prime}$ under special conditions. The relationship between, $\lambda^{\prime}, K_{c}, c$, and $\emptyset$ has been derived by Christian 44 for the following states of stress:

a. Triaxial compression:

$$
\begin{aligned}
& \lambda^{\prime}=\frac{2 \sin \phi^{\prime}}{\sqrt{3}\left(3-\sin \phi^{\prime}\right)} \\
& K_{c}=\frac{6 c^{\prime} \cos \phi^{\prime}}{\sqrt{3}\left(3-\sin \phi^{\prime}\right)}
\end{aligned}
$$

b. Rigid plastic under plane strain conditions:

$$
\begin{aligned}
& \lambda^{\prime}=\frac{\tan \phi^{\prime}}{\sqrt{9+12 \tan ^{2} \emptyset^{\prime}}} \\
& K_{c}=\frac{3 c^{\prime}}{\sqrt{9+12 \tan ^{2} \emptyset^{\prime}}}
\end{aligned}
$$

For cohesionless materials, $c^{\prime}$ is equal to zero. Thus, according to equations $59 \mathrm{~b}$ and $60 \mathrm{~b}, K_{c}$ should also be equal to zero, and equation 58 may be reduced to 


$$
\left(\sqrt{J_{2}^{1}}\right)_{f}=\lambda \cdot \frac{J_{1}}{3}
$$

It has been observed that the value of $\left(\sqrt{J_{2}^{1}}\right)_{f}$ is not exactly similar to $\left(\sqrt{J_{2}^{\prime}}\right)_{u l t}$ and the ratio between the two quantities may be designated by the failure ratio $R_{f}$ such that

$$
R_{f}=\frac{\left(\sqrt{J_{2}^{\prime}}\right)_{f}}{\left(\sqrt{J_{2}^{\prime}}\right)_{u l t}}
$$

Using equations 62,61 , and $56 a$ and after simple substitution, the parameter $\gamma$ may be expressed in terms of $J_{I}$ and $\lambda^{\prime}$ as

$$
\gamma=R_{f} \frac{1}{\lambda\left(\frac{J_{1}}{3}\right)}
$$

Knowing the value of $\gamma$ and $\mu$ from equations 63 and $56 \mathrm{~b}$, respectively, equation 55 may be expressed in the following form:

$$
\sqrt{J_{2}^{\prime}}=\frac{\mu \sqrt{I_{2}^{\prime}}\left[\lambda \cdot\left(\frac{J_{1}}{3}\right)\right]}{\mu R_{f} \sqrt{I_{2}^{\prime}}+\lambda^{\prime}\left(\frac{J_{1}}{3}\right)} .
$$

The value of $J_{1} / 3$ can be eliminated from equation 64 by using its approximate value as expressed in equation 51 ; thus,

$$
\sqrt{J_{2}^{\prime}}=\frac{\mu \sqrt{I_{2}^{\prime}} \lambda \cdot \sigma_{0}\left(e^{\beta I_{I}}-1\right)}{\mu R_{f} \sqrt{I_{2}^{\prime}}+\lambda \sigma_{0}\left(e^{\beta I_{I}}-1\right)}
$$

The values of $\sqrt{J_{2}^{\prime}}$ and $J_{1} / 3$ as expressed in equations 65 and 51 , respectively, can be used in equation 44 to obtain the desired constitutive equation

$$
\sigma_{i j}=\sigma_{0}\left(e^{\beta I_{1}}-1\right) \delta_{i j}+\frac{\mu \lambda \cdot \sigma_{0}\left(e^{\beta I_{1}}-1\right)}{\mu R_{f} \sqrt{I_{2}^{\prime}}+\lambda \cdot \sigma_{0}\left(e^{\beta I_{1}}-1\right)}\left(\varepsilon_{i j}-\frac{I_{1}}{3} \delta_{i j}\right)
$$

It should be noted that equation 66 can be expressed in terms of the 
angle of internal friction by substituting. $\lambda^{\prime}$ for $\emptyset$ as indicated in equations 59a and 59b. Also, it can be expressed in terms of the shear modulus by substituting $\mu=2 G$. 
PART IV: EXXERIMENTAL DETERMINATION OF MATERIAL CONSTANTS

59. Two types of test are necessary to evaluate the parameters needed for the constitutive model: isotropic compression and triaxial shear tests. Other tests such as uniaxial strain and plane strain shear tests could also be used to develop the model. In this study, the material constants were obtained from isotropic compression, triaxial compression, and plane strain shear tests. However, results from uniaxial strain tests were used to verify the predictability of the model.

\section{Material Parameters $\sigma_{0}$ and $\beta$}

60. The material parameters $\sigma_{0}$ and $\beta$ describe the behavior of the granular material under a spherical state of stress (i.e., isotropic compression). The mathematical expression involving these constants is given in equation 51. The experimental data and the mathematical fit for crushed Napa basalt and Painted Rock materiul are shown in plates 1 and 2, respectively. The values of $\sigma_{0}$ and $\beta$ for the material tests are presented in table 2 .

\section{Material Parameters $\alpha$ and $Y$.}

61. The material constants $\alpha$ and $\gamma$ can be deteriuined from either triaxial compression or plane strain shear stress-strain curves. To conveniently obtain these constants, equation 55 should be linearized in the form

$$
\frac{\sqrt{I_{2}^{\prime}}}{\sqrt{J_{2}^{\prime}}}=\alpha+\gamma \sqrt{I_{2}^{\prime}}
$$

where $\alpha$ is the intercept on the $\sqrt{I_{2}^{1}} / \sqrt{J_{2}^{1}}$ axis and $\gamma$ is the slope of the line.

62. The transformed stress-strain curves for crushed Napa basalt and Painted Rock Dam material are shown in plates 3-6 for triaxial 
compression tests and plates 7-10 for plane strain shear tests. Values of $\alpha$ and $\gamma$ obtained from straight lines that best fit the transformed stress-strain curves are listed in table 3 and were used in formulating the hyperbolic function described in equation 55. Comparisons of the calculated stress-strain curves and the experimental curves are shown in plates 11-14 for triaxial compression tests and in plates 15-18 for plane strain shear tests. These plots show satisfactory agreement between the experimental and calculated stress-strain curves, indicating that the proposed rectangular hyperbola reasonably predicts the stressstrain behavior when expressed in terms of $\sqrt{J_{2}^{\prime}}$ and $\sqrt{I_{2}^{\prime}}$.

63. The ultimate value of the second invariant of the stress deviatoric tensor $\left(\sqrt{J_{2}^{\prime}}\right)_{\text {ult }}$, is somewhat larger than the failure value $\left(\sqrt{J_{2}^{\prime}}\right)_{f}$. This would be expected since the hyperbola remains below the asymptote for all finite values of $\sqrt{I_{2}^{\prime}}$. The relationship between the failure value and the asymptotic value of $\sqrt{\mathrm{J}_{2}^{\prime}}$ is defined as the failure ratio $R_{f}$, as indicated in equation 62. Plate 19 shows the relationship between $\left(\sqrt{J_{2}^{\prime}}\right)_{f}$ and $\left(\sqrt{J_{2}^{\prime}}\right)_{u l t}$ for the crushed Napa basalt and Painted Rock Dam material under triaxial compression, and plate 20 shows the same relationship for plane strain shear tests. These plots indicate that $R_{f}$ is 0.83 for crushed Napa basalt and 0.89 for Painted Rock Dam material when tested in triaxial compression, and 0.59 for crushed Napa basalt and 0.69 for Painted Rock Dam material when tested under plane strain shear conditions.

\section{Material Constant $\lambda^{\prime}$}

64. As indicated in equation 61 , the material constant $\lambda^{\prime}$ can be obtained by measuring the slope of the generalized Mohr-Coulomb envelopes as suggested by Drucker and Prager. 43 These failure envelopes were constructed by plotting $\sqrt{\mathrm{J}_{2}^{\prime}}$ as a function of $\mathrm{J}_{1} / 3$ at failure for various stress levels as shown in plates 21-24. It can be seen that the failure envelopes are not straight lines passing through the origin, and the curvature is more pronounced for material tested in triaxial 
compression (plates 21 and 22) than for that tested under plane strain conditions (plates 23 and 24). However, the failure envelopes were approximated by straight lines passing through the origin with slopes equal to $\lambda^{\prime}$. A summary of the values of $\lambda^{\prime}$ for the materials tested is shown in table 4 .

\section{Material Parameter $\mu$}

65. With the exception of the unconsolidated undrained tests on saturated soil, the initial slope of the stress-strain curve cannot be expected to remain constant under different confining pressures. Such variation in the initial slope $\mu$ is clearly shown in plates 11-18. The values of $\mu$ obtained from the inverse of $a$ for the crushed Napa basalt and the Painted Rock Dam material are presented in table 5 . Previous studies 29,30 on granular materials have indicated that the initial shear modulus varies exponentially with the mean normal stress. Since $\mu$ is directly related to the shear modulus, it can be expected that the value of $\mu$ will vary exponentially with $\mathrm{J}_{1} / 3$.

66. The relationships between $\mu$ and $J_{1} / 3$ ior the crushed Napa basalt and the Painted Rock Dam material are shown in plates 25-28. These plots indicated that the relationship between the two variables may be approximated by a straight line, resulting in a convenient expression for $\mu$,

$$
\mu=c\left(\frac{J_{1}}{3}\right)^{n}
$$

where $\mathrm{C}$ and $\mathrm{n}$ are constants whose values can be obtained from the experimental data (see table 6).

67. The value of $\mu$ in equation 68 may be expressed in terms of the first strain invariant $I_{1}$ using equation 51 as

$$
\mu=c\left[\sigma_{0}\left(e^{\beta I_{1}}-1\right)\right]^{n}
$$


By substituting equation 68 in equation 66 , the stress tensor $\sigma_{\text {if }}$ may be expressed as

$$
\sigma_{i j}=\sigma_{0}\left(e^{\beta I_{1}}-1\right) \delta_{i j}+\frac{C \lambda \cdot \sigma_{0}\left(e^{\beta I_{1}}-1\right)}{C R_{f} \sqrt{I_{2}^{\prime}}+\lambda \cdot\left[\sigma_{0}\left(e^{\beta I_{1}}-1\right)\right]^{1-n}}\left(\varepsilon_{i j}-\frac{I_{1}}{3} \delta_{i j}\right)(70)
$$

where $\sigma_{0}, C, n, R_{f}, B$, and $\lambda^{\prime}$ are soil parameters; $I_{1}$ is the first strain invariant; $I_{2}^{\prime}$ is the second invariant of the deviatoric strain; and $\delta_{i f}$ is Kronecker's delta.

68. Fig. 10 summarizes the flow diagram for evaluating the material constants used in equation 69 . 


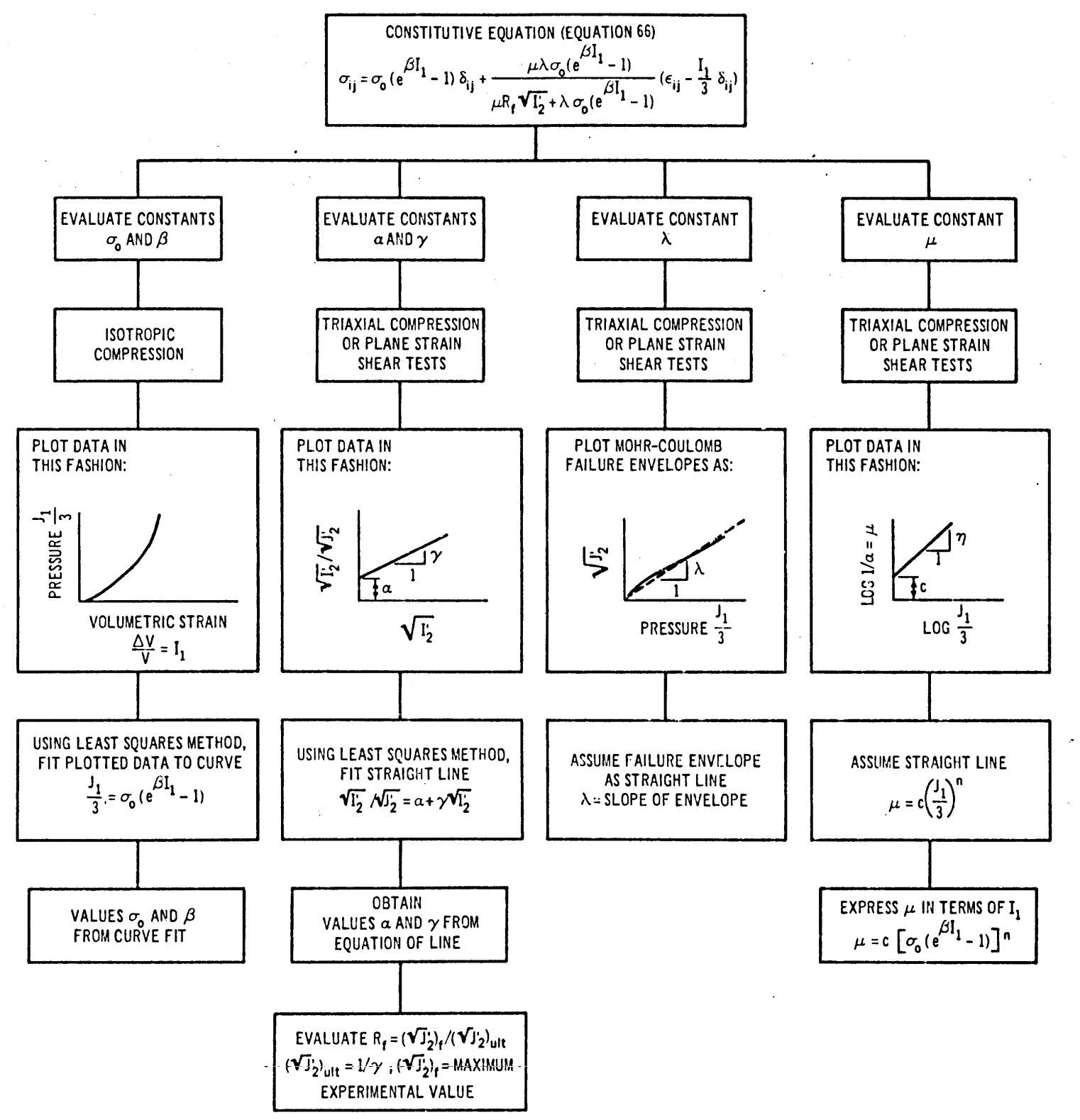

Fig. 10. Flow diagram for evaluating material constants used in the constitutive equation 
69. In previous Parts of this report, a constitutive equation was derived and the soil parameters associated with it were evaluated for both crushed Napa basalt and Painted Rock Dam material. In the following paragraphs, the procedure of examining the constitutive equation is illustrated by using examples of simple states of stresses and deformations.

\section{Hydrostatic State of Stress}

70. The conditions of a hydrostatic state of stress (i.e., spherical state of stress) are

$$
\sigma_{i j}=\left|\begin{array}{lll}
\sigma_{11} & 0 & 0 \\
0 & \sigma_{11} & 0 \\
0 & 0 & \sigma_{11}
\end{array}\right|, \varepsilon_{i j}=\left|\begin{array}{ccc}
\varepsilon_{11} & 0 & 0 \\
0 & \varepsilon_{11} & 0 \\
0 & 0 & \varepsilon_{11}
\end{array}\right|
$$

Applying the above conditions in the expression $\varepsilon_{i j}-\left(I_{l} / 3\right) \delta_{i j}$ yields

and

$$
\text { for } i=j, \quad \varepsilon_{i j}-\frac{I_{1}}{3} \delta_{i j}=0
$$

$$
\text { for } i \neq j, e_{i j}-\frac{I_{1}}{3} \delta_{i j}=0
$$

Thus, equation 69 for the hydrostatic stress state becomes

$$
\sigma_{i j}=\sigma_{0}\left(e^{B I_{1}}-1\right) \delta_{i j}
$$

The above equation exists only for the case in which $i=j$ or $J_{1} / 3=\sigma_{0}\left(e^{\beta I_{1}}-1\right)$, which is the exact form of equation 51. The relationship between the observed and predicted stress-strain relationships for the hydrostatic stress state is shown in plates 1 and 2 . A good correlation between the observed and predicted values should be 
anticipated since the constitutive model was derived from experimental data from hydrostatic compression tests.

\section{Uniaxial State of Strain}

71. The uniaxial state of strain, commonly known as the $K_{0}$ condition, can be described as

$$
\sigma_{i j}=\left|\begin{array}{ccc}
\sigma_{11} & 0 & 0 \\
0 & \sigma_{33} & 0 \\
0 & 0 & \sigma_{33}
\end{array}\right|, \varepsilon_{i j}=\left|\begin{array}{lll}
\varepsilon_{11} & 0 & 0 \\
0 & 0 & 0 \\
0 & 0 & 0
\end{array}\right|
$$

Also, $\quad \sqrt{I_{2}^{\prime}}=\frac{1}{\sqrt{3}} \varepsilon_{11}, I_{1}=\varepsilon_{11}$

For $i \neq j$, both $\varepsilon_{i j}$ and $\delta_{i j}$ vanish and equation 69 is equal to zero for all values of $\sigma_{i j}$, which is in compliance with the conditions of the uniaxial state of strain. However, for $i=j$ the constitutive equation takes the form

$$
\sigma_{11}=\sigma_{0}\left(e^{B \varepsilon_{11}}-1\right)+\frac{2 \lambda^{\prime} \operatorname{Co}\left(e_{0}^{B \varepsilon_{11}}-1\right)}{\sqrt{3} \mathrm{CR}_{f^{\varepsilon} \varepsilon_{11}}+3 \lambda^{\prime}\left[\sigma_{0}\left(e^{B \varepsilon_{11}}-1\right)\right]^{1-n} \varepsilon_{11}}
$$

and

$$
\sigma_{33}=\sigma_{0}\left(e^{\beta \varepsilon} I 1-1\right)-\frac{\lambda \cdot C \sigma\left(e^{\beta \varepsilon_{11}}-1\right)}{\sqrt{3} \mathrm{CR}_{f^{\varepsilon} \varepsilon_{11}}+3 \lambda^{\prime}\left[\sigma_{0}\left(e^{\beta \varepsilon_{11}}-1\right)\right]^{1-n} \varepsilon_{11}}
$$

The predicted stress-strain relation was compared with $K_{0}$ test data on the crushed Napa basalt and the Painted Rock Dam material as shown in plates 29 and 30. The results showed that, even though there is a difference in the values of the predicted and observed stresses, the results are in agreement in at least a qualitative sense.

72. The lack of quantitative agreement between the predicted and the actual data for the uniaxial state of strain (i.e., $K_{0}$ test) may 
be due to many factors. However, the most serious one is the assumption that the volumetric strain $I_{1}$ is only the result of the applied mean normal stress $\mathrm{J}_{1} / 3$. This assumption is a crude approximation of the actual behavior of granular material.

Interpretation of Volumetric Deformation of Granular Material

73. It has been observed that the volumetric deformation of granular material during drained shear ranges from dilatational to compressional, depending on many factors such as density of material, stress level, strain condition, and shape and size of particles. If secondary effects are ignored, the total volumetric strain can be assumed to consist of two components: one component is related to the applied mean normal stress, and the other is due to shear deformations exhibited by the soil.

$$
\frac{\Delta v}{v}=I_{1}=I_{1 c}+I_{1 d}
$$

where $I_{1}$ is the total volumetric strain, $I_{1 c}$ is the component of volumetric strain due to compressional stresses, and $I_{1 d}$ is the component of volumetric strain due to shear deformation.

74. The value of $I_{1 c}$ can be obtained directly in terms of $J_{1} / 3$ using equation 51. The value of $I_{l d}$ can be obtained directly from a pure shear test; however, \& pure shear test is very difficult to perform in the laboratory. As an alternative, $I_{I d}$ could be obtained by shearing soil under a constant mean normal stress, which is much easier to perform than the pure shear test. Unfortunately, the experimental data needed to obtain $I_{I d}$ are not available at the present time, but it is hoped that such tests may be conducted on crushed Napa basalt and Painted Rock Dam material in the future.

75. An early study by Stroganov 45 on sand under plane strain deformation showed that $I_{1 d}$ is directly related to the shear deformation. For three-dimensional problems, Stroganov's hypothesis may be interpreted by 


$$
I_{1 d}=f\left(\sqrt{I_{2}^{\prime}}\right)
$$

where $f$ is some unknown function of $\sqrt{I_{2}^{\prime}}$ that can be determined from appropriate experimental data.

76. It has been pointed out by Stroganov that $f$ is constant, and he referred to it as the friability coefficient. However, preliminary examination made on crushed Napa basalt, by assigning different values for $f$ as shown in plate 3l, indicated that $f$ is not constant and can be positive or negative depending on the density of the material. Therefore, unless the actual value of $f$ is obtained, it is not possible to obtain quantitative agreement between the predicted and the experimental data.

\section{Cylindrical State of Strain}

77. The cylindrical state of strain, commonly known as triaxial compression, can be defined as

$$
\sigma_{i j}=\left|\begin{array}{lll}
\sigma_{11} & 0 & 0 \\
0 & \sigma_{33} & 0 \\
0 & 0 & \sigma_{33}
\end{array}\right|, \varepsilon_{1 j}=\left|\begin{array}{ccc}
\varepsilon_{11} & 0 & 0 \\
0 & \varepsilon_{33} & 0 \\
0 & 0 & \varepsilon_{33}
\end{array}\right|
$$

Also,

$$
I_{1}=\varepsilon_{11}+2 \varepsilon_{33}, \sqrt{I_{2}^{\prime}}=\frac{1}{\sqrt{3}}\left(\varepsilon_{11}-\varepsilon_{33}\right)
$$

78. The same procedure can be used to obtain the components of the stress tensor. In the conventional triaxial test, $\sigma_{33}$ is usually constant and can be designated as $P$; the only stress component is $\sigma_{11}$ - According to equation 69 , the major principal stress and deviatoric stress can be expressed as 


$$
\begin{gathered}
\sigma_{11}=\sigma_{0}\left[e^{\beta\left(\varepsilon_{11}+2 \varepsilon_{33}\right)}-1\right]+\frac{C \lambda \sigma_{0}\left[e^{\beta\left(\varepsilon_{11}+2 \varepsilon_{33}\right)}-1\right]}{\frac{1}{\sqrt{3}} C R_{f}\left(\varepsilon_{11}-\varepsilon_{33}\right)+\lambda\left\{\sigma_{0}\left[e^{\beta\left(\varepsilon_{11}+2 \varepsilon_{33}\right)}-1\right]\right\}^{1-n} \frac{2}{3}\left(\varepsilon_{11}-\varepsilon_{33}\right)} \\
\left(\sigma_{11}-\sigma_{33}\right)= \\
\frac{C \lambda \sigma_{0}\left[e^{\beta\left(\varepsilon_{11}+2 \varepsilon_{33}\right)}-1\right]}{\sqrt{3} C R_{f}\left(\varepsilon_{11}-\varepsilon_{33}\right)+\lambda\left\{\sigma_{0}\left[e^{\beta\left(\varepsilon_{11}+2 \varepsilon_{33}\right)}-1\right]\right\}^{1-n}\left(\varepsilon_{11}-\varepsilon_{33}\right)} .
\end{gathered}
$$

Predicted and Experimental Correlation for the

\section{Cylindrical state of Strain}

79. For the cylindrical state, the mean normal stress can be expressed as

$$
\frac{J_{1}}{3}=\frac{1}{3}\left(\sigma_{11}-\sigma_{33}\right)+\sigma_{33}
$$

Combining equations 78 and 51 yields

$$
\sigma_{0}\left(e^{B I_{1}}-1\right)=\frac{1}{3}\left(\sigma_{11}-\sigma_{33}\right)+\sigma_{33}
$$

By substituting equation 79 in equation 77 , the resulting equation may be expressed as

$$
\left(\sigma_{11}-\sigma_{33}\right)=\frac{\operatorname{c\lambda }\left[\frac{1}{3}\left(\sigma_{11}-\sigma_{33}\right)+\sigma_{33}\right]\left(\varepsilon_{11}-\varepsilon_{33}\right)}{\frac{1}{\sqrt{3}} \operatorname{CR}_{f}\left(\varepsilon_{11}-\varepsilon_{33}\right)+\lambda\left[\frac{1}{3}\left(\sigma_{11}-\sigma_{33}\right)+\sigma_{33}\right]^{1-n}}
$$

or

$$
\left(\varepsilon_{11}-\varepsilon_{33}\right)=\frac{\lambda\left(\sigma_{11}-\sigma_{33}\right)\left[\frac{1}{3}\left(\sigma_{11}-\sigma_{33}\right)+\sigma_{33}\right]^{1-n}}{\operatorname{C\lambda }\left[\frac{1}{3}\left(\sigma_{11}-\sigma_{33}\right)+\sigma_{33}\right]-\frac{1}{\sqrt{3}} \operatorname{CR}_{f}\left(\sigma_{11}-\sigma_{33}\right)}
$$

It should be noted that the experimental data for the conventional triaxial tests (i.e., cylindrical state of strain) were obtained under constant value of $\sigma_{33}$. Thus, by incrementing $\sigma_{11}$, the corresponding values of $\left(\varepsilon_{11}-\varepsilon_{33}\right)$ can be generated.

80. The correlation between the experimental stress-strain curves 
and those predicted by equation 81 is shown in plates 32 and 33 for the Painted Rock Dam material and in plates 34 and 35 for the crushed Napa. basalt. Once again, the predicted and the experimental results are in reasonable agreement in a qualitative sense.

\section{Plane Strain State}

81. For plane strain deformation, the stress and strain tensors may be expressed by

$$
\begin{gathered}
\sigma_{1 j}=\left|\begin{array}{ccc}
\sigma_{11} & 0 & 0 \\
0 & \sigma_{22} & 0 \\
0 & 0 & \sigma_{33}
\end{array}\right|, \varepsilon_{1 j}=\left|\begin{array}{ccc}
\varepsilon_{11} & 0 & 0 \\
0 & 0 & 0 \\
0 & 0 & \varepsilon_{33}
\end{array}\right| \\
I_{1}=\varepsilon_{11}+\varepsilon_{33} \\
\sqrt{J_{2}^{\prime}}=\frac{1}{\sqrt{2}}\left[\left(\frac{2 \varepsilon_{11}-\varepsilon_{33}}{3}\right)^{2}+\left(\frac{2 \varepsilon_{33}-\varepsilon_{11}}{3}\right)^{2}+\left(\frac{\varepsilon_{11}+\varepsilon_{33}}{3}\right)^{2}\right]^{1 / 2}=\sqrt{2}\left(\varepsilon_{1}^{2}+\varepsilon_{3}^{2}-\varepsilon_{1} \varepsilon_{3}\right)
\end{gathered}
$$

The above equations can be substituted in equation 69 to obtain the governing equation for plane strain deformation. 
82. The purpose of this study was twofold: first, to summarize the methodology and procedures used in modeling soils; secondly, to develop a mathematical model which can describe and predict the nonlinear behavior of granular soils.

83. Based on the literature review it was found that the majority of soil models (i.e., linear, bilinear, trilinear, and hyperbolic) used in numerical techniques such as the finite element method are based on theories of elasticity and curve fittings. While these models provide good agreement between the observed and predicted soil behavior under restricted conditions, they cannot be used to predict stress-strain behavior for other than those conditions from which they were derived. Consequently, they cannot be classified as constitutive models. Constitutive models based on higher order elastic continuum are probably the only models which realistically represent material behavior. However, the procedure used in developing such models is difficult from the analytical as well as the experimental point of view.

84. A nonlinear elastic constitutive model was derived for two granular materials: crushed Napa basalt and Painted Rock Dam material. The derived model was based on the following experimental observations:

a. The hydrostatic stress-strain curve for granular soil can be approximated by exponential function relating $\mathrm{J}_{1} / 3$ and $\mathrm{I}_{1}$.

b. The magnitude of stress prior to failure for the soil tested is a function of the total strain.

c. The stress-strain relationship as expressed in terms of $\sqrt{J_{2}^{\prime}}$ versus $\sqrt{I_{2}^{\prime}}$ can be approximated by a rectangular hyperbola for both triaxial compression and plane strain shear.

d. The failure points for both crushed Napa basalt and Painted Rock Dam material fell on the Drucker-Prager 43 failure envelope.

e. The portion of the stress-strain curve beyond the failure point could not be accounted for; therefore, material which exhibits strain softening characteristics cannot be approximated by the proposed constitutive model. 
85. The proposed model is the simplest type of nonlinear constitutive model, and it does not account for shear-dilatancy phenomena. Therefore, while there is a qualitative agreement between the predicted and actual material behavior, the quantitative agreement needs to be improved. Thus, a higher order constitutive equation, which includes shear-dilatancy phenomena, should be studied in order to significantly improve the accuracy of the model. It is also recomended that the analytical and experimental research be continued to include a plasticity model in an effort to improve the existing knowledge with regard to nonlinear behavior of soils. 
1. Al-Hussaini, M. M., "Investigation of Plane Strain Shear Testing; Tests on Crushed Napa Basalt," Technical Report S-71-2, Report 2, Jun 1971, U. S. Army Engineer Waterways Experiment Station, CE, Vicksburg, Miss.

2. "Investigation of Plane Strain Shear Testing; Plane Strain and Triaxial Compression Tests on Painted Rock Dam Material," Technical Report S-71-2, Report 3, Sep 1972, U. S. Army Engineer Waterways Experiment Station, $\mathrm{CE}$, Vicksburg, Miss.

3. , "Investigation of Plane Strain Shear Testing; WES HighCapacity Plane Strain Shear Apparatus," Technical Report S-71-2, Report 1, Mar 1971, U. S. Army Engineer Waterways Experiment Station, CE, Vicksburg, Miss.

4. "The Influence of End Restraint and the Method of Consolidation on the Drained Triaxial Compressive Strength of Crushed Napa Basalt," Miscellaneous Paper S-70-18, Jun 1970, U. S. Army Engineer Waterways Experiment Station, CE, Vicksburg, Miss.

5. Hetenyi, M. I., Beams on Elastic Foundation, 7 th ed., University of Michigan Press, Ann Arbor, Mich., 1964.

6. Yoder, E. J., Principles of Pavement Design, $2 \mathrm{~d}$ ed., Wiley, New York, 1963.

7. Girijavallabhan, C. V. and Reese, L. S., "Finite-Element Method for Problems in Soil Mechanics," Journal, Soil Mechanics and Foundations Division, American Society of Civil Engineers, Vol 94, No. SM2, Mar 1968, pp 473-496.

8. Duncan, J. M., Monismith, C. L., and Wilson, E. L., "Finite Element Analyses of Pavements," Soil Stresses and Pavement Element Analyses, Highway Research Record No. 228, pp 18-33, 1968, Highway Research Board - National Research Council, Washington, D. C.

9. Michelo, J., "Analysis of Stresses and Displacements in an N-Layered Elastic System Under a Load Uniformly Distributed on a Circular Area,". Internal Report, Sep 1963, California Research Corp.

10. Duncan, J. M. and Dunlop, P., "Slopes in Stiff-Fissured Clays and Shales," Journal, Soil Mechanics and Foundations Division, American Society of Civil Engineers, Vol 95, No. SM2, Mar 1969, pp 467-492.-

11. D'Appolonia, D. J. and Lambe, T. W., "Method for Predicting Initial Settlement," Journal, Soil Mechanics and Foundations Division, American Society of Civil Engineers, Vol 96, No. SM2, Mar 1970, pp 523-544.

12. Dunlop, P. and Duncan, J. M., "Development of Failure Around Excavated Slopes," Journal, Soil Mechanics and Foundations Division, American Society of Civil Engineers, Vol 96, No. SM2, Mar 1970, pp 471-493. 
13. Ellison, R. D., D'Appolonia, E., and Thiers, G. R., "LoadDeformation Mechanism for Bored Piles," Journal, Soil Mechanics and Foundations Division, American Society of Civil Engineers, Vol 97 , No. SM4, Apr 1971, pp 661-678.

14. Desai, C. S. and Abel, J. F., Introduction to the Finite Element Method, A Numerical Method for Engineering Analysis, Van Nostrand Reinhold Co., New York, 1972.

15. Kondner, R. L., "Hyperbolic Stress-Strain Response: Cohesive Soils," Journal, Soil Mechanics and Foundations Division, American Society of Civil Engineers, Vol 89, No. SMI, Feb 1963, pp 115-143.

16. Kondner, R. L. and Zelasko, J. S., "Void Ratio Effects on the Hyperbolic Stress-Strain Response of a Sand," Proceedings, Second Pan-American Conference on Soll Mechanics and Foundation Engineering, Vol 1, 1963, pp 289-333.

17. Hansen, T. B., Discussion of "Hyperbolic Stress-Strain Response: Cohesive Solls," Journal, Soll Mechanics and Foundations Division, American Soclety of Civil Engineers, Vol 89, No. SM4, Jul 1963, pp 241-242.

18. Duncan, J. M. and Chang, C. Y., "Nonlinear Analysis of Stress and Strain in Soils," Journal, Soil Mechanics and Foundations Division, American Society of Civil Engineers, Vol 96, No. SM5, Sep 1970, pp 1629-1653.

19. Chang, C. Y. and Duncan, J. M., "Analysis of Soil Movement Around a Deep Excavation," Journal, Soil Mechanics and Foundations Division, American Society of Civil Engineers, Vol 96, No. SM5, Sep 1970, pp 1655-1681.

20. Kulhawy, F. H., Duncan, J. M., and Seed, H. B., "Finite Element Analyses of Stresses and Movements in Embankments During Construction," Contract Report S-69-8, Nov 1969, U. S. Army Engineer Waterways Experiment Station, CE, Vicksburg, Miss.; prepared under Contract No. DACW39-68-C-0078 by College of Engineering, Office of Research Services, University of California, Berkeley, Calif.

21. Palmerton, J. B., "Application of Three-Dimensional Finite Element Analysis," Proceedings of the Symposium, Applications of Finite Element Method in Geotechnical Engineering, Vicksburg, Miss., Sep 1972, pp 155-214.

22. Ahlberg, J: H., Nilson, E. N., and Walsh, J. L., Theory of Splines and Their Applications, Academic Press, New York, 1967.

23. Cheek, J. B., Jr., Radhakrishnan, N., and Tracy, F. T., "Application of Spline Interpolation Methods to Engineering Problems," Miscellaneous Paper 0-71-2, Jul 1971, U. S. Army Engineer Waterways Experiment Station, CE, Vicksburg, Miss.

24. Greville, T. N. E., "Data Fitting by Spline Functions," Technical Summary Report No. 893, Jun 1968, U. S. Army Máthematical Research Center, University of Wisconsin, Madison, Wis. 
25. Desai, C. S., "Nonlinear Analyses Using Spline Functions," Journal, Soil Mechanics and Foundations Division, American Society of Civil Engineers, Vol 97, No. SM10, Oct 1971, pp 1461-1480.

26. Clough, R. W. and Woodward, R. J. III, "Analysis of Embankment Stresses and Deformations," Journal, Soil Mechanics and Foundations Division, American Society of Civil Engineers, Vol 93, No. SM4, Jul 1967, pp 529-549.

27. Ko, H. Y, and Scott, R. F., "Deformation of Sand in Hydrostatic Compression," Journal, Soil Mechanics and Foundations Division, American Society of Civil Engineers, Vol 93, No. SM3, May 1967, pp 137-156.

28. E1-Sohby, M. A., "Elastic Behavior of Sand," Journal, Soil Mechanics and Foundations Division, American Society of Civil Engineers, Vol 95, No. SM6, Nov 1969, pp 1393-1409.

29. Domaschuk, L. and Wade, N. H., "A Study of Bulk and Shear Moduli of a Sand," Journal, Soil Mechanics and Foundations Division, American Society of Civil Engineers, Vol 95, No. SM2, Mar 1969, pp 561-581.

30. Al-Hussaini, M. M. and Radhakrishnan, N., "Analysis of Plane Strain Tests Using the Finite Element Method," Proceedings of the Symposium, Application of the Finite Element Method in Geotechnical Engineering, Vicksburg, Miss., Sep 1972, pp 215-257.

31. Clough, G. W. and Duncan, J. M., "Finite Element Analyses of Port Allen and Old River Locks," Contract Report S-69-6, Sep 1969, U. S. Army Engineer Waterways Experiment Station, CE, Vicksburg, Miss.; prepared under Contract No. DACW39-68-C-0040 by College of Engineering, Office of Research Services, University of California, Berkeley, Calif.

32. Girijavallabhan; C. V. and Mehta, K. C., "Stress-Strain Relationship from Compression Tests on Nonlinear Materials," Proceedings of the Symposium, Application of Finite Element Methods in Civil Engineering, Nov 1969, pp 457-480.

33. Eringen, A. C., Nonlinear Theory of Continuous Media, McGraw-Hill, New York, 1962.

34. Prager, W., Introduction to Mechanics of Continua, Ginn and Co., Boston, 1961 .

35. Truesdell, C. A., "Hypoelasticity," Journal of Rational Mechanics and Analysis, Vol 4, No. 83, 1955, pp 83-133.

36. Rivlin, R. S. and Ericksen, J. I., "Stress-Deformation Relation for Isotropic Material," Journal of Rational Mechanics and Analysis, Vol 4, 1955, pp 323-425.

37. Rohani, B., "Constitutive Equation for Continuous Media" (in preparation), U. S. Army Engineer Waterways Experiment Station, CE, Vicksburg, Miss. 
38. Rohani, B., A Nonlinear Elastic-Viscoplastic Constitutive Relationship for Earth Material, Ph. D. Dissertation, 1970, Texas A\&M University, College Station, Tex.

39. Chang, T. Y. et al., "An Integrated Approach to the Stress Analysis of Granular Materials," 1967, California Institute of Technology, Pasadena, Calif.

40. Nelson, I. and Baron, M. L., "Investigation of Ground Shock Effects in Nonlinear Hysteretic Media; Development of Mathematical Material Model," Contract Report S-68-1, Report 1, Mar 1968, U. S. Army Engineer Waterways Experiment Station, $\mathrm{CE}$, Vicksburg, Miss.; prepared under Contract No. DACA39-67-C-0048 by Paul Weidlinger, Consulting Engineers, New York.

41. Coon, M. D. and Evans, R. J., "Recoverable Deformation of Cohesionless Soils," Journal, Soil Mechanics and Foundations Division, American Society of Civil Engineers, Vol 97, No. SM2, Feb 1971, pp 375-391.

42. Timoshenko, S. and Goodier, J. N., Theory of Elasticity, $2 d$ ed., McGraw-Hill, New York, 1951, p 372.

43. Drucker, D. C. and Prager, W., "Soil Mechanics and Plastic Analysis of Limit Design," Quarterly of Applied Mathematics, Vol 10, No.2, 1952, pp 157-175.

44. Christian, J. T., "Two-Dimensional Analysis of Stress and Strain in Soils; Plane-Strain Deformation Analysis of Soil," Contract Report 3-129, Report 3, Dec 1966, U. S. Army Engineer Waterways Experiment Station, CE, Vicksburg, Miss;; prepared under Contract No. DA-22-079-eng-47I by Massachusetts Institute of Technology, Cambridge, Mass.

45. Stroganov, A. V., "Plane Plastic Deformation of Soil," Brussel Conference on Earth Pressure Problems, Vol 1, 1958, pp 94-103. 
Table I

Relationships Between Various Elastic Constants for Isotropic Soils

\begin{tabular}{|c|c|c|c|c|c|c|}
\hline- & - & $\lambda$ & $G$ & $\mathrm{E}$ & $v$ & $\mathrm{~K}$ \\
\hline \multirow[t]{4}{*}{$\lambda$} & G & $\cdots$ & $\cdots$ & $\frac{G(3 \lambda+2 G)}{\lambda+G}$ & $\frac{\lambda}{2(\lambda+G)}$ & $\frac{3 \lambda+2 G}{3}$ \\
\hline & $\mathbf{E}$ & $\cdots$ & $\frac{A^{*}+(E-3 \lambda)}{4}$ & $\cdots$ & $\frac{A-(E+\lambda)}{4 \lambda}$ & $\frac{A+(3 \lambda+E)}{6}$ \\
\hline & $\nu$ & $\cdots$ & $\frac{\lambda(1-2 v)}{2 v}$ & $\frac{\lambda(1+v)(1-2 v)}{v}$ & ... & $\frac{\lambda(1+v)}{3 v}$ \\
\hline & $\mathrm{K}$ & $\cdots$ & $\frac{3(K-\lambda)}{2}$ & $\frac{9 K(K-\lambda)}{3 K-\lambda}$ & $\frac{\lambda}{3 K-\lambda}$ & \\
\hline \multirow[t]{3}{*}{ G } & $\mathbf{E}$ & $\frac{G(2 G-E)}{E-3 G}$ & $\cdots$ & $\cdots$ & $\frac{E-2 G}{2 G}$ & $\frac{G E}{3(3 G-E)}$ \\
\hline & $v$ & $\frac{2 G v}{1-2 v}$ & $\cdots$ & $2 G(1+v)$ & $\cdots$ & $\frac{2 G(1+v)}{3(1-2 v)}$ \\
\hline & $\mathrm{K}$ & $\frac{3 K-2 G}{3}$ & $\cdots$ & $\frac{9 K G}{3 K+G}$ & $\frac{3 K-2 G}{2(3 K+G)}$ & \\
\hline \multirow[t]{2}{*}{$E$} & $v$ & $\frac{v E}{(1+v)(1-2 v)}$ & $\frac{E}{2(1+v)}$ & $\cdots$ & . & $\frac{E}{3(1-2 v)}$ \\
\hline & $K$ & $\frac{3 K(3 K-E)}{9 K-E}$ & $\frac{3 E K}{9 K-E}$ & $\ldots$ & $\frac{3 K-E}{6 K}$ & \\
\hline$v$ & $\mathrm{~K}$ & $\frac{3 K v}{I+v}$ & $\frac{3 K(1-2 v)}{2(1+v)}$ & $3 K(1-2 v)$ & $\cdots$ & \\
\hline
\end{tabular}

* $A \equiv \sqrt{(E+\lambda)^{2}+8 \lambda^{2}}$. 
Table 2

Summary of $\sigma_{0}$ and $\beta$ for the Material Tests

\begin{tabular}{|c|c|c|c|c|}
\hline & Crushed & Basalt & Painted Rock Dam & Material \\
\hline $\begin{array}{l}\text { Material } \\
\text { Constant } \\
\end{array}$ & $\begin{array}{l}\mathrm{D}_{r}=100 \\
\text { percent }\end{array}$ & $\begin{array}{l}D_{r}=70 \\
\text { percent }\end{array}$ & $\begin{array}{l}D_{r}=100 \\
\text { percent }\end{array}$ & $\begin{array}{l}\mathrm{D}_{r}=70 \\
\text { percent }\end{array}$ \\
\hline$\sigma_{0}$ & 47 & 47 & 18 & 18 \\
\hline B & 66.6 & 36.3 & 133 & 94 \\
\hline
\end{tabular}


Table 3

Summary of $\alpha$ and $\gamma$ Values

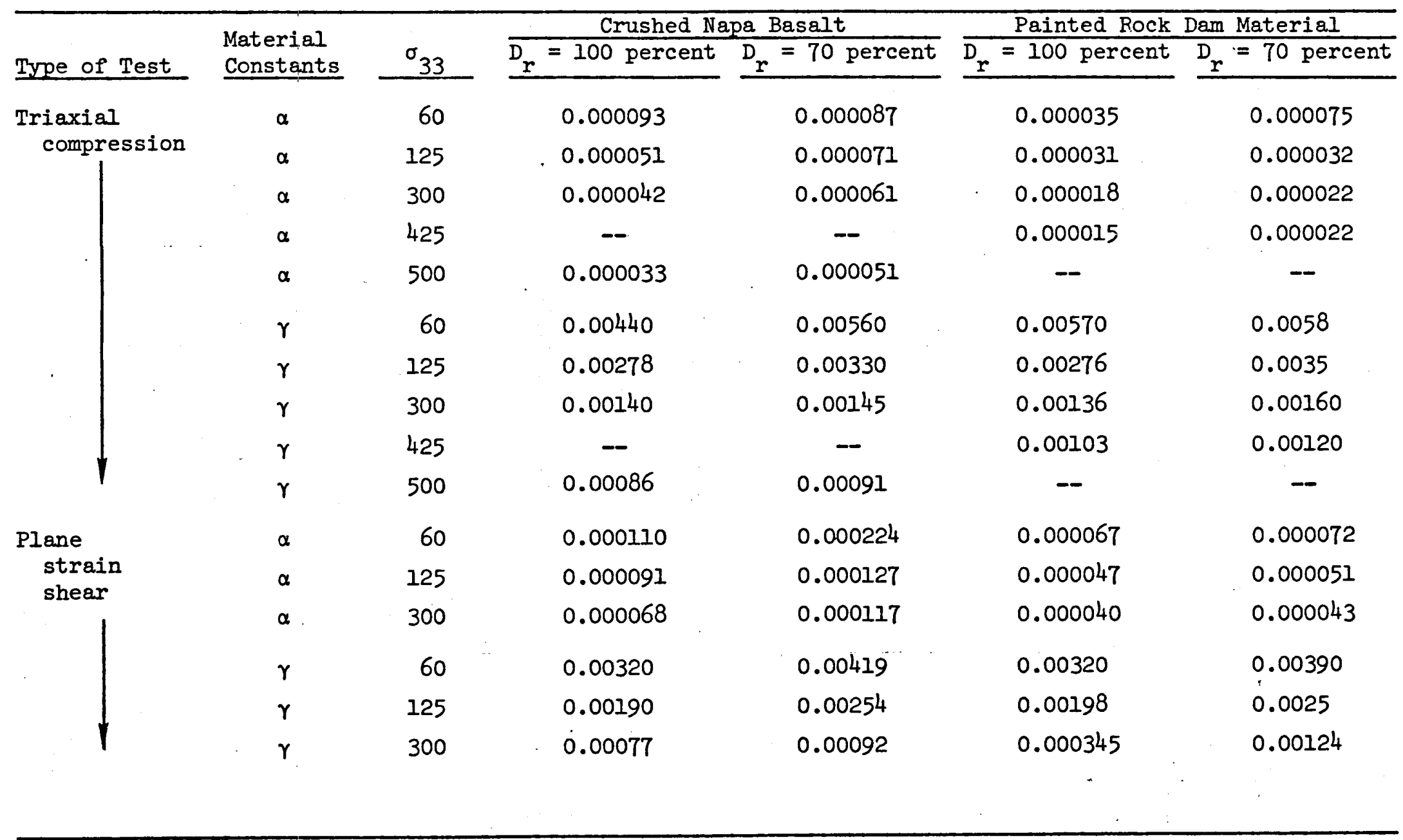


Table 4

Summary of $\lambda^{\prime}$ Values

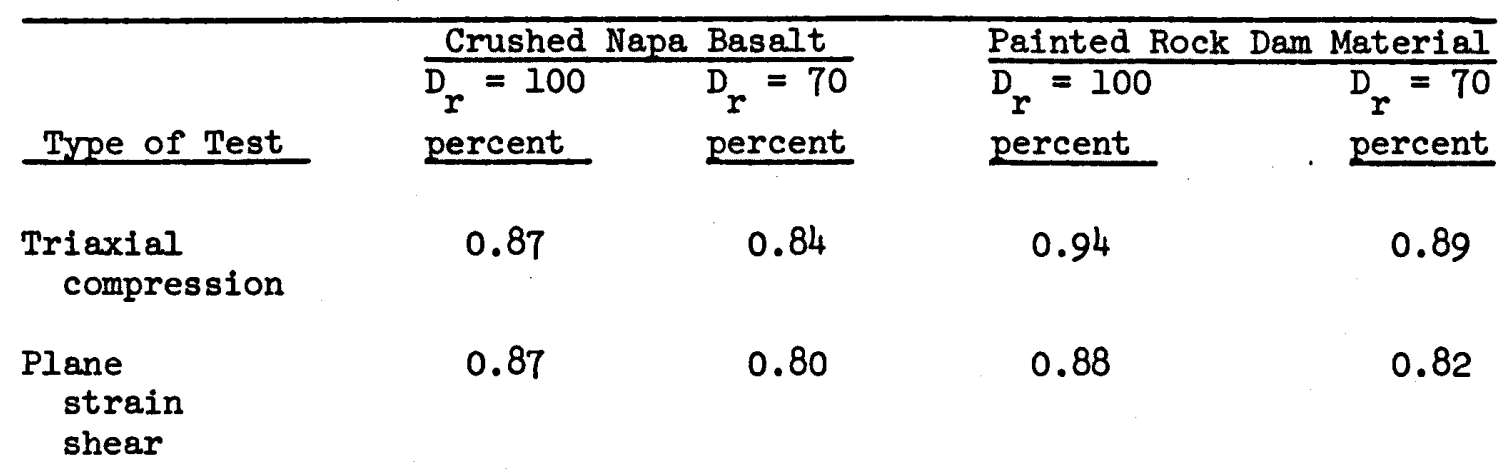

Table 5

Summary of $\dot{\mu}$ Values

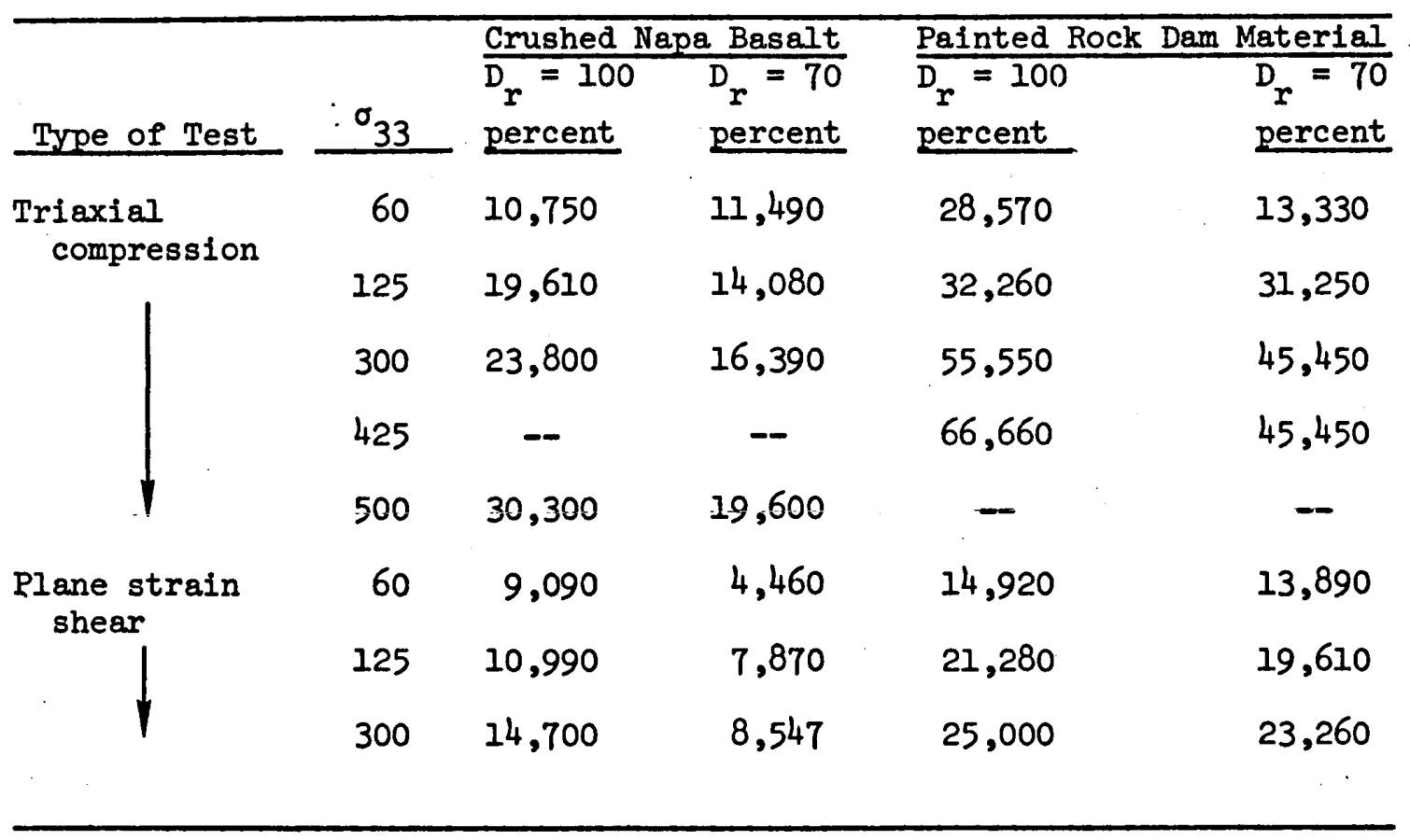


Table 6

Summary of $C$ and $n$ Values

Crushed Napa Basalt Triaxial Compression Plane Strain Shear $\mathrm{D}_{r}=100 \quad \mathrm{D}_{r}=70 \quad \mathrm{D}_{r}$

Parameters

C

n percent

0.268

0.374 percent

percent

0.288

0.384

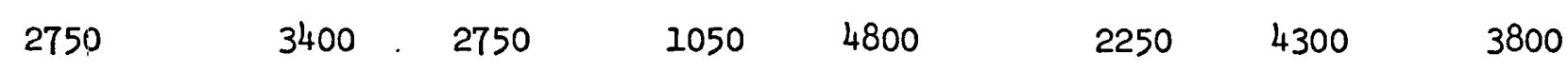

Triaxial Compression Plane Strain Shear

$\begin{array}{llll}D_{r}=100 & D_{r}=70 & D_{r}=100 & D_{r}=70\end{array}$

percent percent percent percent

0.414

0.493

0.315

0.315 


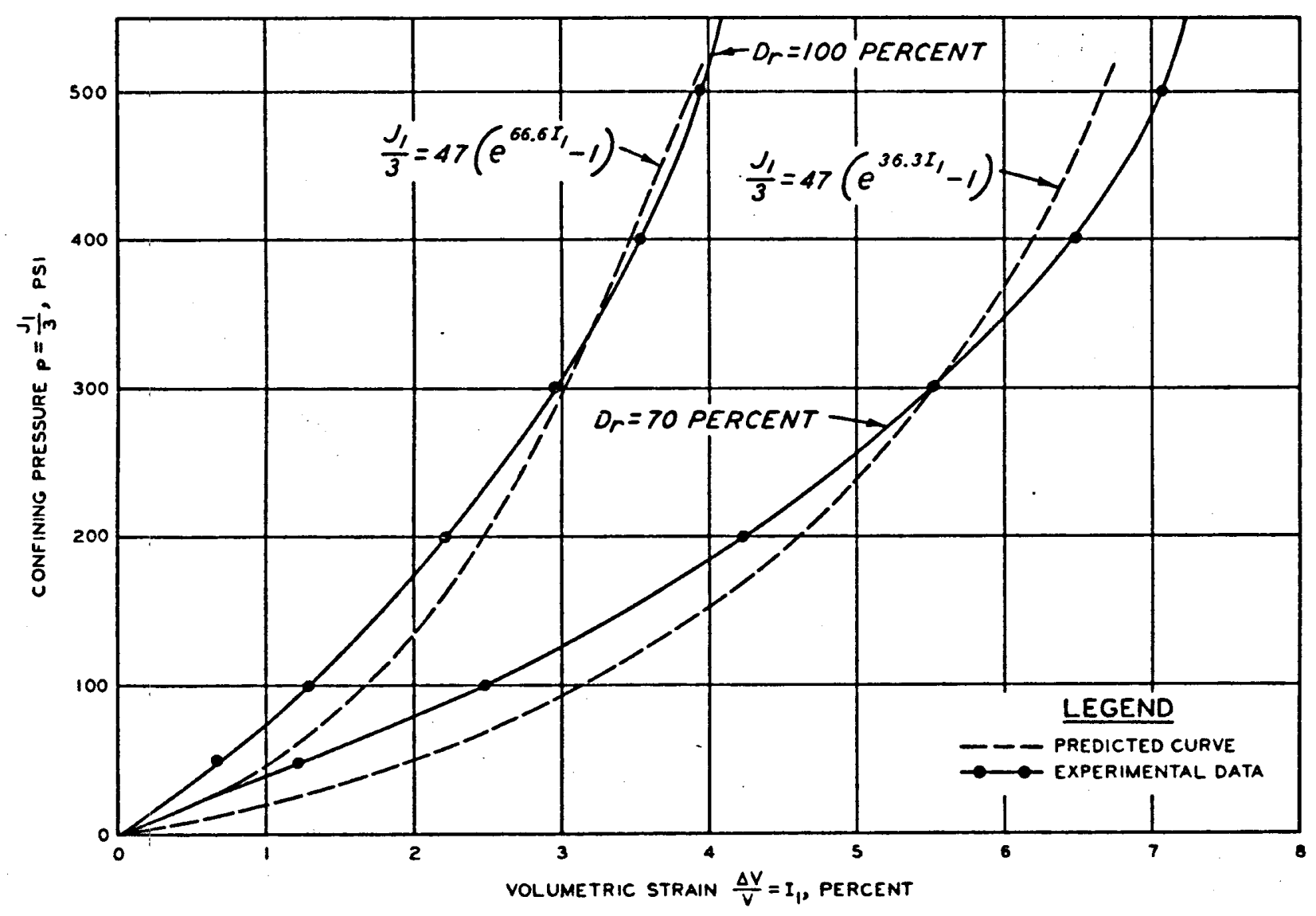

窇

PRESSURE - VOLUMETRIC STRAIN

RELATIONSHIP FOR CRUSHED NAPA BASALT 


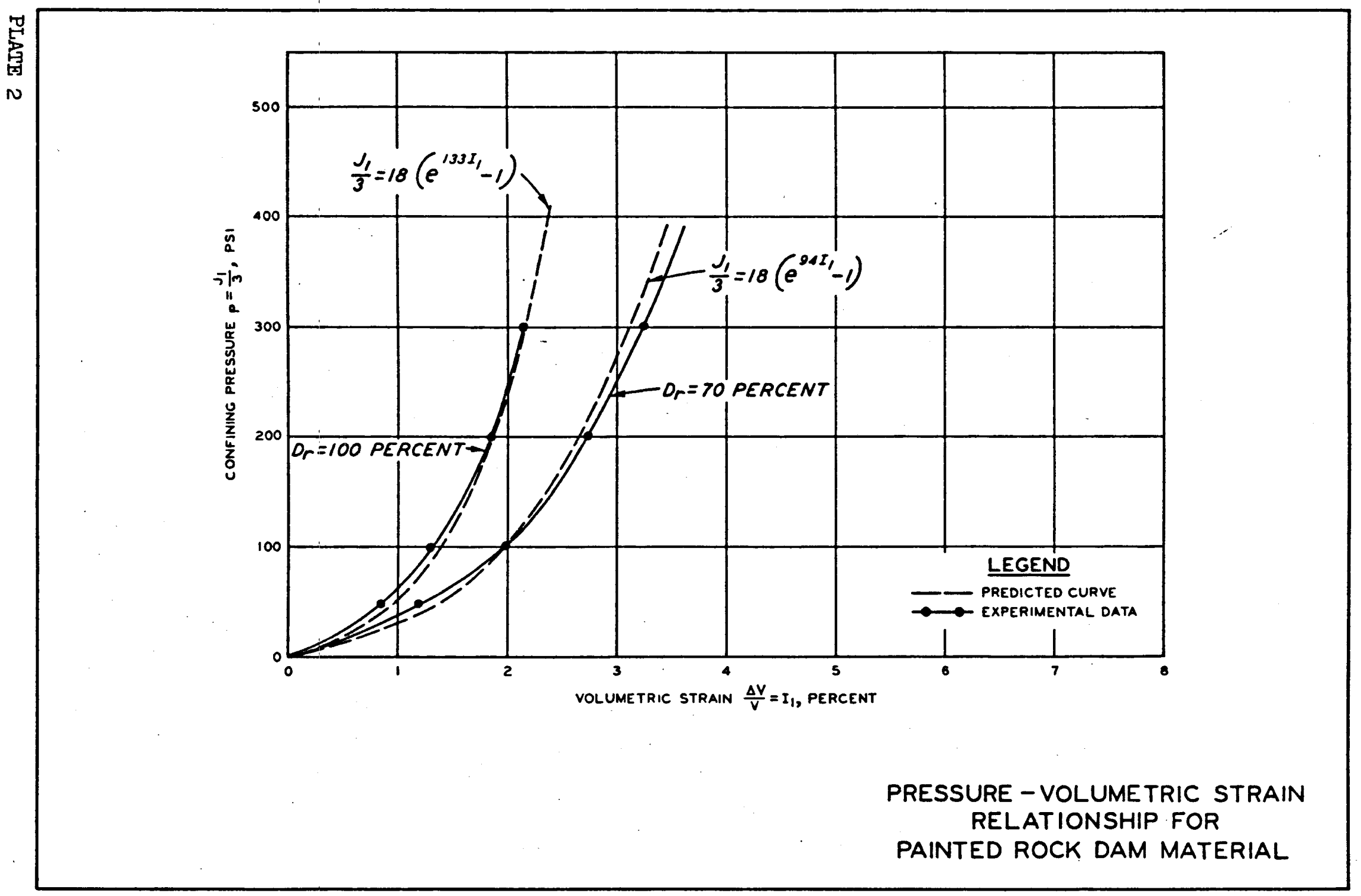




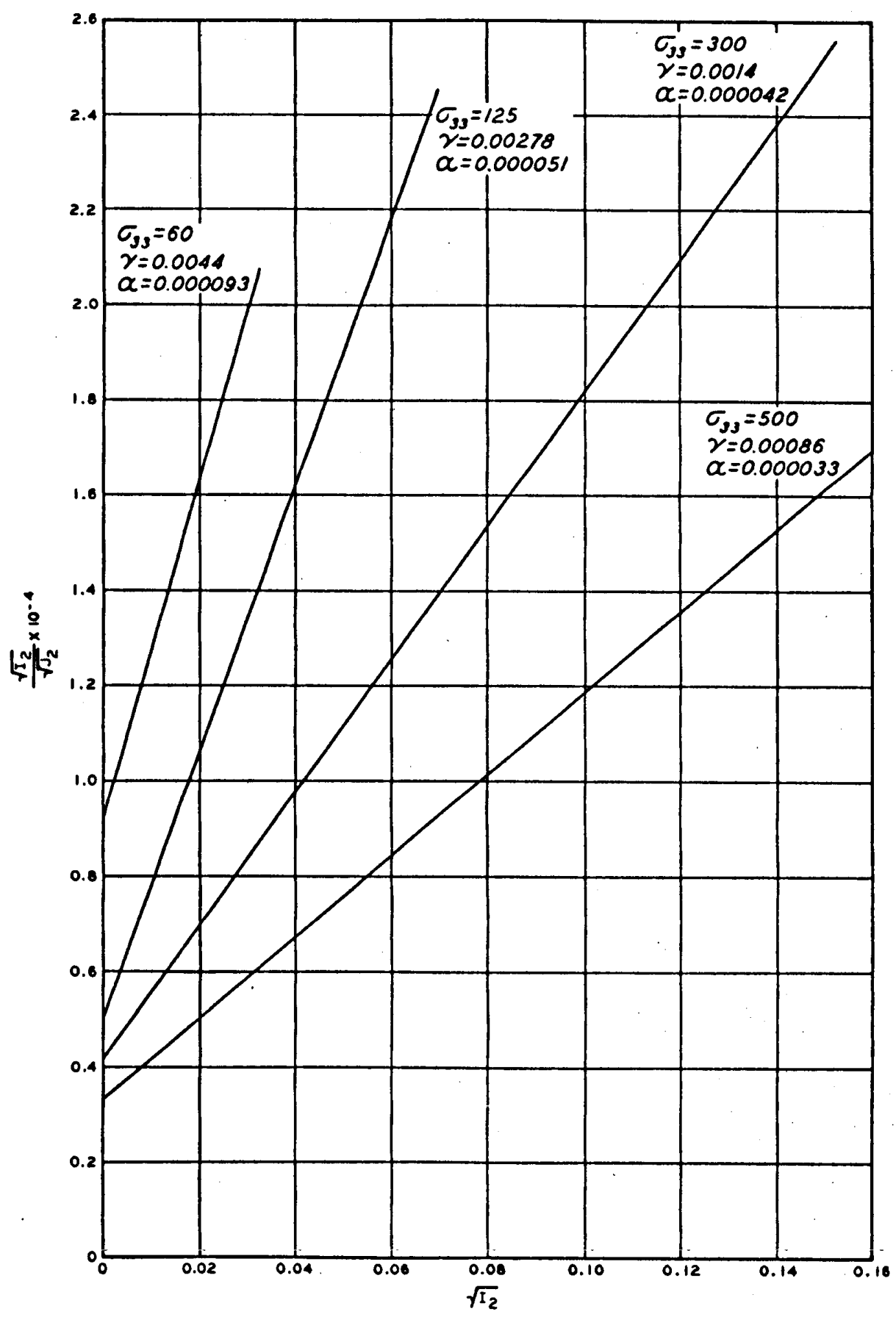

TRANSFORMED

STRESS - STRAIN CURVES FOR CRUSHED NAPA

BASALT UNDER

TRIAXIAL COMPPEESSION

$D_{r}=100$ PERCENT 


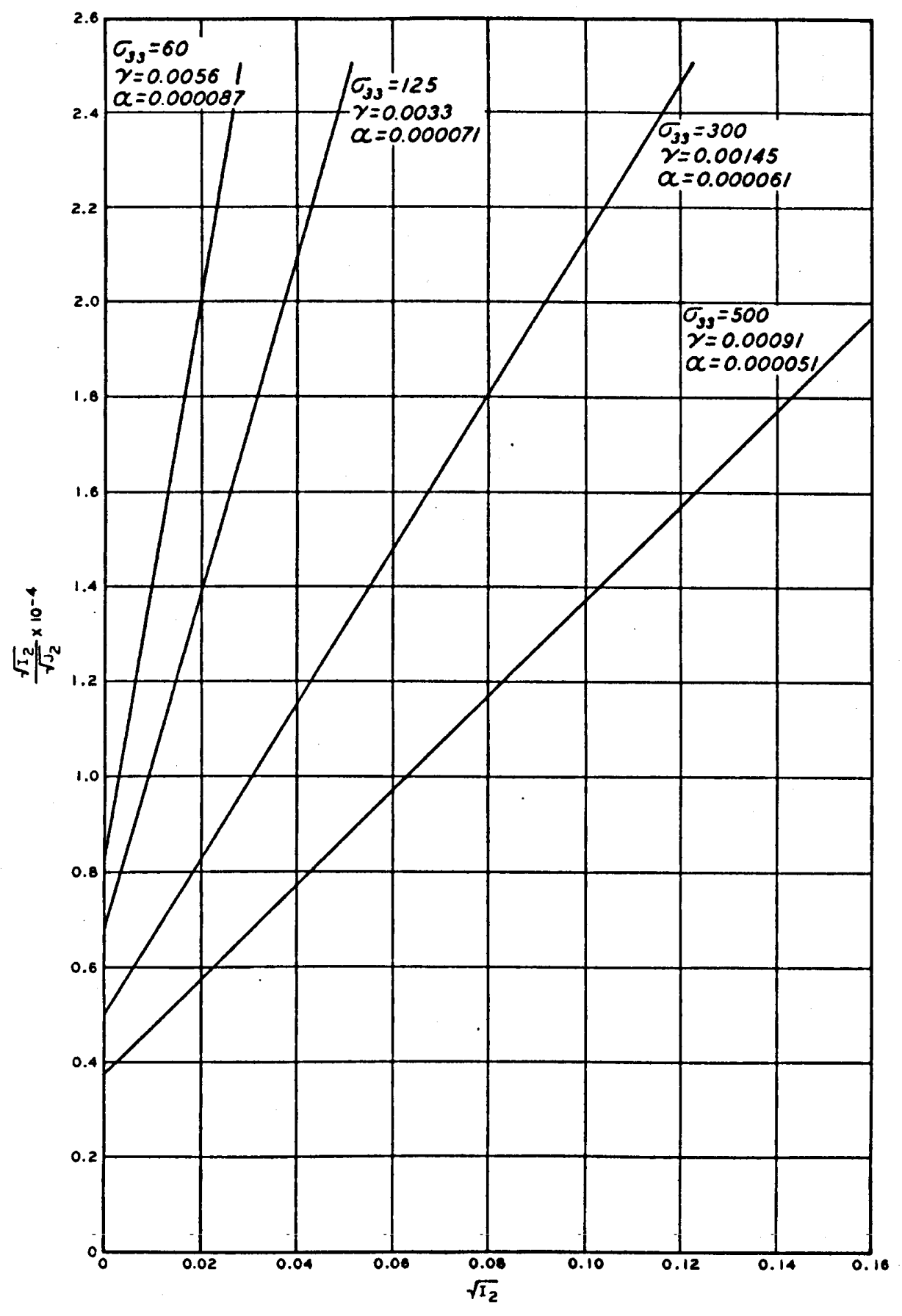

TRANSFORMED

STRESS - STRAIN CURVES FOR CRUSHED NAPA

BASALT UNDER TRIAXIAL COMPRESSION

$$
D_{r}=70 \text { PERCENT }
$$




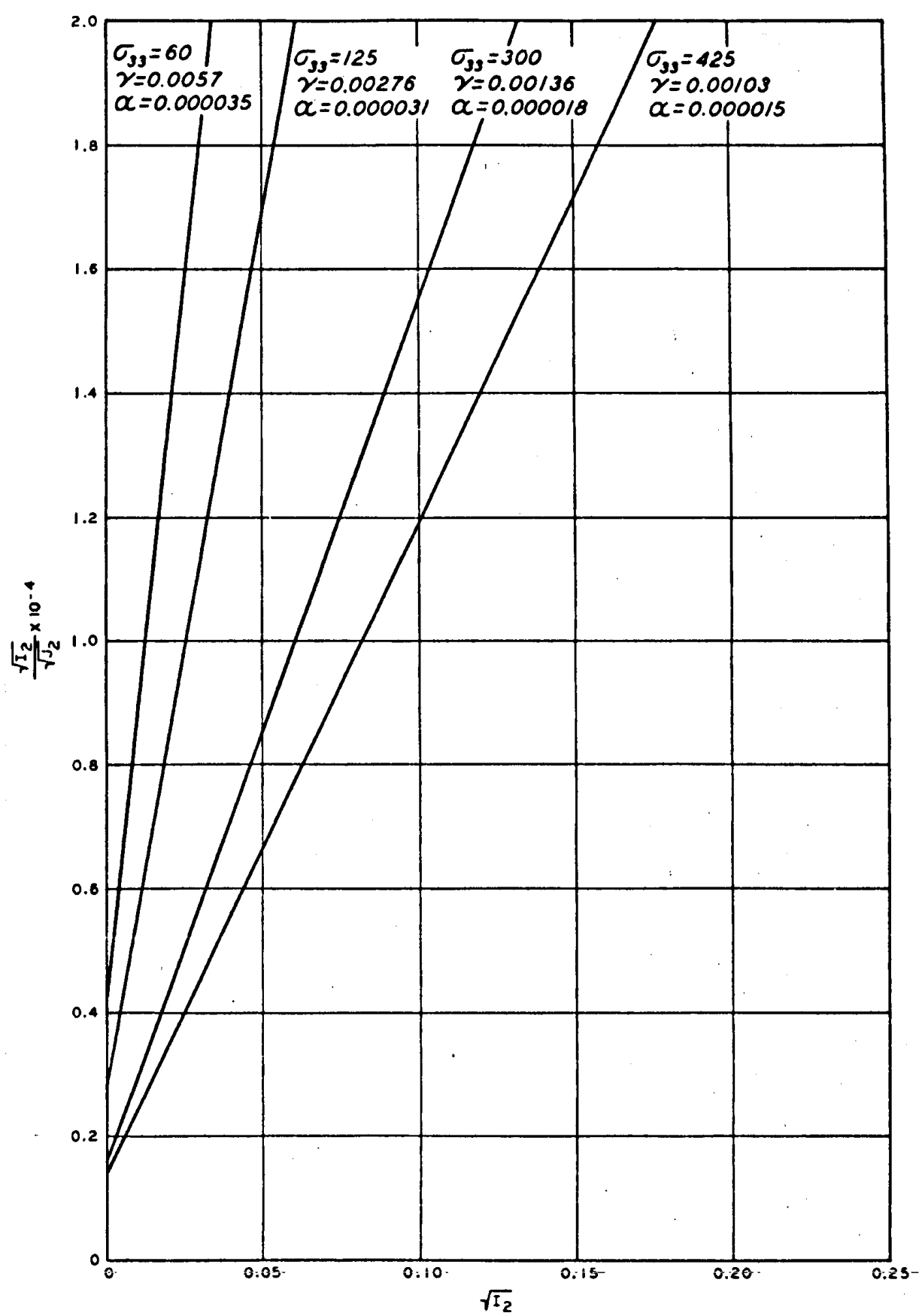

TRANSFORMED

STRESS-STRAIN CURVES FOR PAINTED ROCK

DAM MATERIAL UNDER TRIAXIAL COMPRESSION $D_{r}=100$ PERCENT 


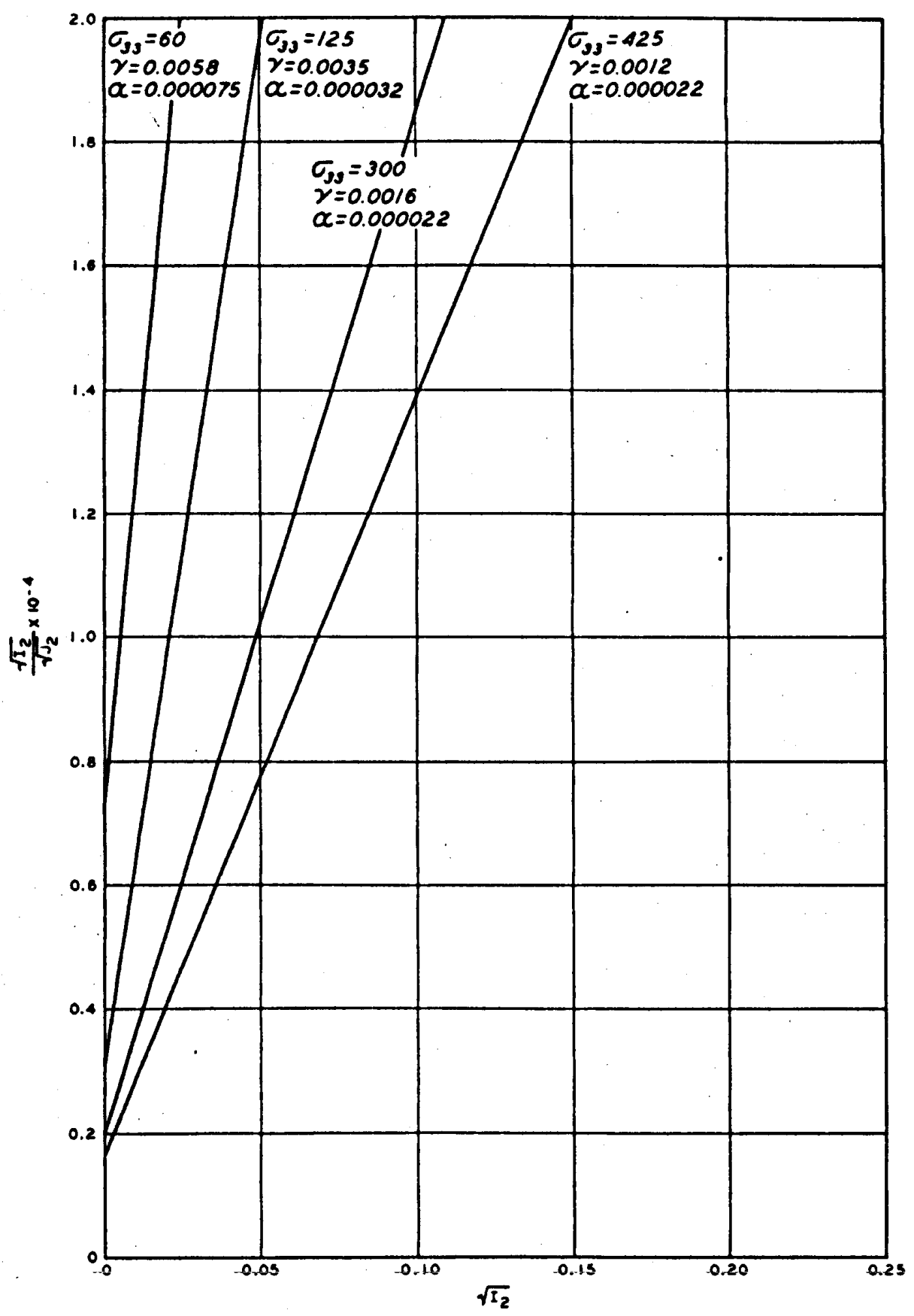

TRANSFORMED

STRESS - STRAIN CURVES FOR PAINTED ROCK DAM MATERIAL UNDER TRIAXIAL COMPRESSION

$$
D_{r}=70 \text { PERCENT }
$$




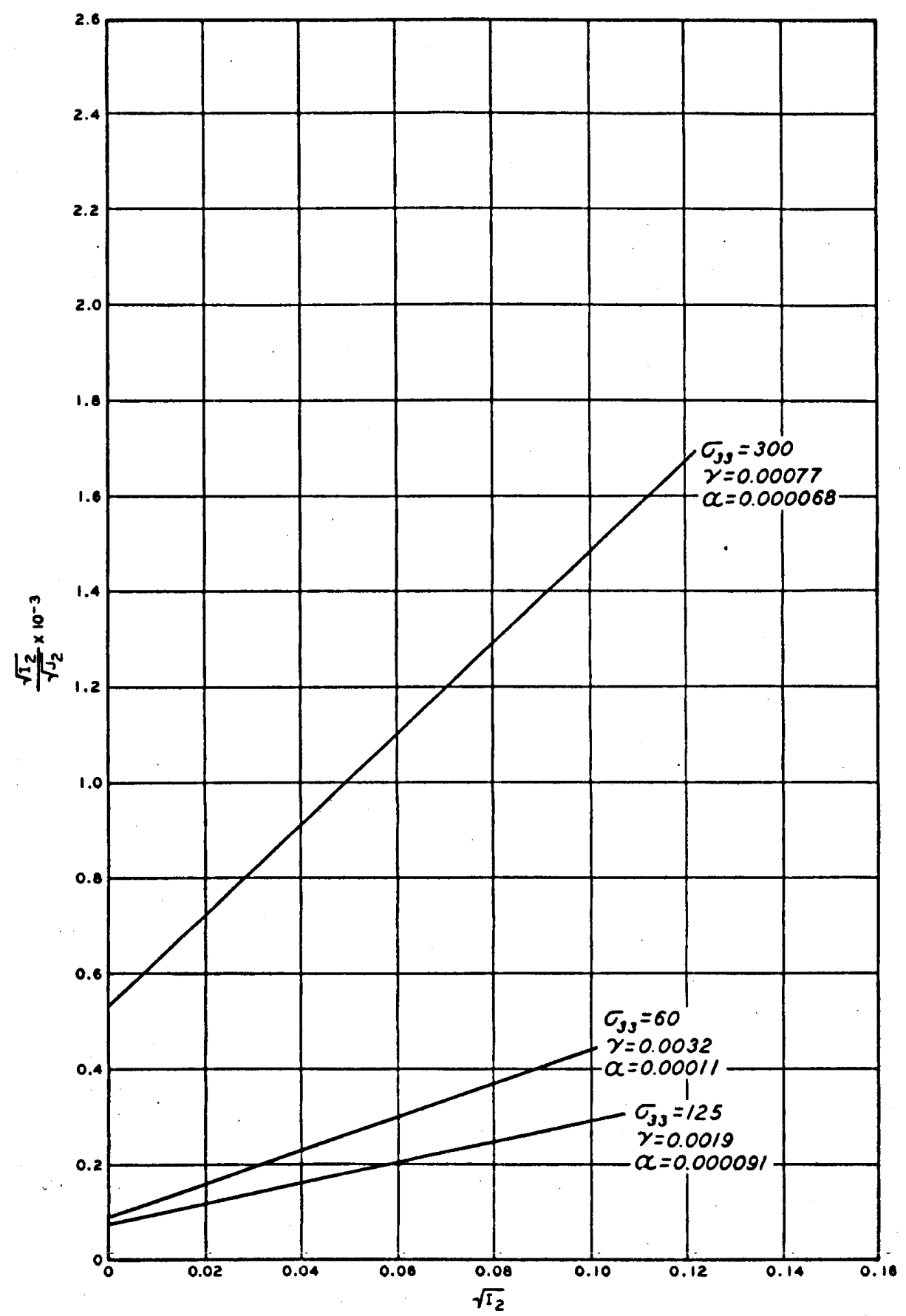

TRANSFORMED

STRESS - STRAIN CURVES

FOR CRUSHED NAPA

BASALT UNDER

PLANE STRAIN SHEAR

$D_{r}=100$ PERCENT 


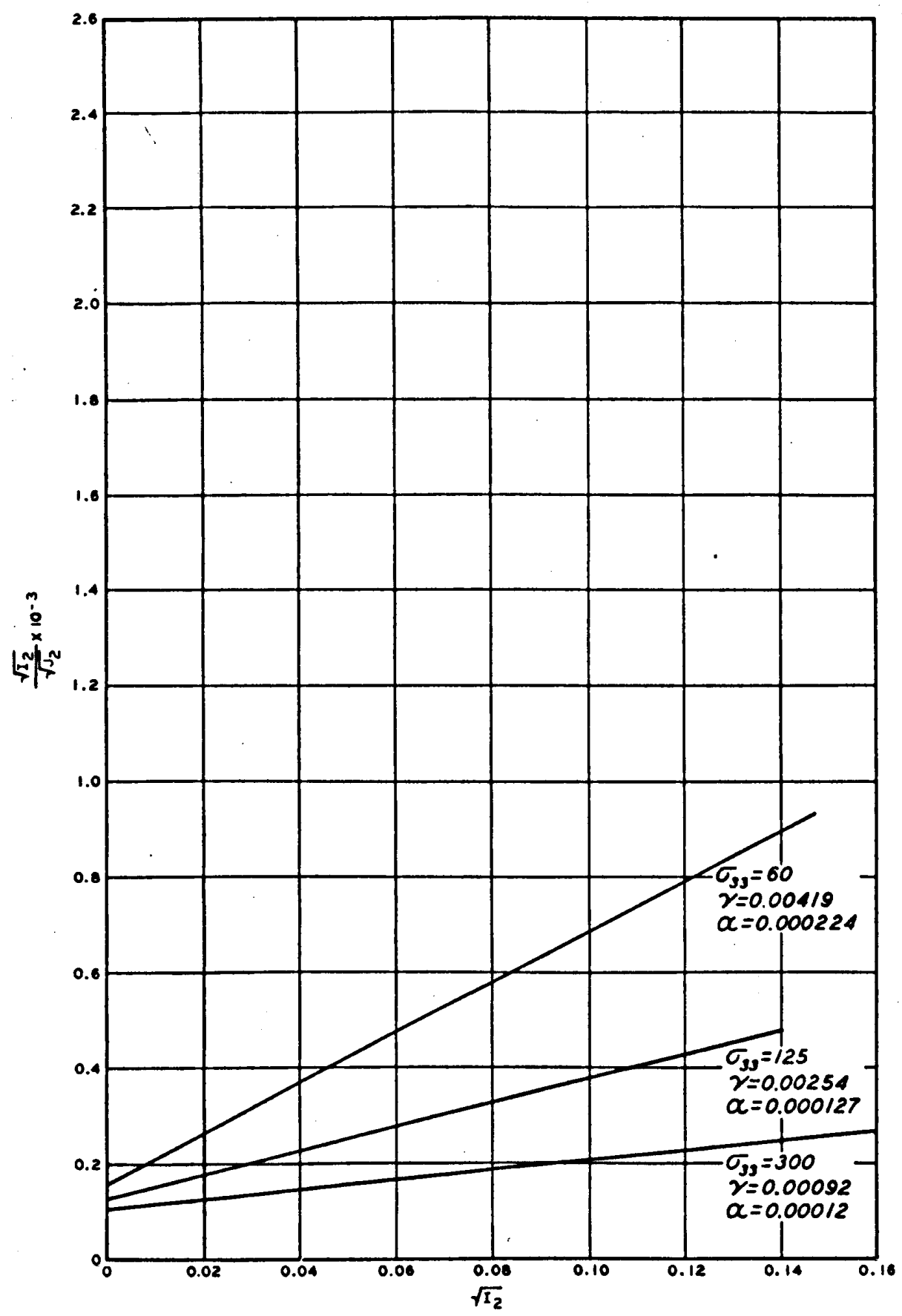

TRANSFORMED

STRESS - STRAIN CURVES

FOR CRUSHED NAPA

BASALT UNDER

PLANE STRAIN SHEAR

$D_{r}=70$ PERCENT 


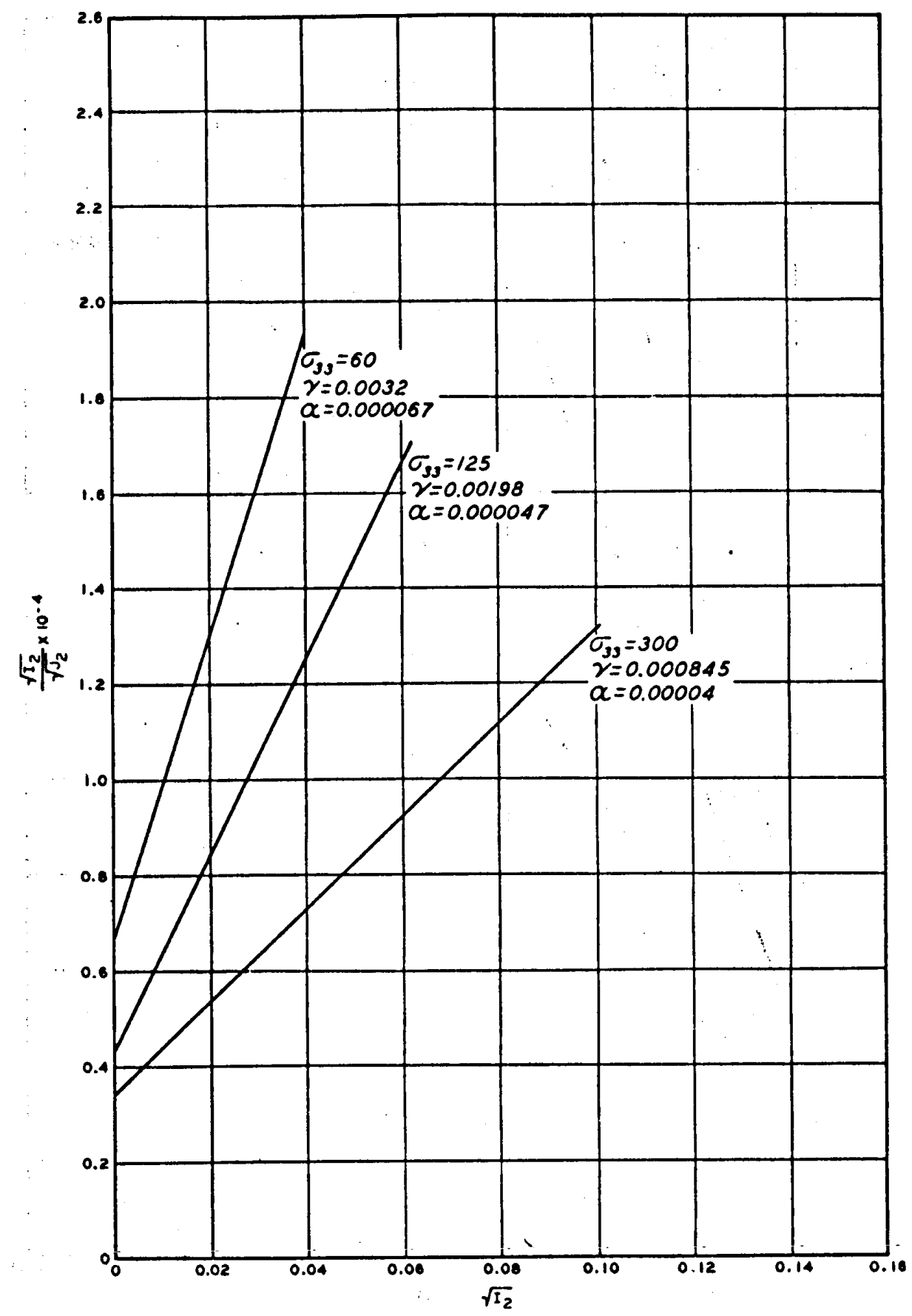

TRANSFORMED

STRESS - STRAIN CURVES FOR PAINTED ROCK DAM MATERIAL UNDER PLANE STRAIN SHEAR $D_{r}=100$ PERCENT 


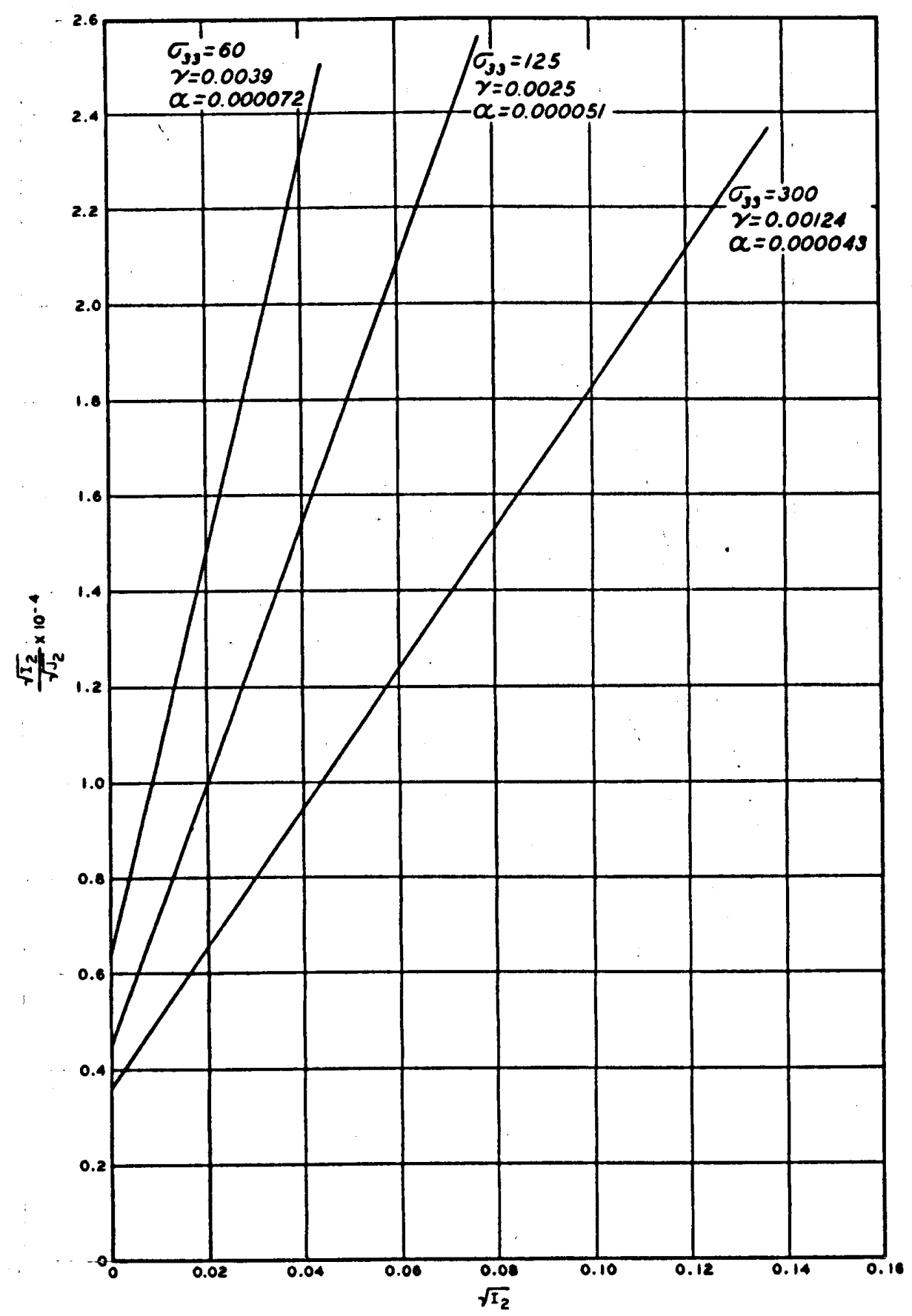

TRANSFORMED

STRESS - STRAIN CURVES FOR PAINTED ROCK DAM MATERIAL UNDER PLANE STRAIN SHEAR $D_{r}=70$ PERCENT 

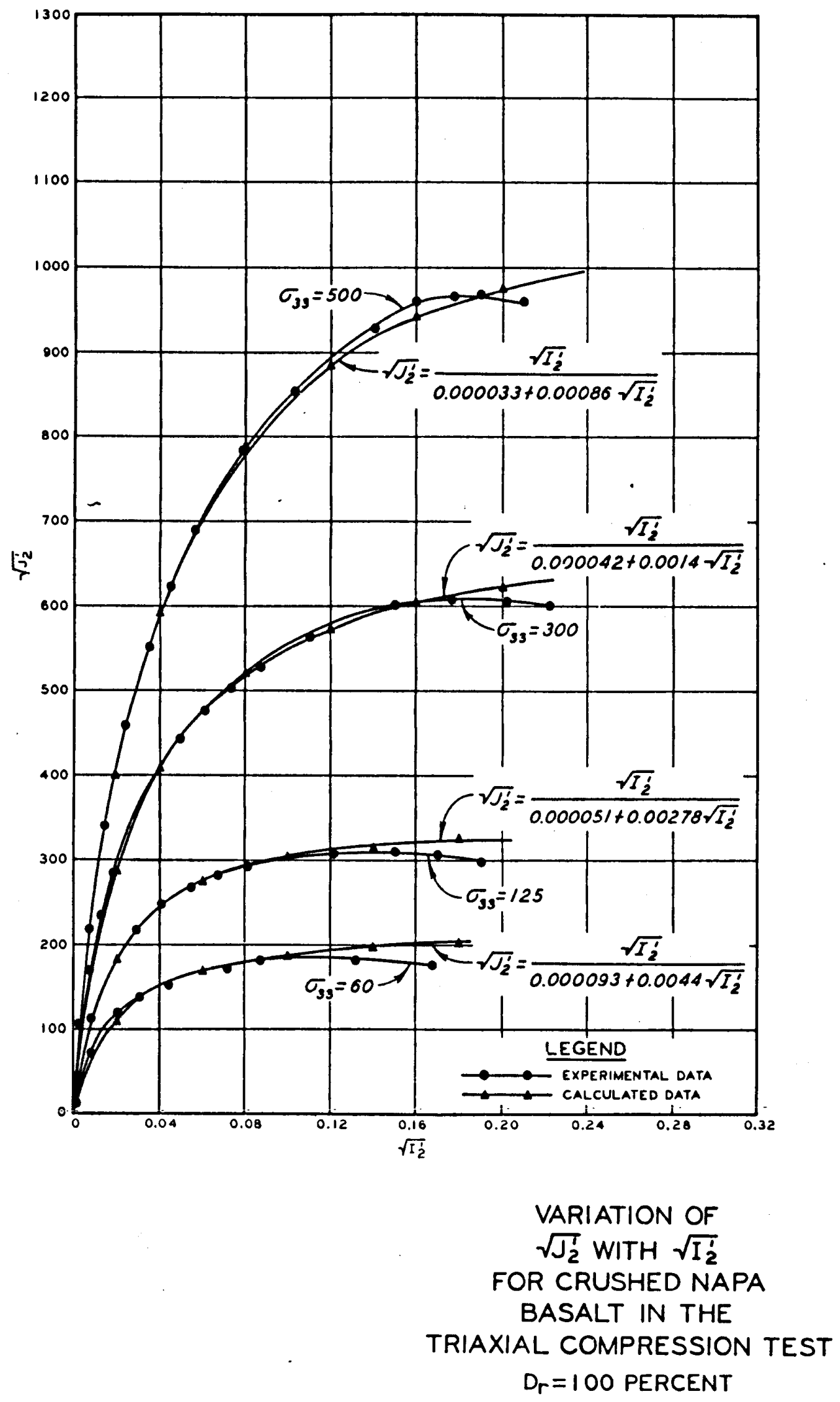


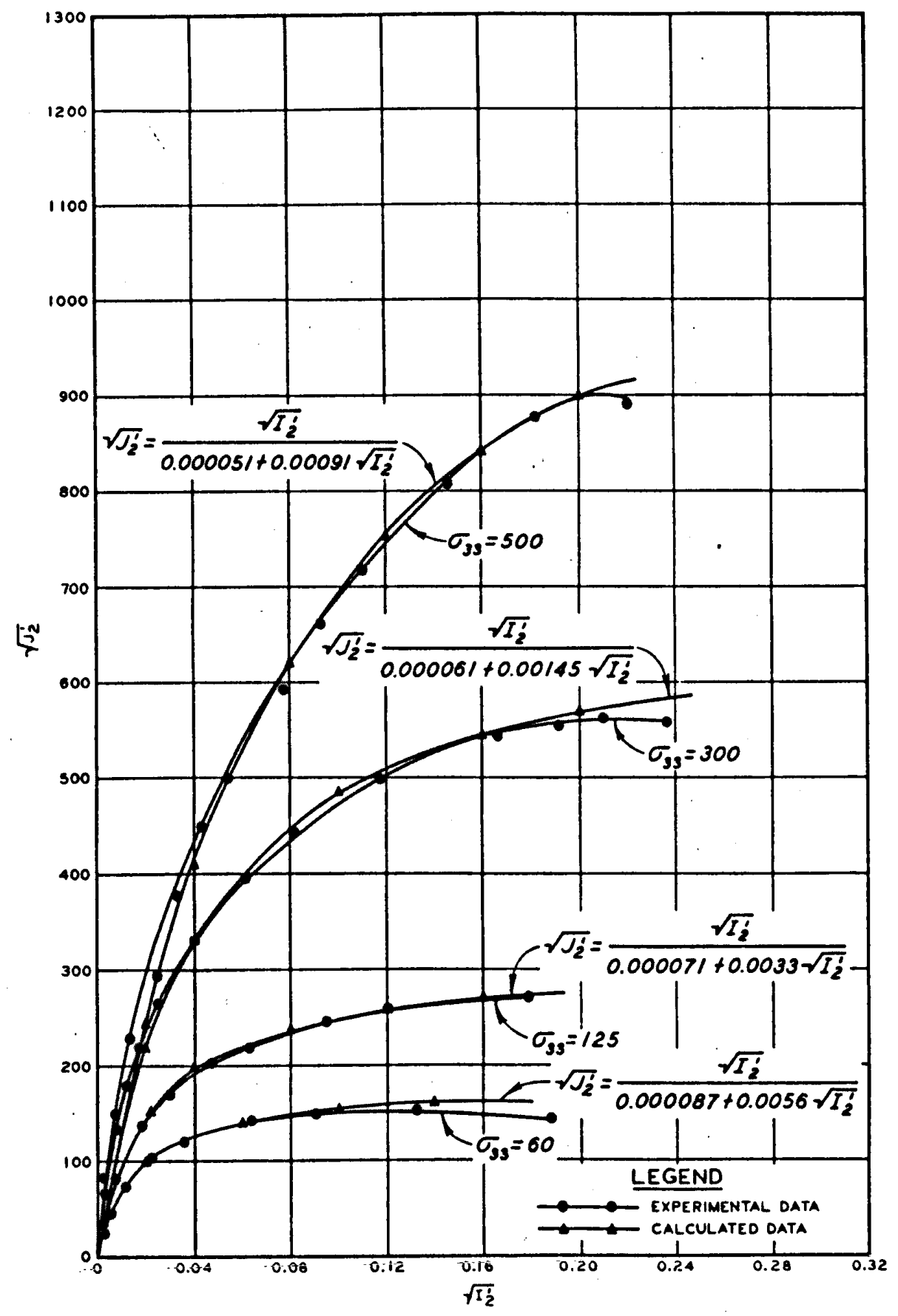
VARIATION OF $\sqrt{J_{2}^{\prime}}$ WITH $\sqrt{I_{2}^{\prime}}$ FOR CRUSHED NAPA
BASALT IN THE
TRIAXIAL COMPRESSION TEST $D_{r}=70$ PERCENT




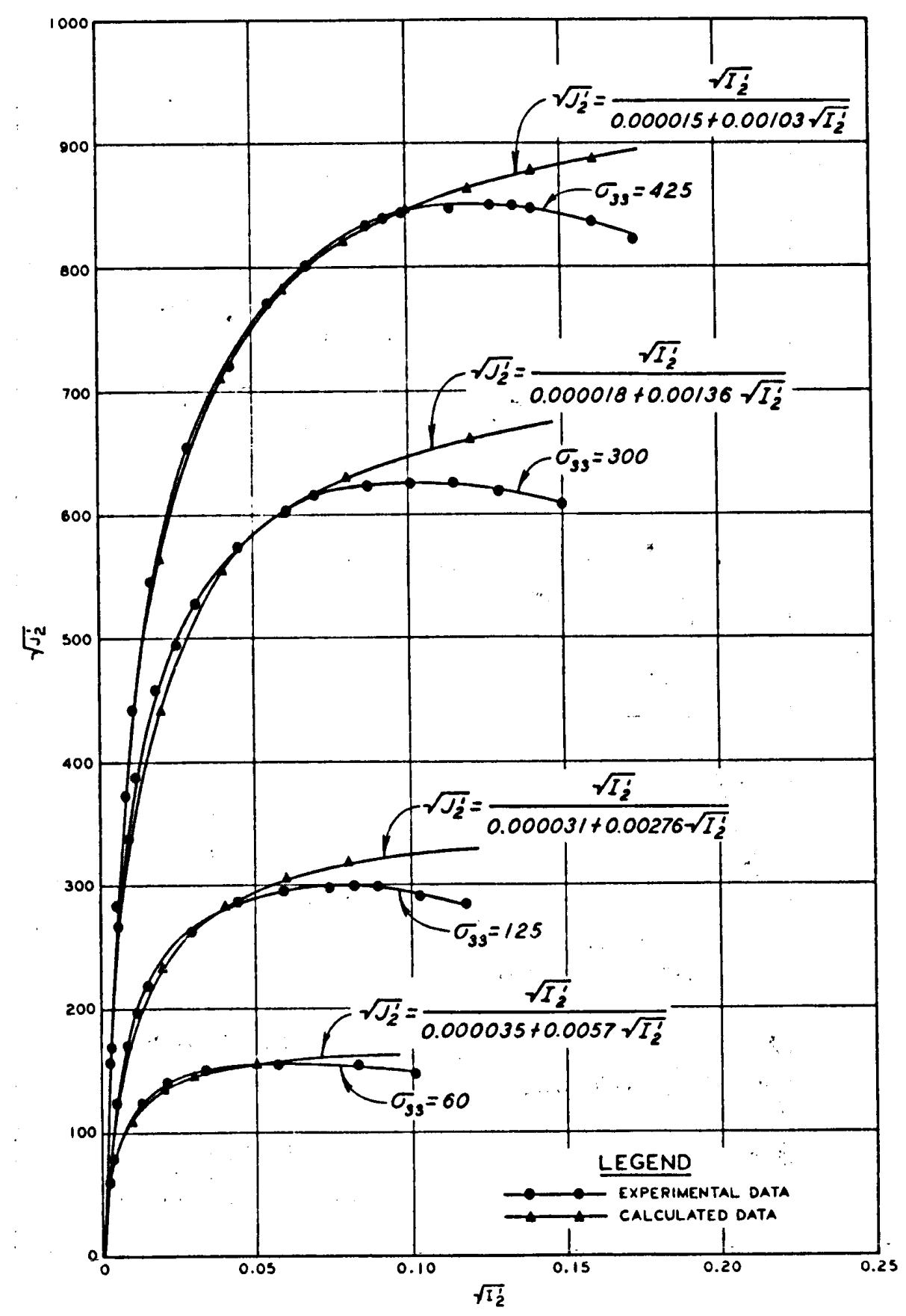

\author{
VARIATION OF \\ $\sqrt{J_{2}^{\prime}}$ WITH $\sqrt{I_{2}^{\prime}}$ \\ FOR PAINTED ROCK DAM \\ MATERIAL IN THE \\ TRIAXIAL COMPRESSION TEST \\ $D_{r}=100$ PERCENT
}



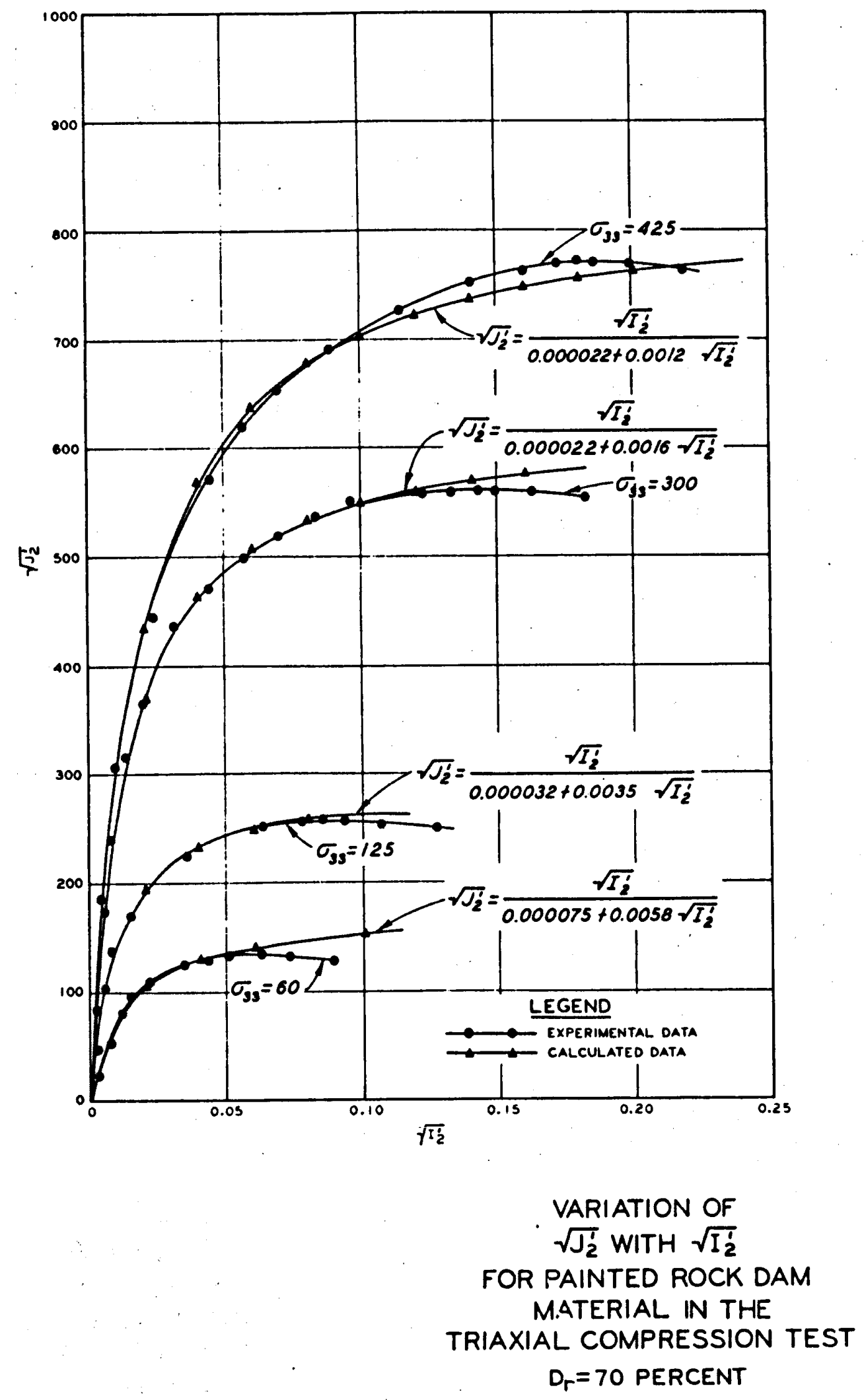


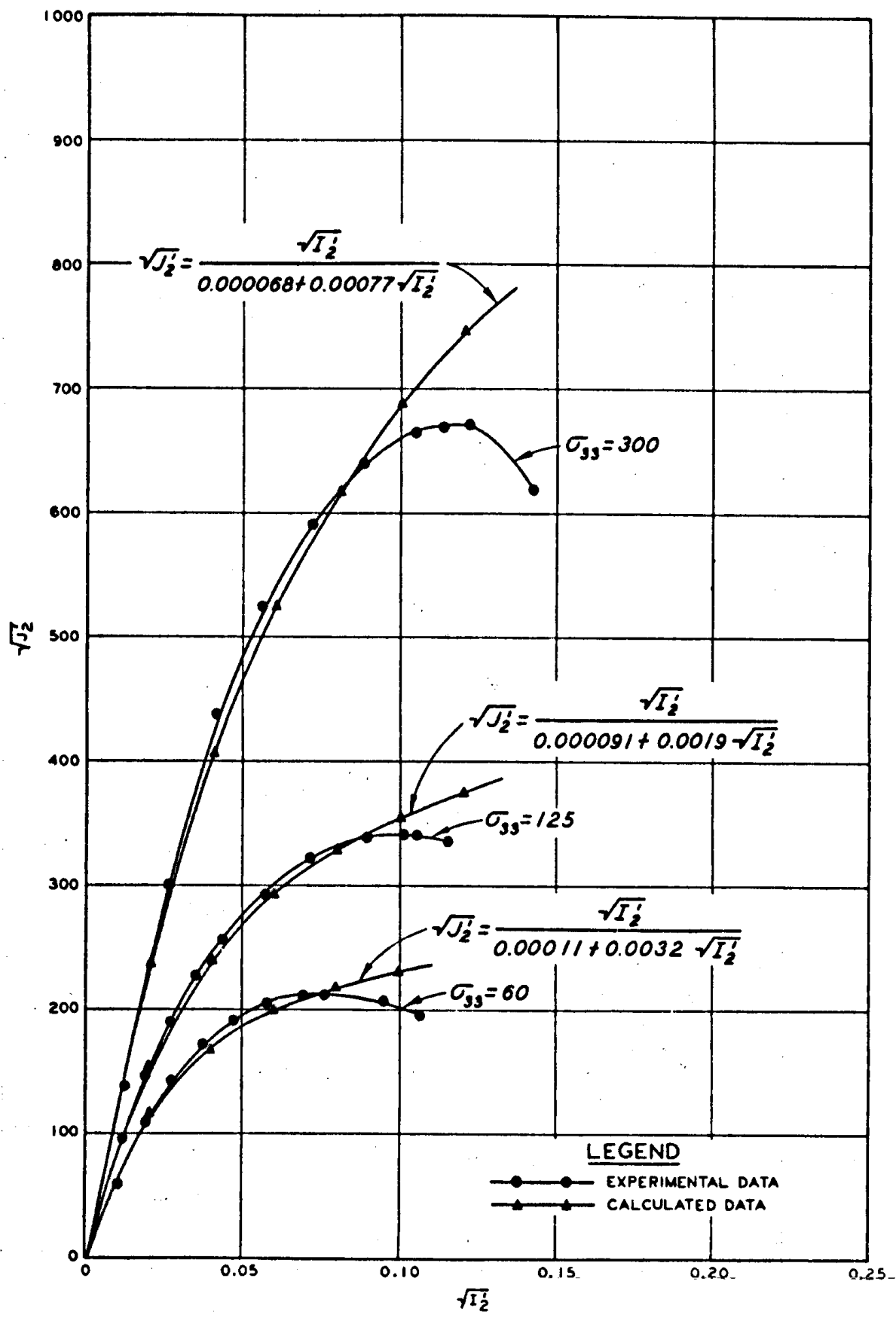

VARIATION OF

$\sqrt{J_{2}^{\prime}}$ WITH $\sqrt{I_{2}^{\prime}}$

FOR CRUSHED NAPA

BASALT IN THE

PLANE STRAIN SHEAR TEST

$D_{r}=100$ PERCENT 

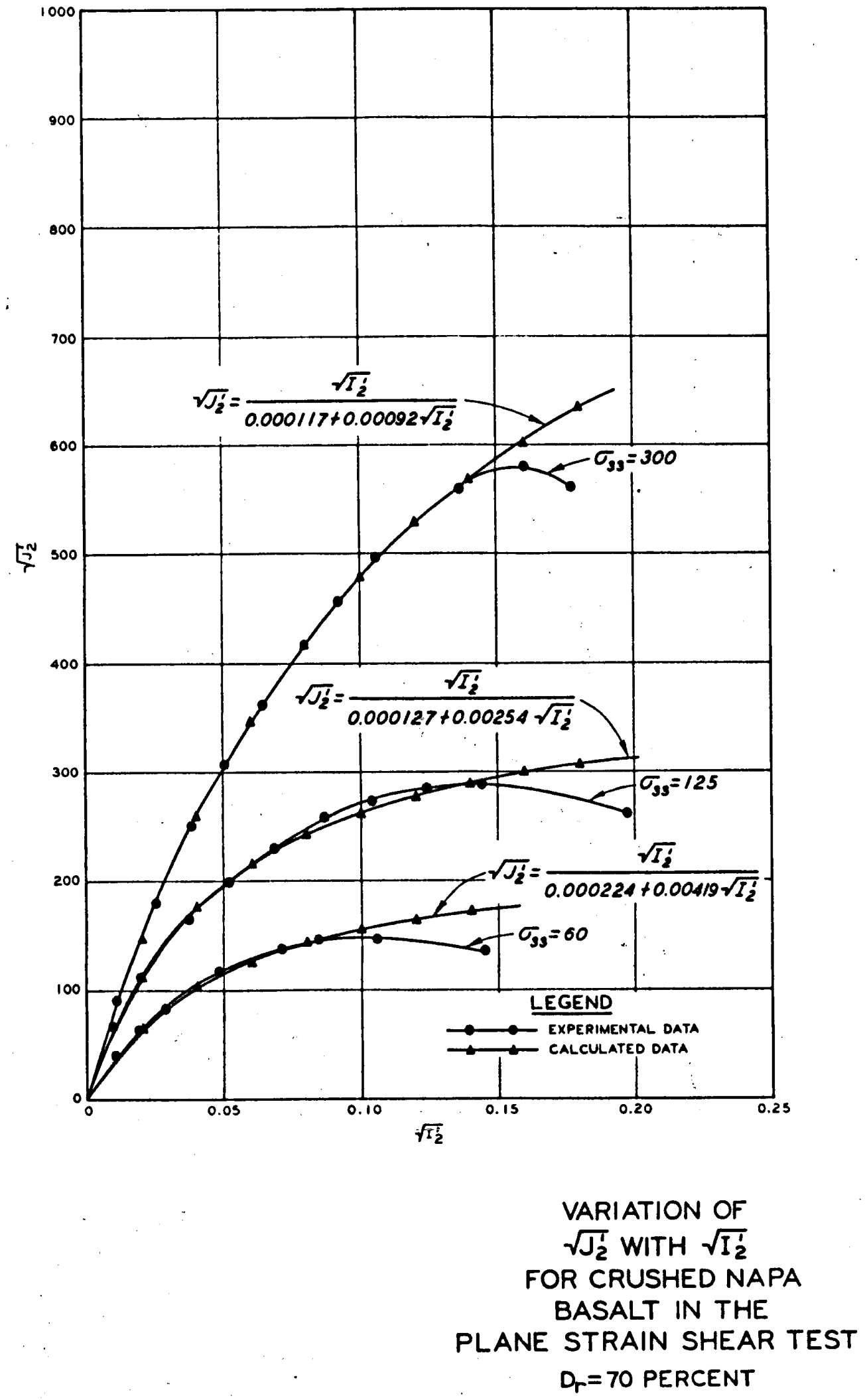


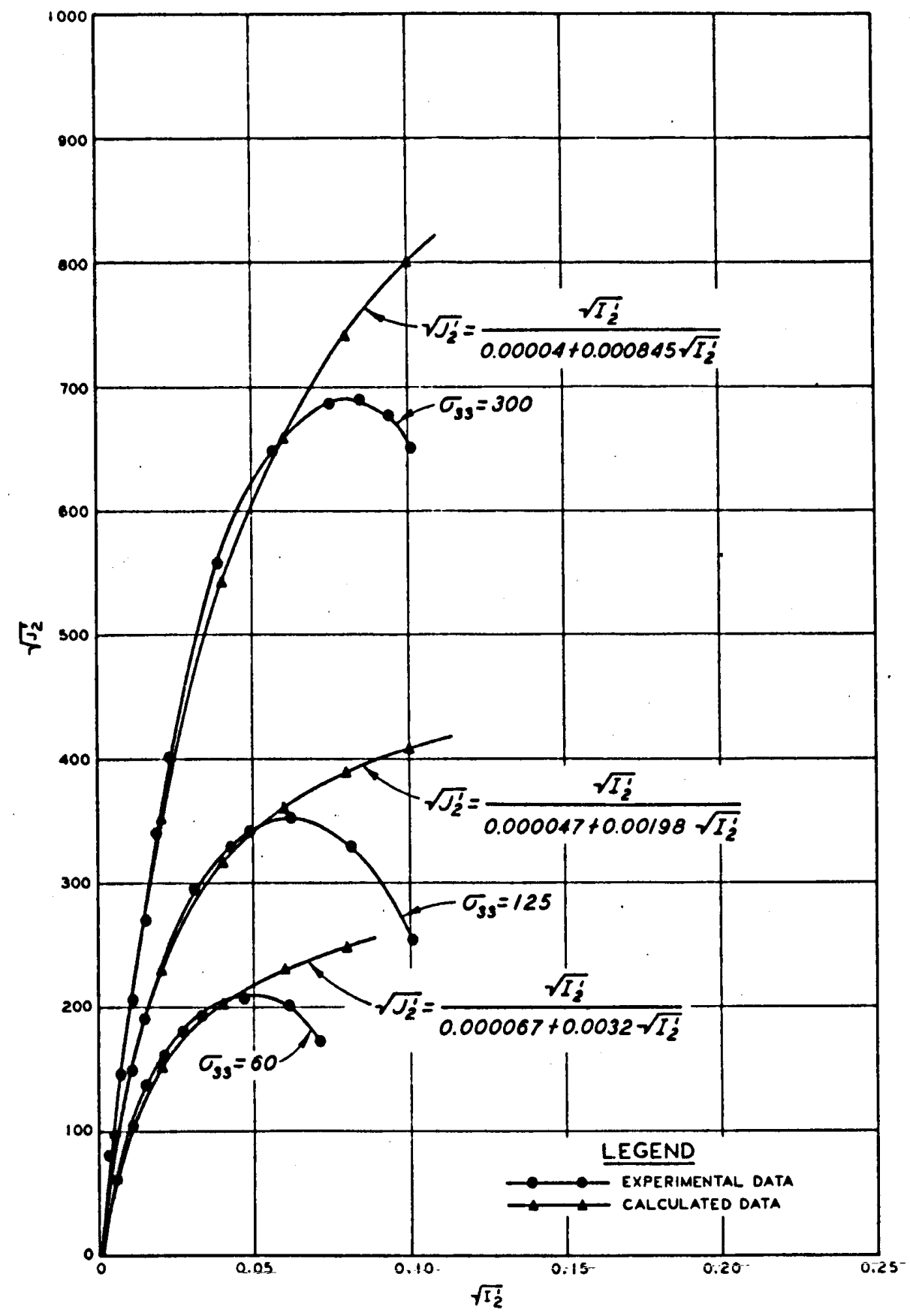

VARIATION OF $\sqrt{J_{2}^{\prime}}$ WITH $\sqrt{I_{2}^{\prime}}$

FOR PAINTED ROCK DAM

MATERIAL IN THE

PLANE STRAIN SHEAR TEST

$$
D_{r}=100 \text { PERCENT }
$$



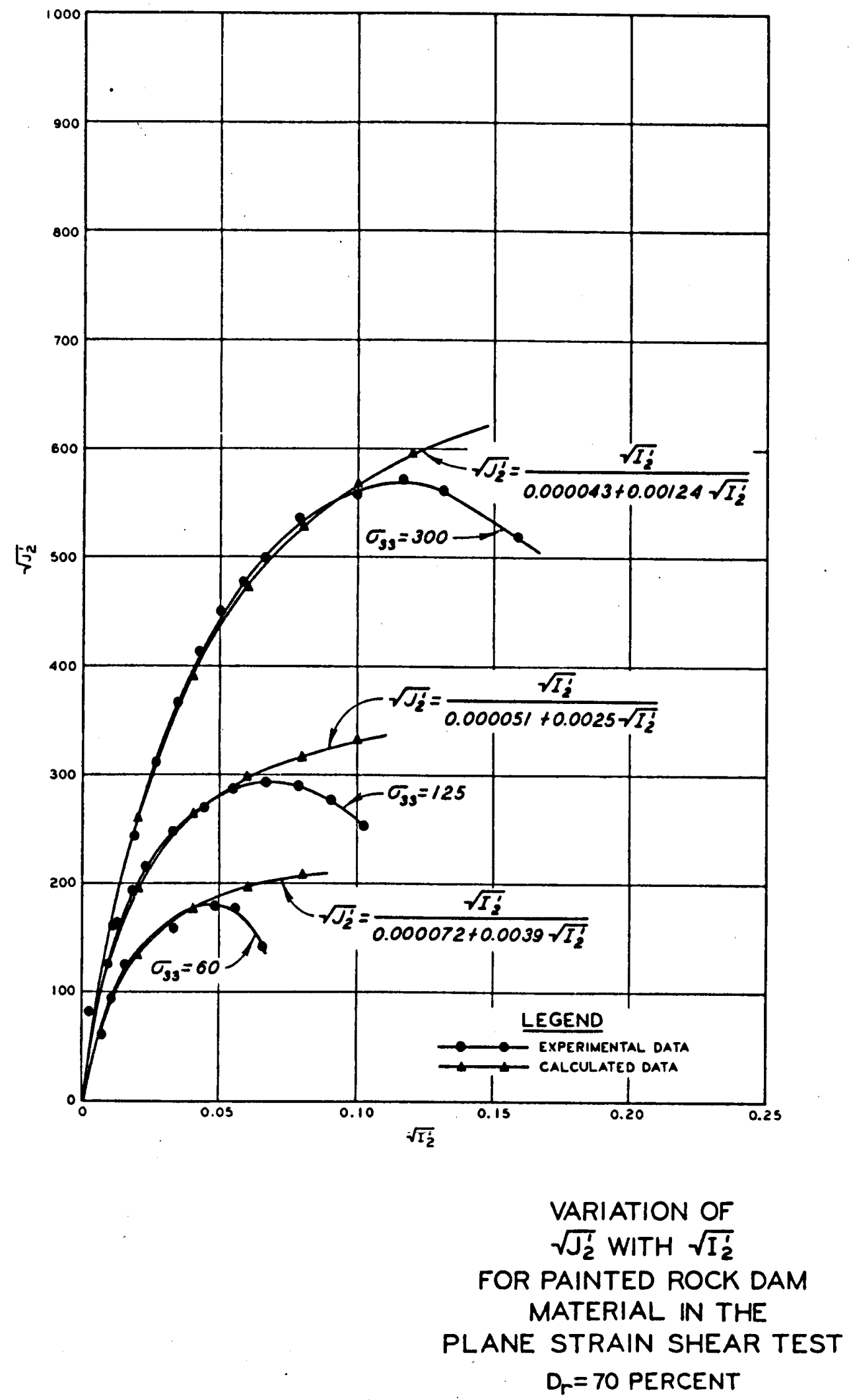

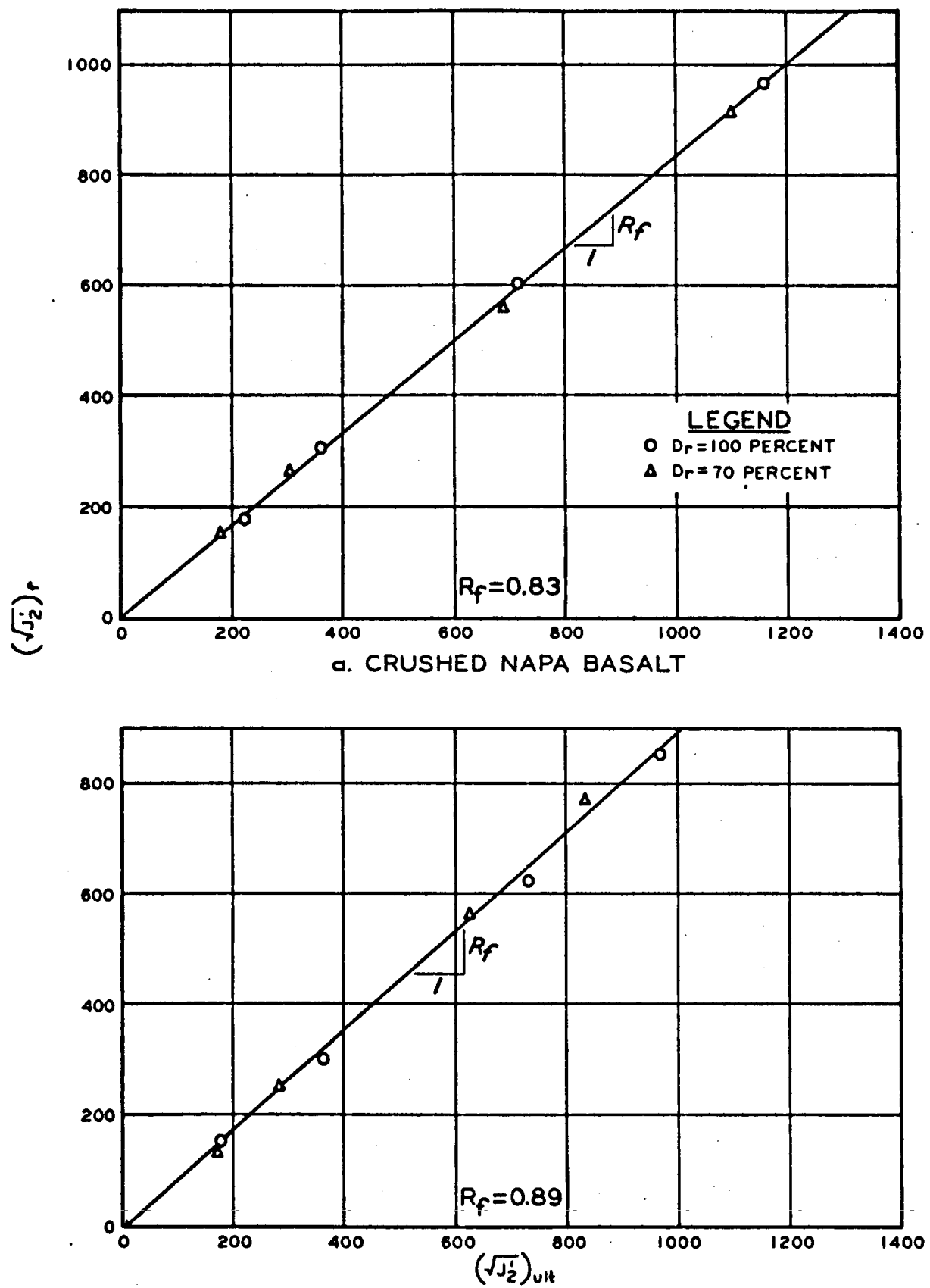

b. PAINTED ROCK DAM MATERIAL

RELATIONSHIP BETWEEN $\left(\sqrt{J_{2}^{\prime}}\right)_{f}$ AND $\left(\sqrt{J_{2}^{\prime}}\right)_{u l t}$ IN THE TRIAXIAL COMPRESSION TEST 

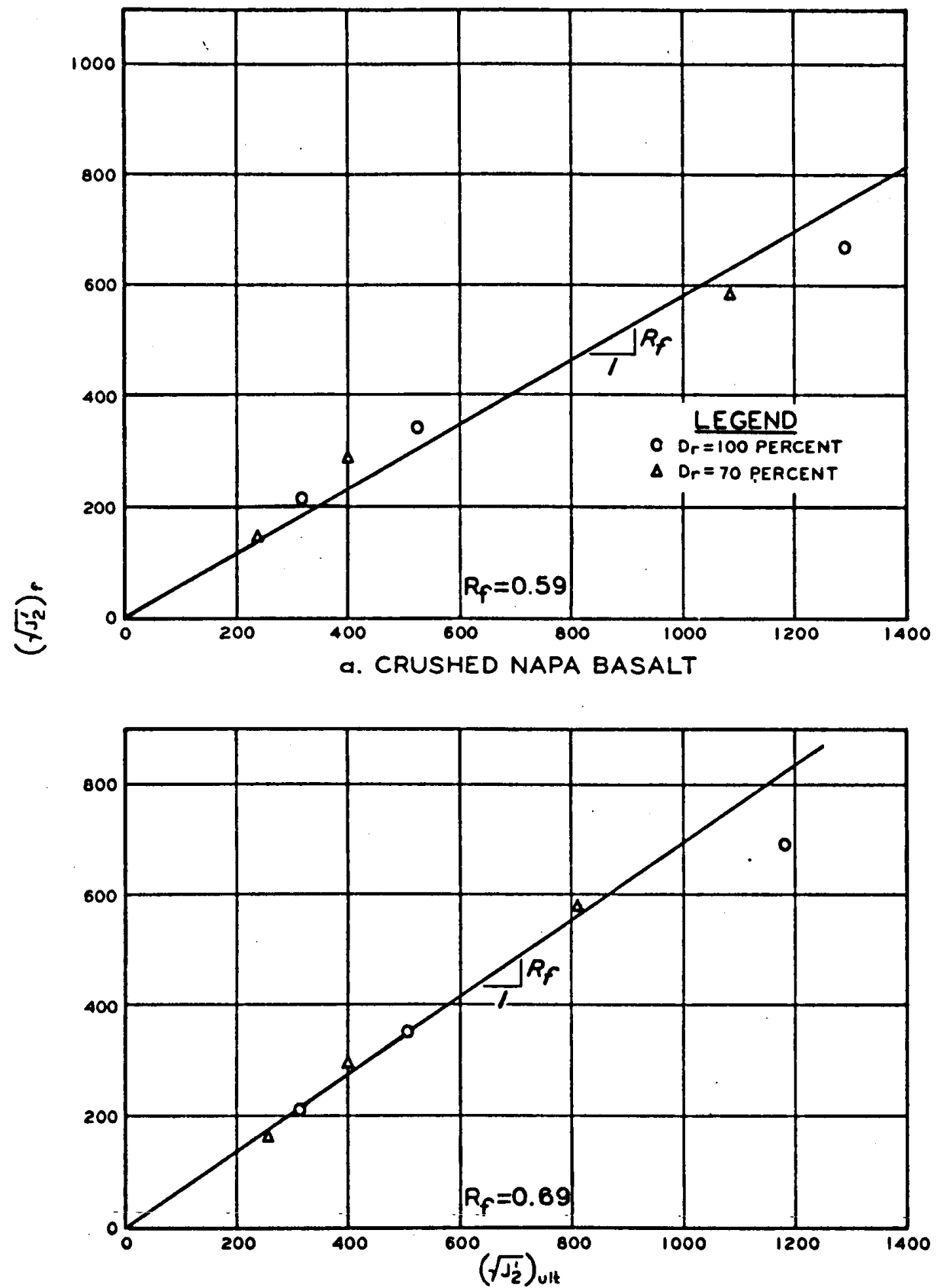

b. PAINTED ROCK DAM MATERIAL

RELATIONSHIP BETWEEN

$\left(\sqrt{J_{2}^{\prime}}\right)_{f}$ AND $\left(\sqrt{J_{2}^{\prime}}\right)_{u l t}$

IN THE PLANE

STRAIN SHEAR TEST 


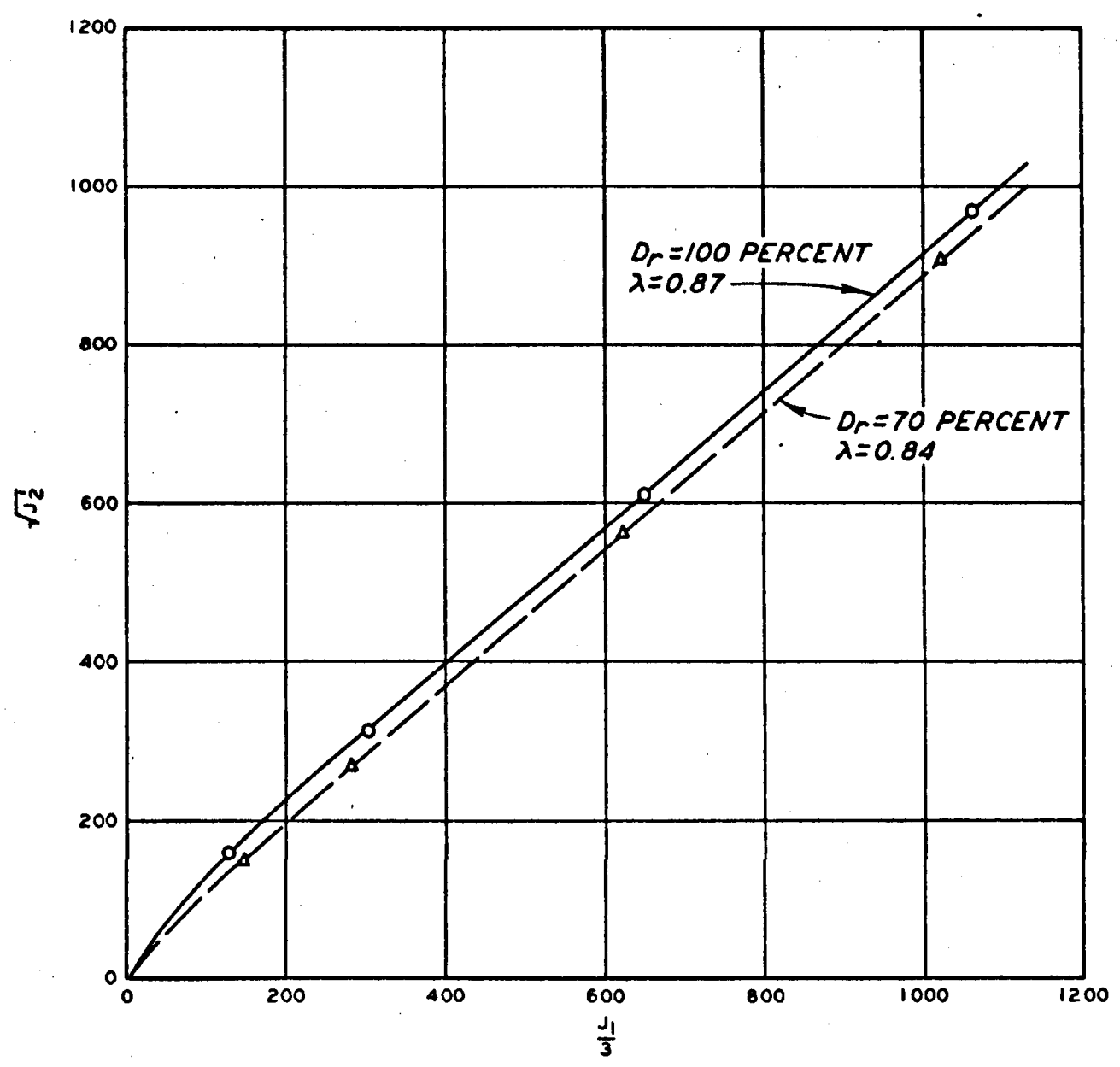

\author{
VARIATION OF $\sqrt{J_{2}^{\prime}}$ WITH $\frac{J_{1}}{3}$ \\ AT YIELD FOR CRUSHED \\ NAPA BASALT IN THE \\ TRIAXIAL COMPRESSION TEST
}




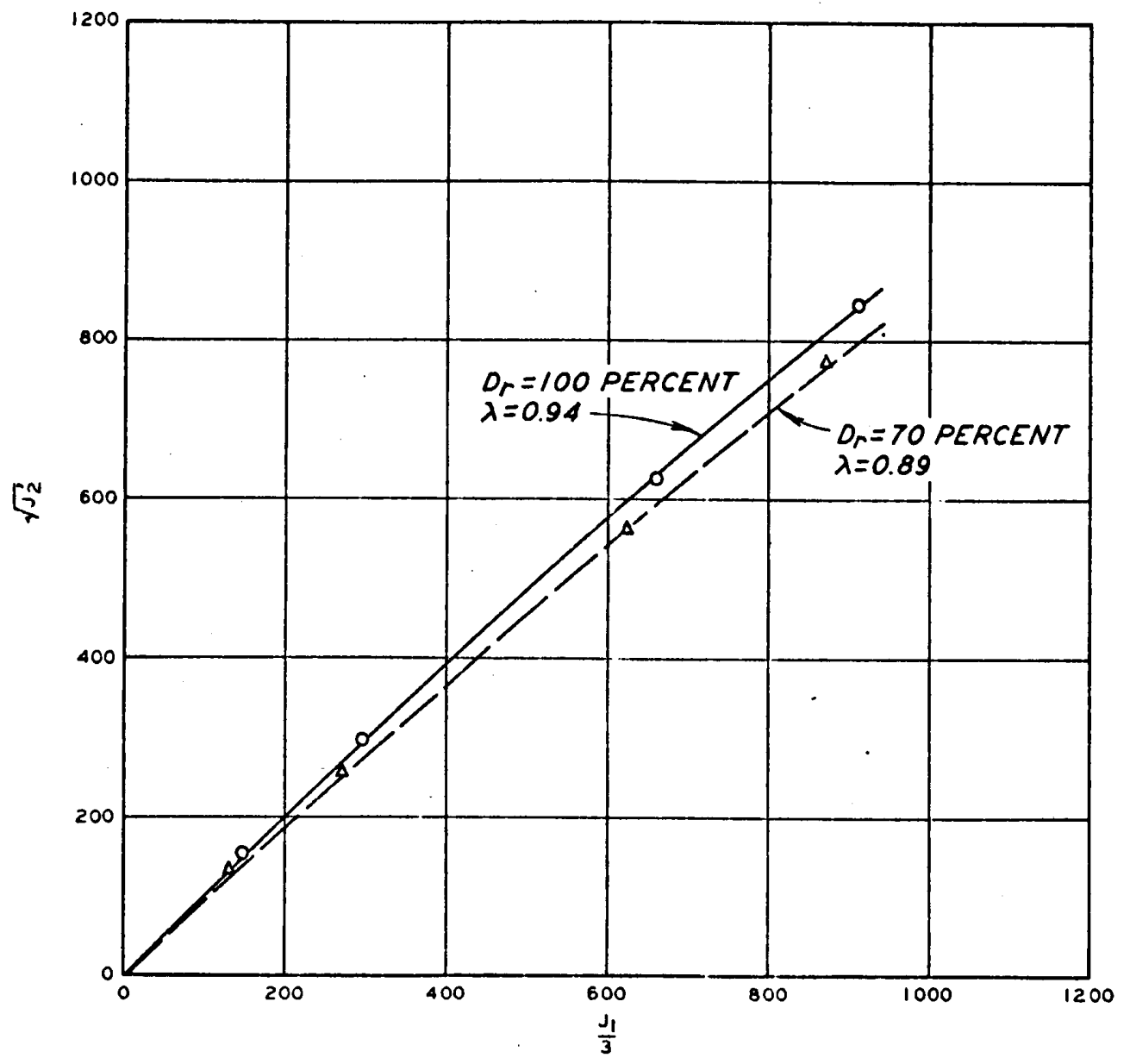

VARIATION OF $\sqrt{J_{2}^{\prime}}$ WITH $\frac{J_{1}}{3}$ AT YIELD FOR PAINTED ROCK DAM MATERIAL IN THE TRIAXIAL COMPRESSION TEST 


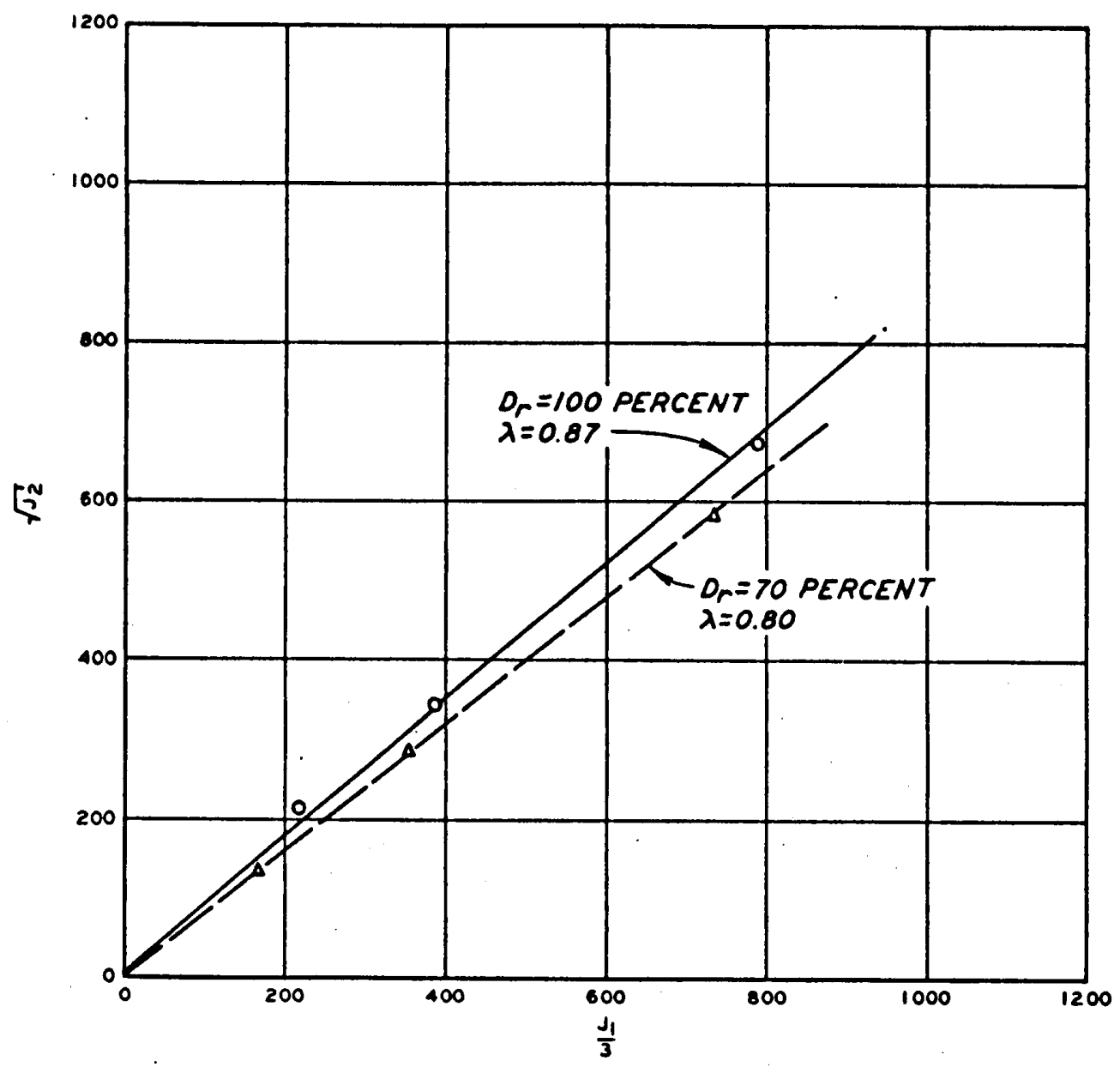

\author{
VARIATION OF $\sqrt{J_{2}^{\prime}}$ WITH $\frac{J_{1}}{3}$ \\ AT YIELD FOR CRUSHED \\ NAPA BASALT IN THE \\ PLANE STRAIN SHEAR TEST
}




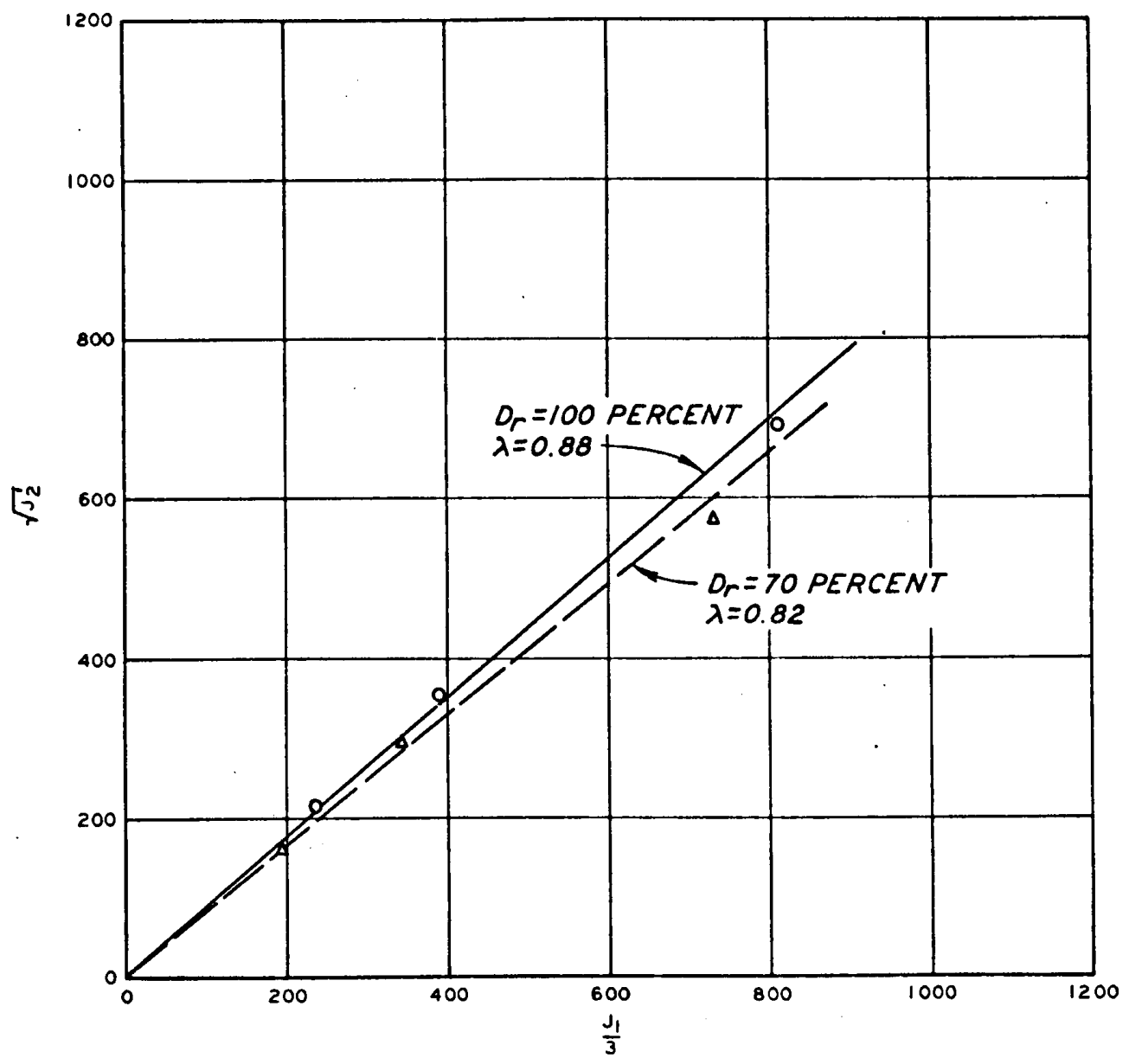

VARIATION OF $\sqrt{J_{2}^{1}}$ WITH $\frac{J_{1}}{3}$ AT YIELD FOR PAINTED ROCK DAM MATERIAL IN THE PLANE STRAIN SHEAR TEST 


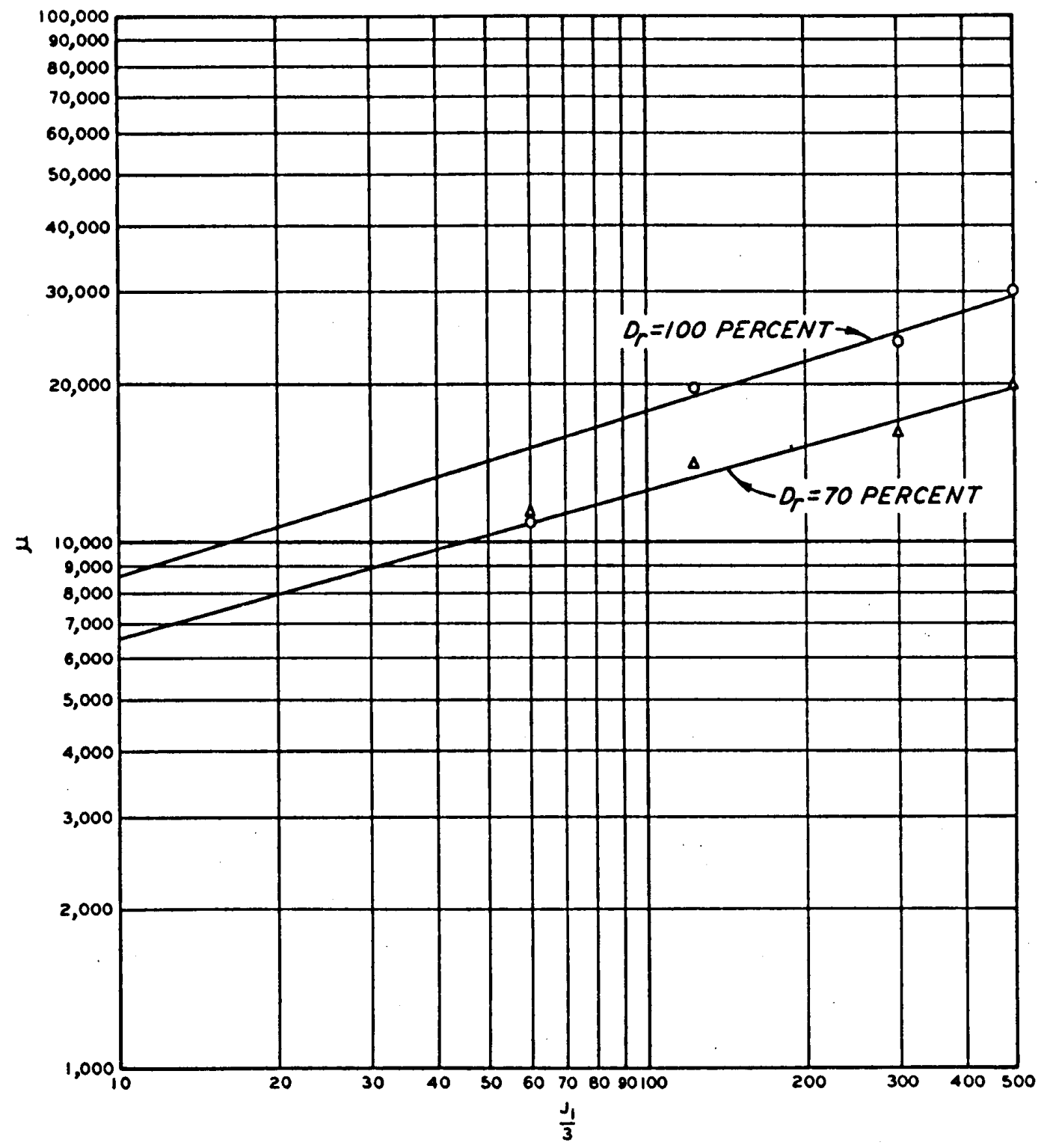

VARIATION OF $\mu$ WITH $\frac{J_{1}}{3}$ FOR CRUSHED NAPA BASALT UNDER TRIAXIAL COMPRESSION 


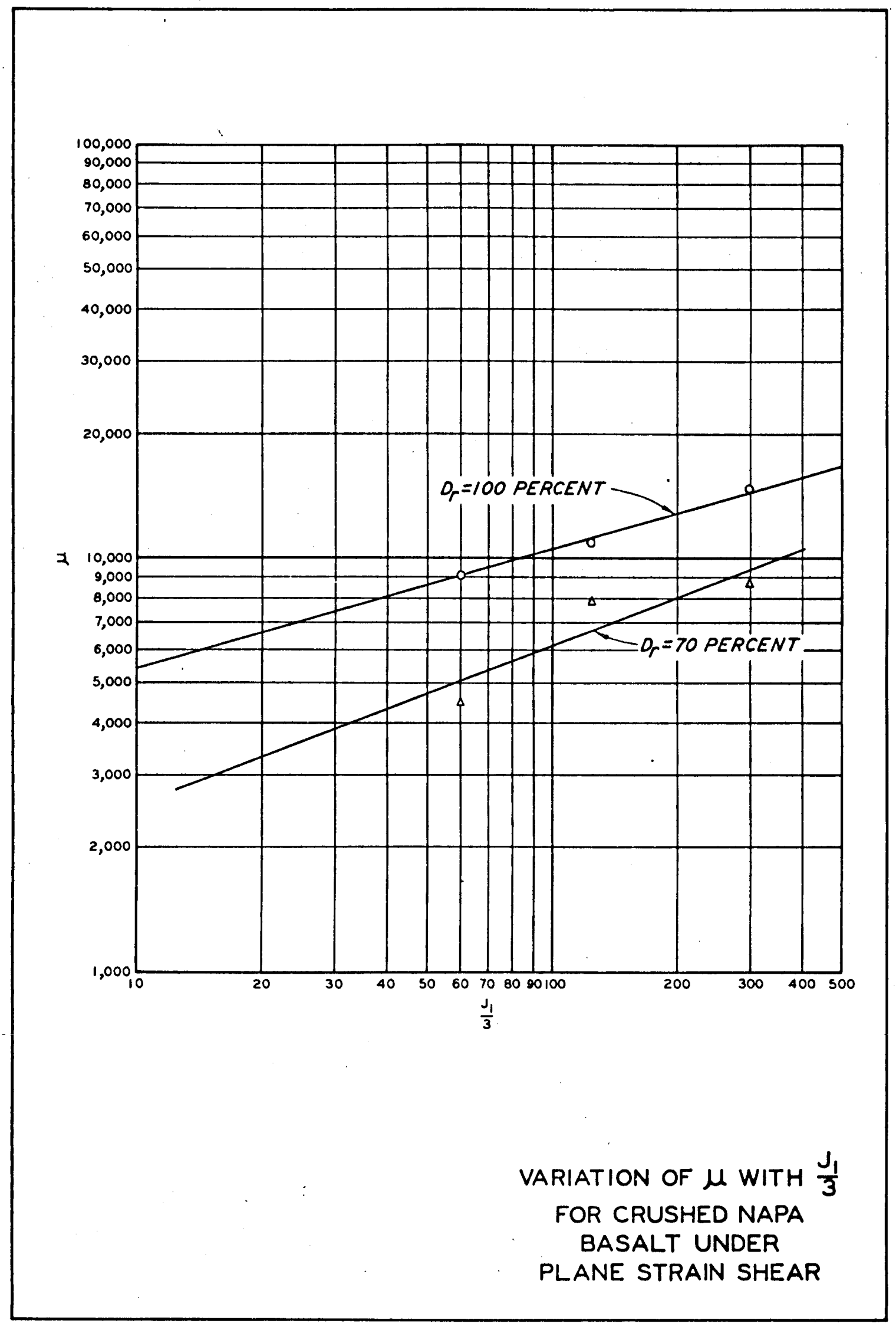




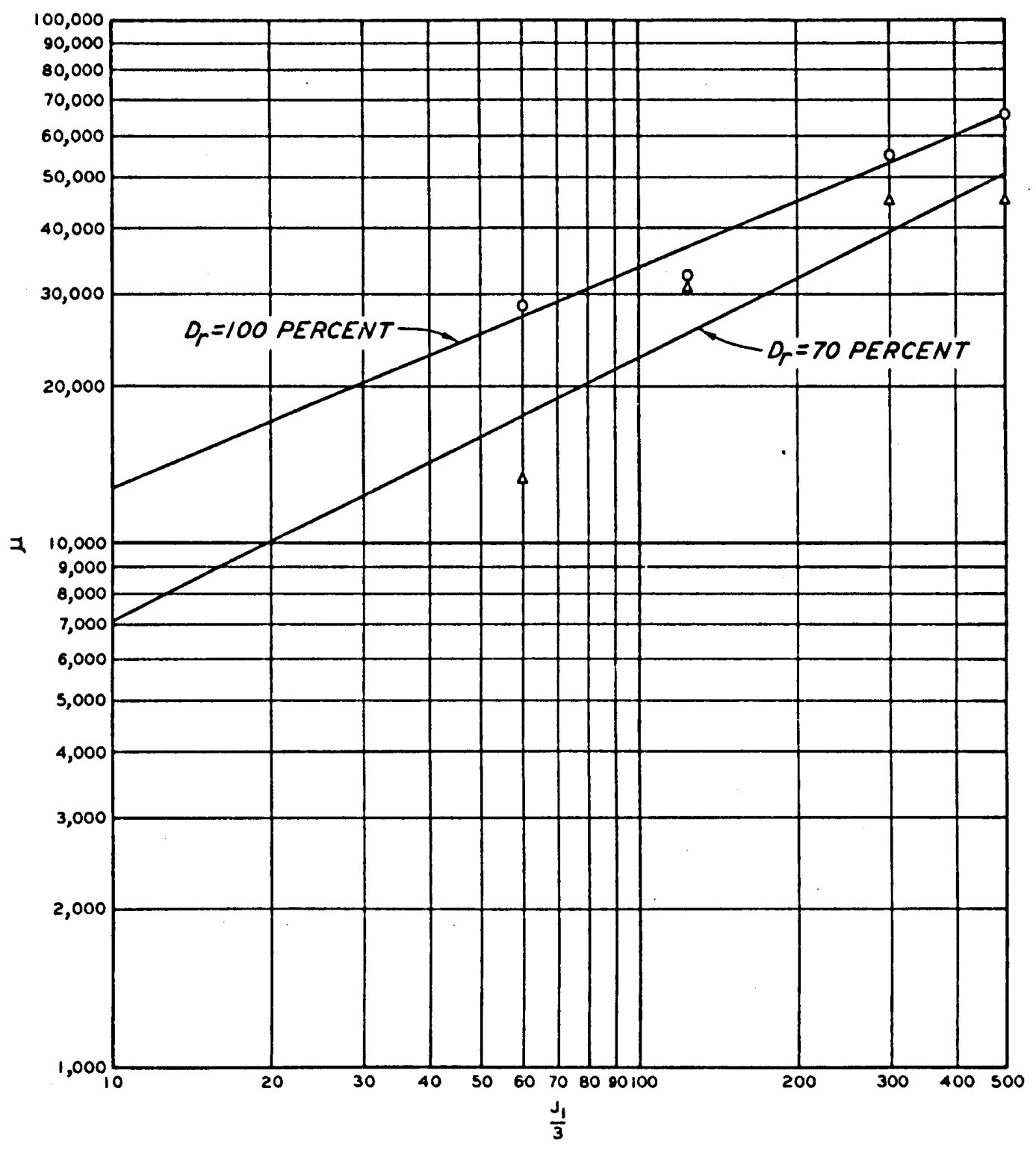

VARIATION OF $\mu$ WITH $\frac{J_{1}}{3}$ FOR PAINTED ROCK DAM MATERIAL UNDER TRIAXIAL COMPRESSION 


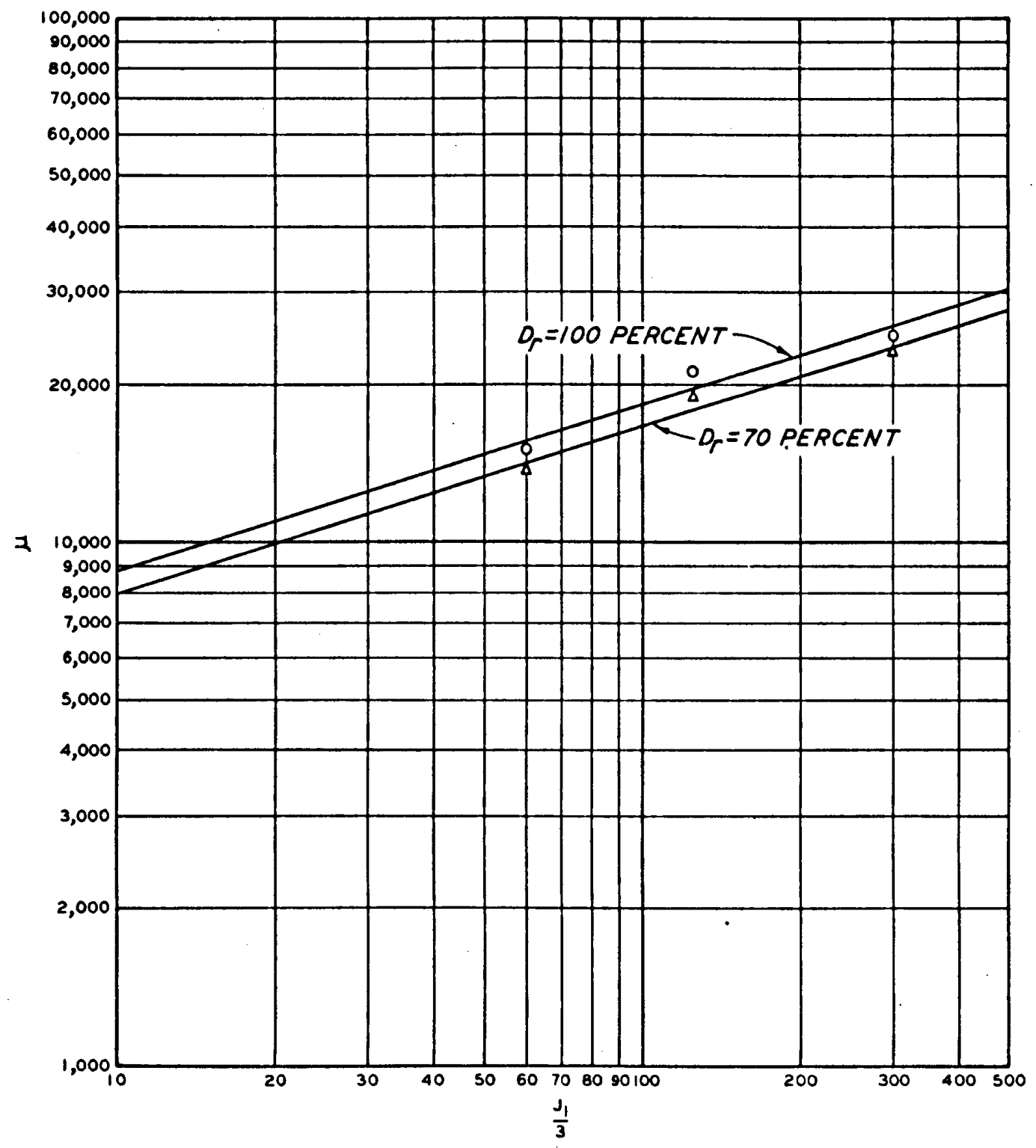

VARIATION OF $\mu$ WITH $\frac{J_{1}}{3}$ FOR PAINTED ROCK DAM MATERIAL UNDER PLANE STRAIN SHEAR 


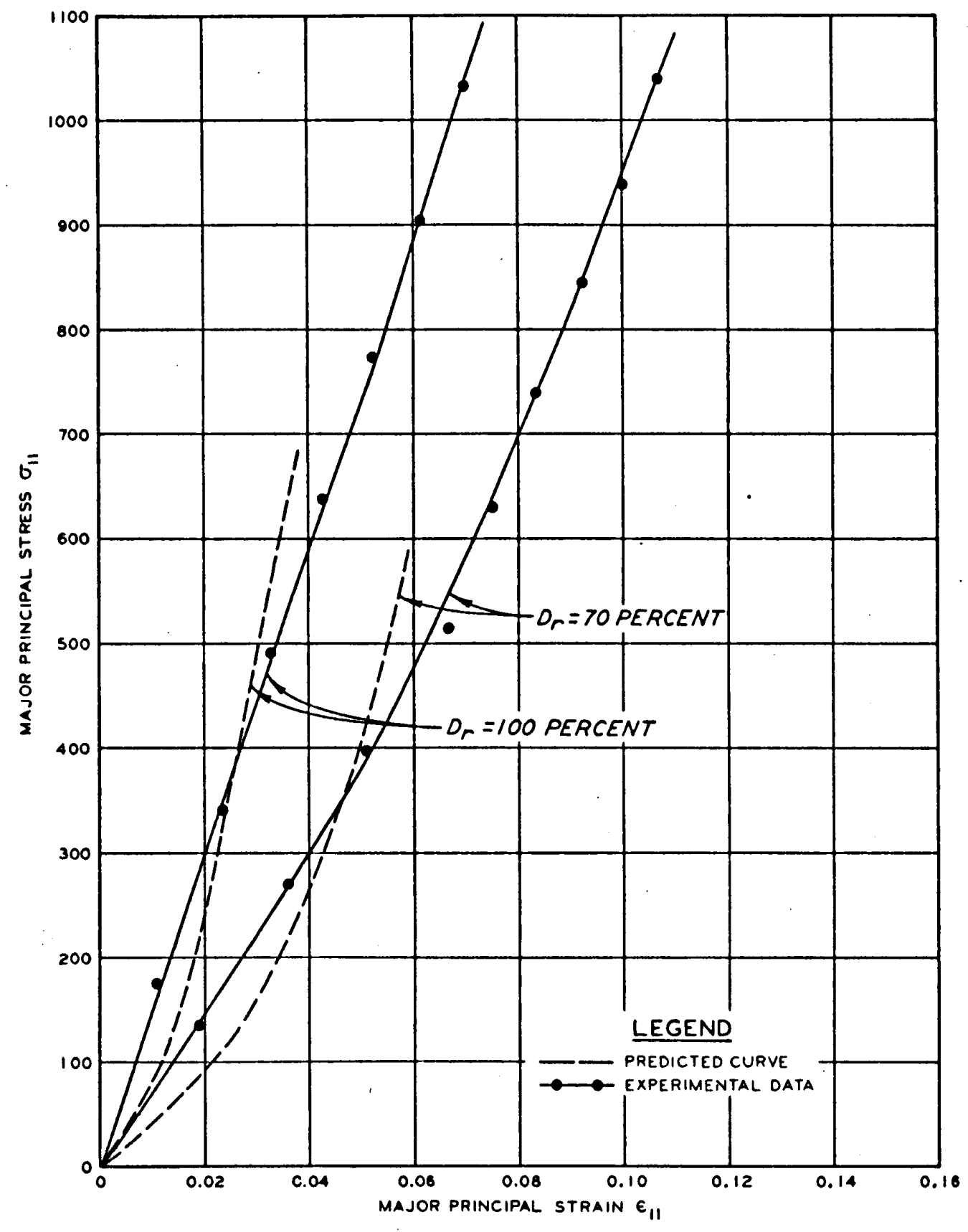

PREDICTED AND EXPERIMENTAL RESULTS FOR THE UNIAXIAL STATE OF STRESS FOR THE CRUSHED NAPA BASALT 


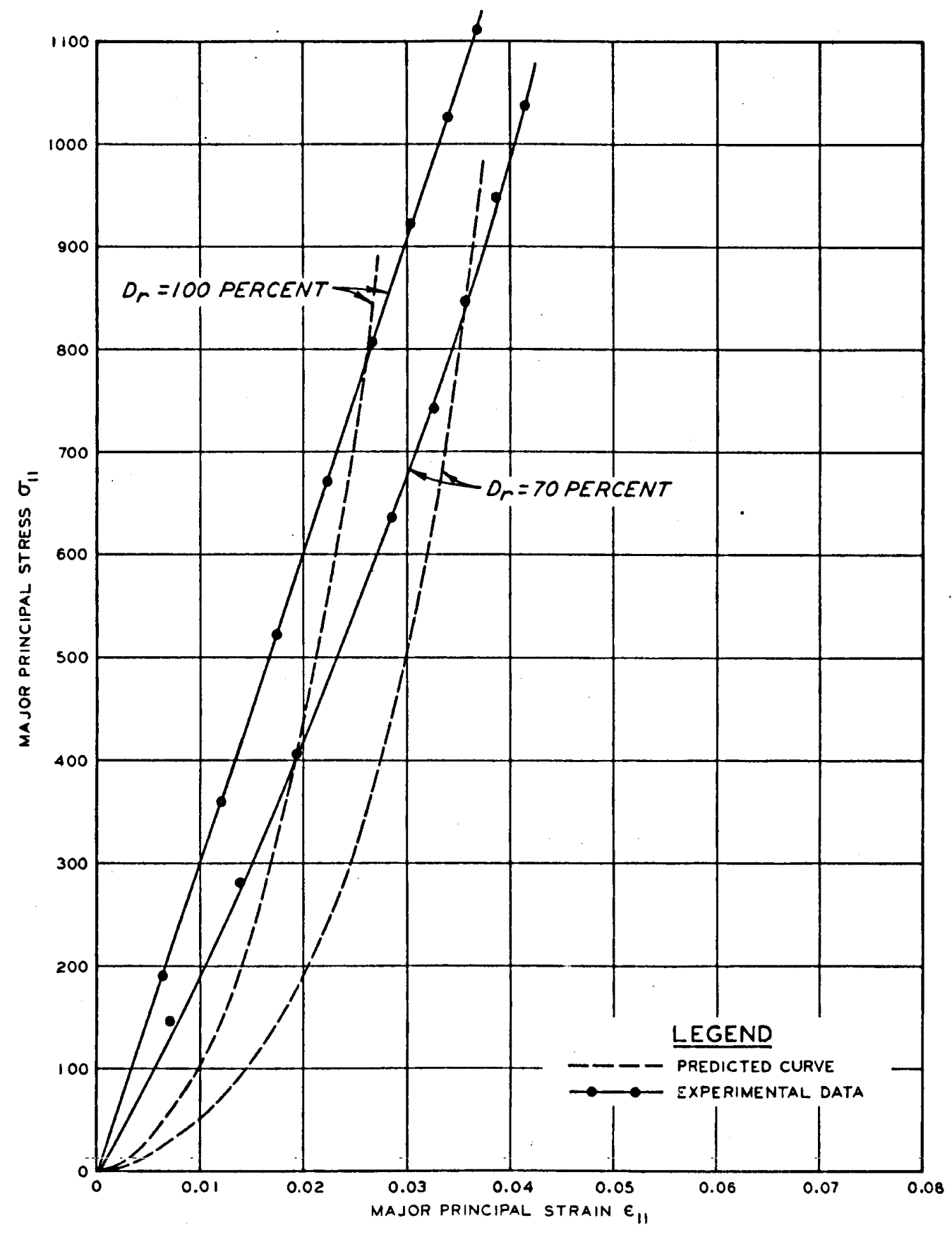

PREDICTED AND

EXPERIMENTAL RESULTS FOR THE UNIAXIAL STATE OF STRESS FOR THE PAINTED ROCK DAM MATERIAL 

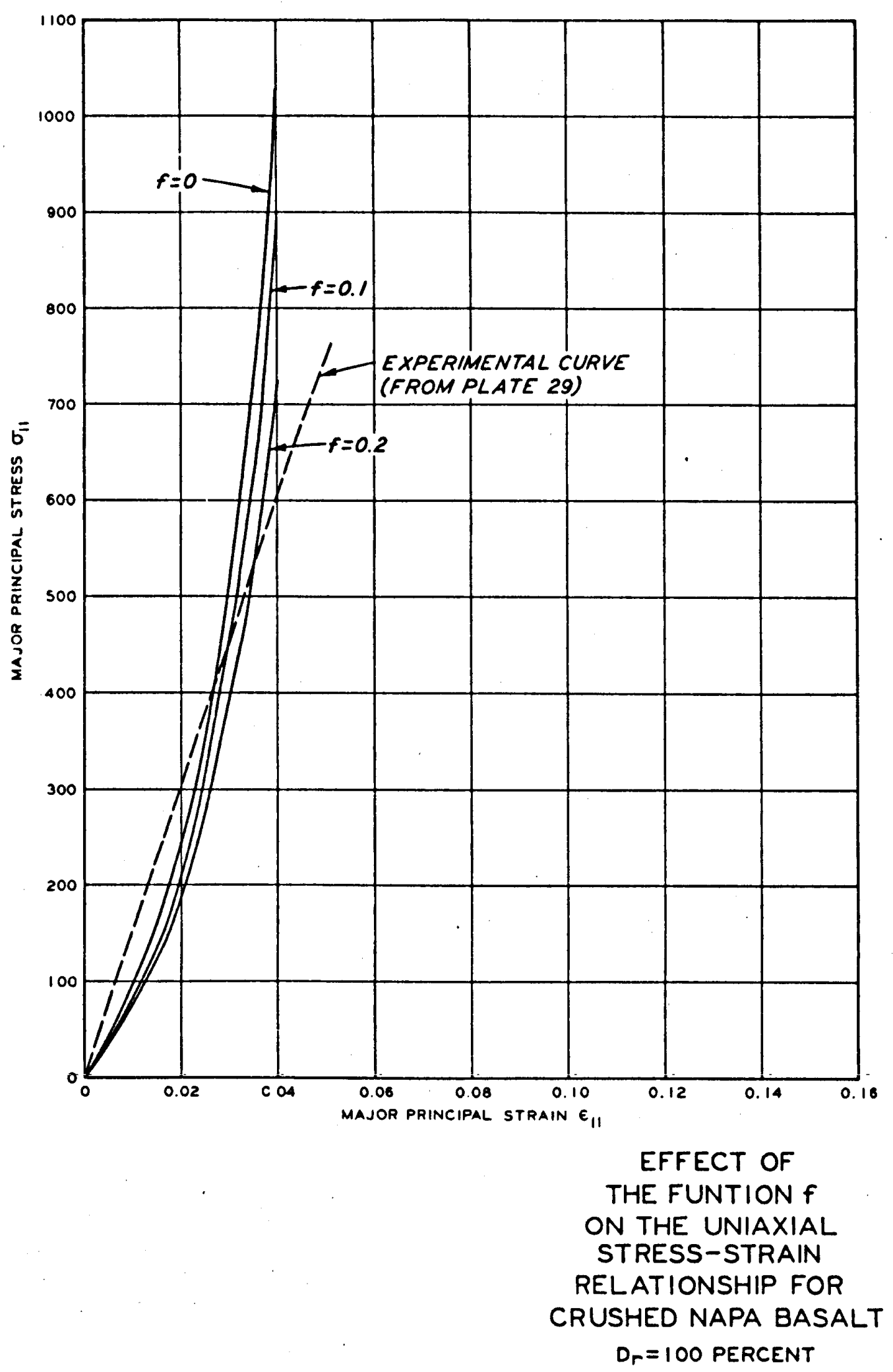


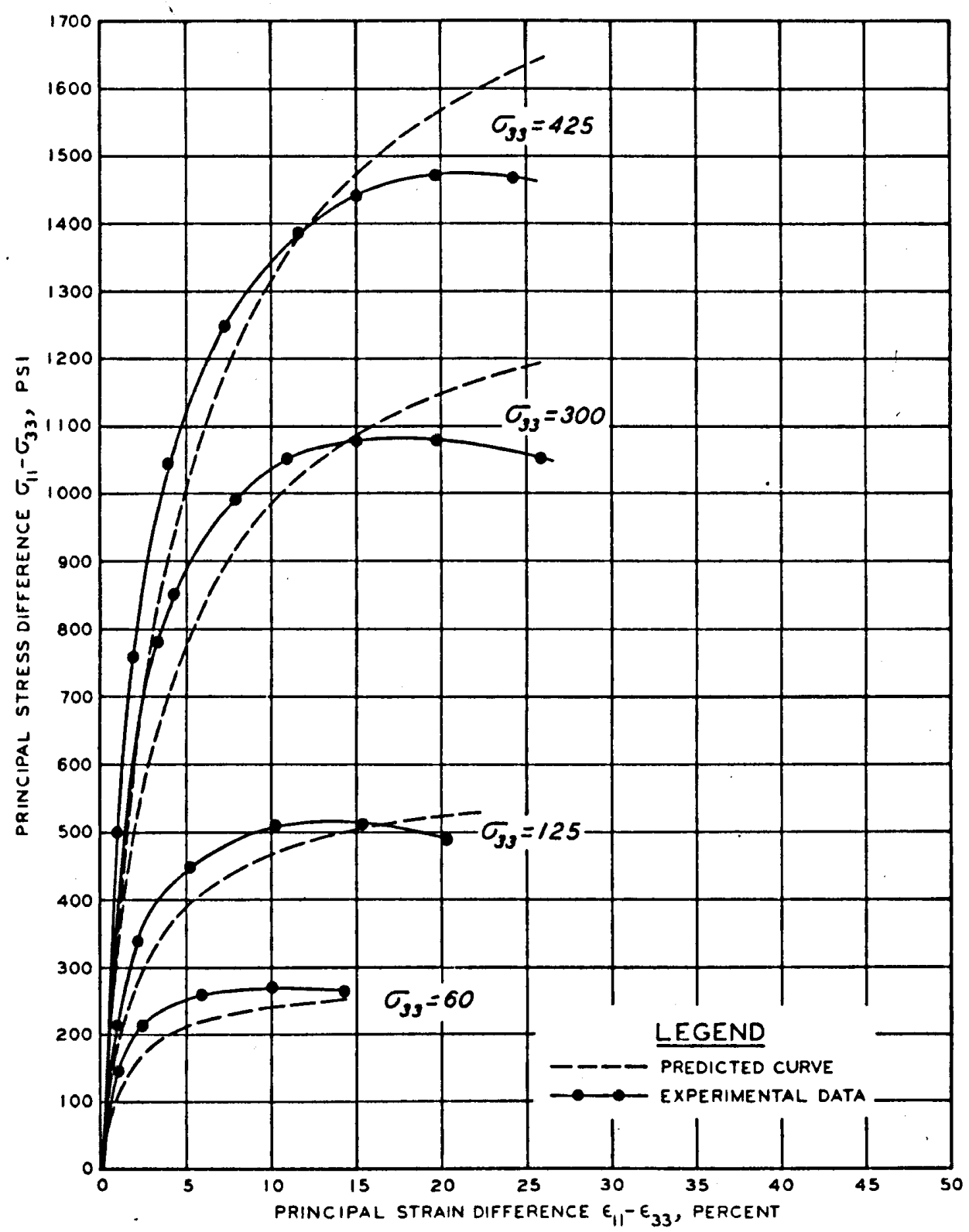

\section{PREDICTED AND OBSERVED STRESS-STRAIN \\ CURVES FOR PAINTED ROCK DAM MATERIAL UNDER TRIAXIAL COMPRESSION

$$
D_{r}=100 \text { PERCENT }
$$




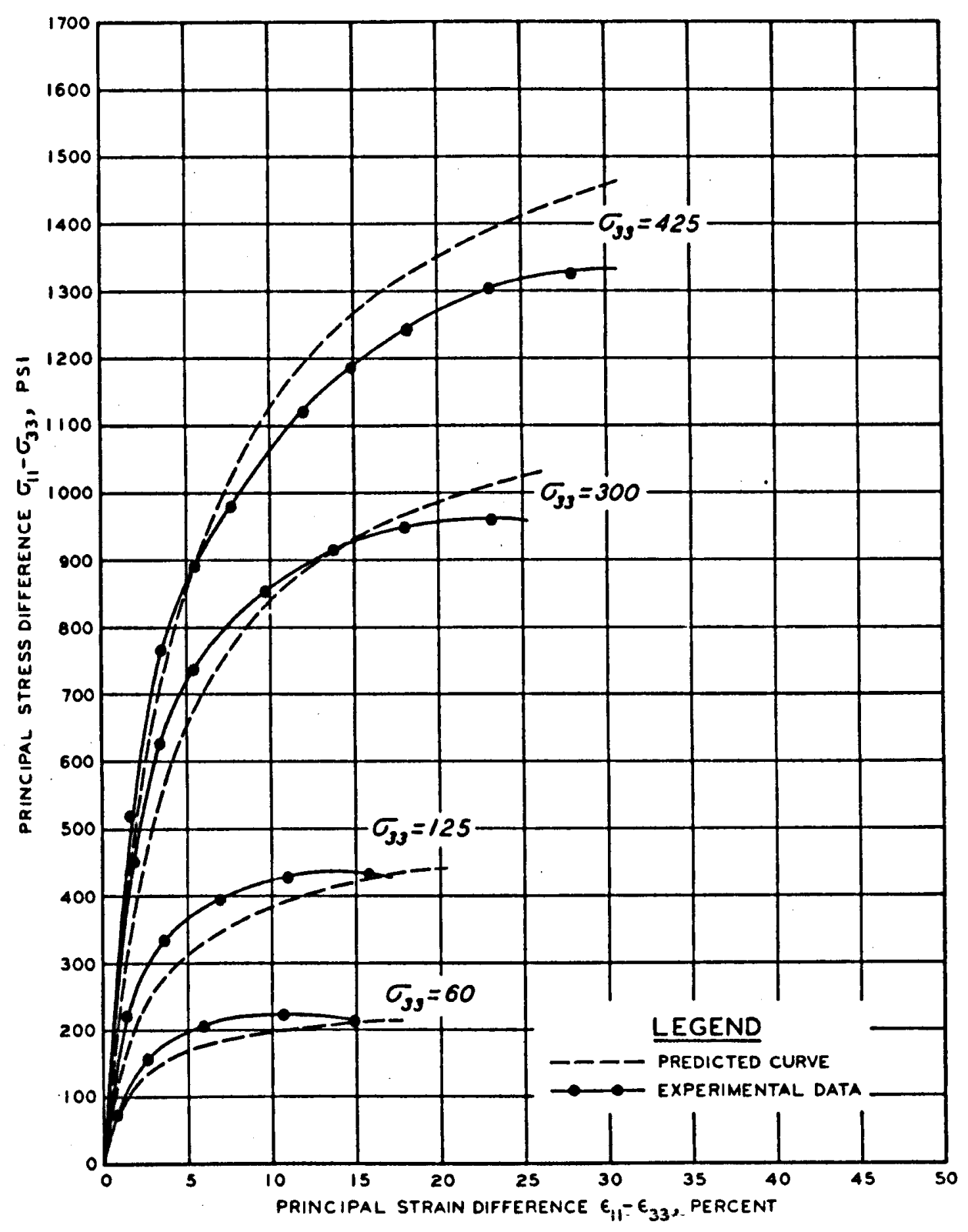

PREDICTED AND OBSERVED STRESS-STRAIN CURVES FOR PAINTED ROCK DAM MATERIAL UNDER TRIAXIAL COMPRESSION

$$
D_{r}=70 \text { PERCENT }
$$




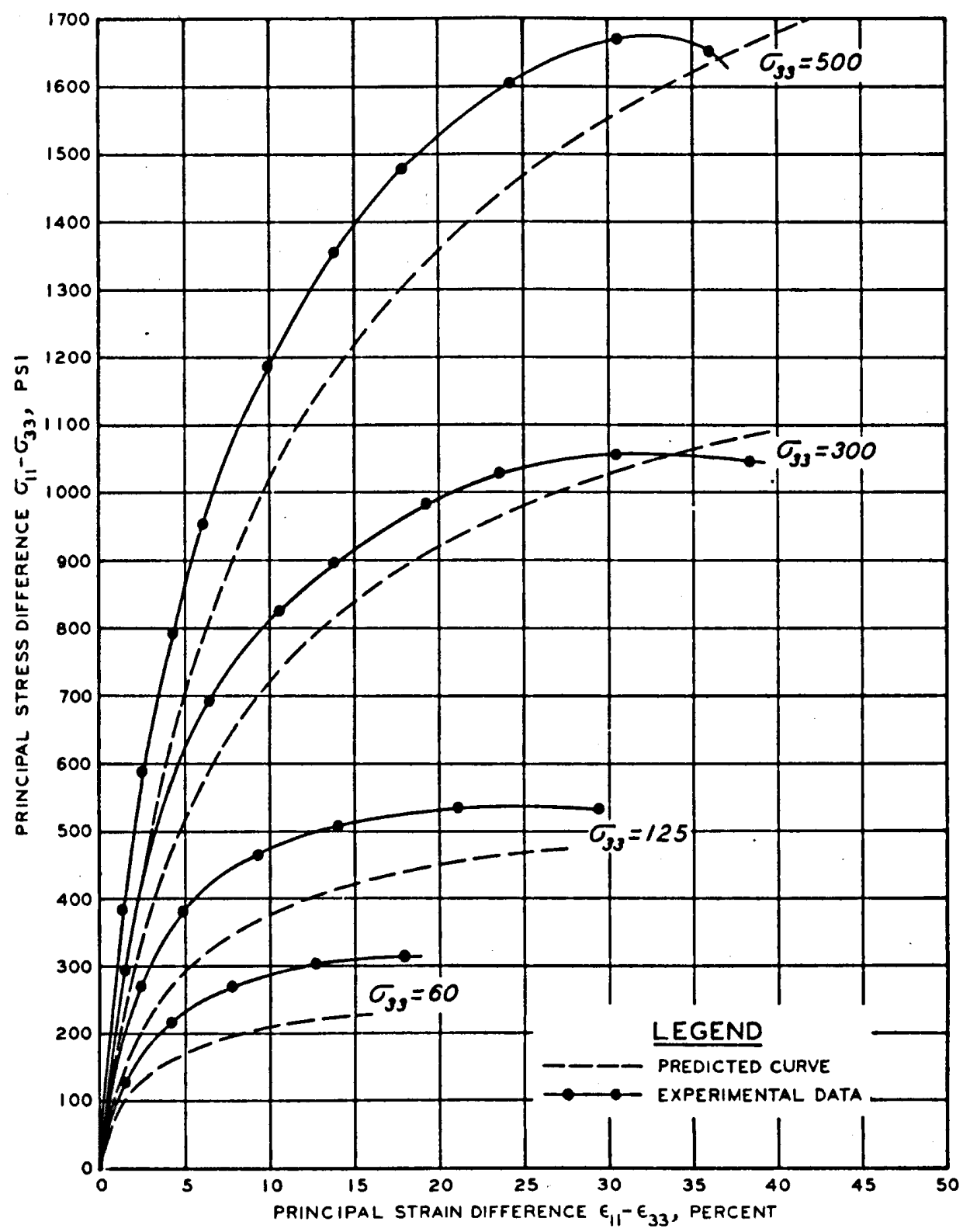

PREDICTED AND OBSERVED STRESS-STRAIN

CURVES FOR CRUSHED

NAPA BASALT UNDER

TRIAXIAL COMPRESSION

$$
D_{r}=100 \text { PERCENT }
$$




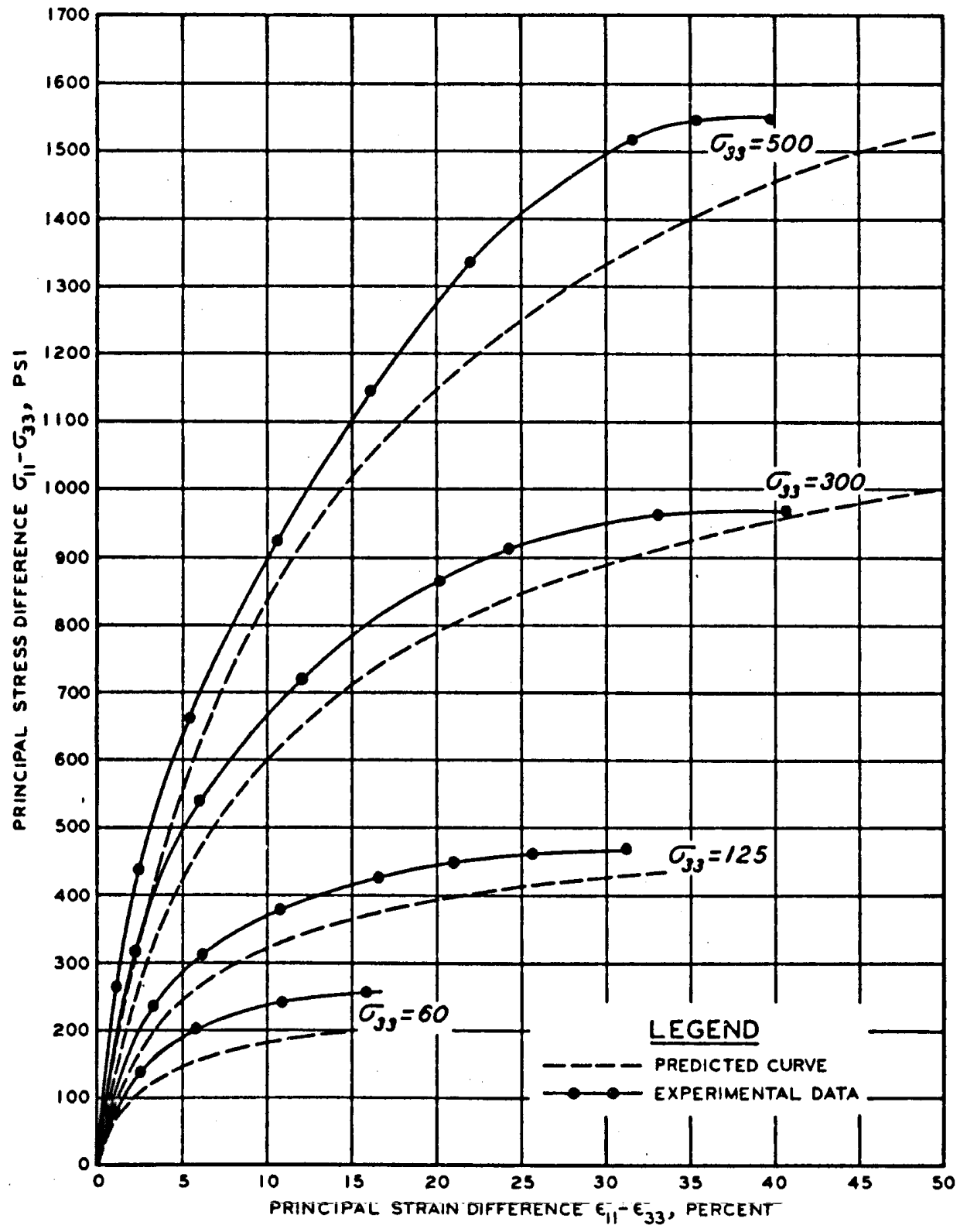

PREDICTED AND OBSERVED STRESS-STRAIN CURVES FOR CRUSHED NAPA BASALT UNDER TRIAXIAL COMPRESSION

$$
D_{r}=70 \text { PERCENT }
$$


Unclassified

DOCUMENT CONTROL DATA - R \& D

(Security clessiflcation of title, body of abstract and indexine annolation must be entered when the overall report le claseltled) 1. ORIGINATING ACTIVITV (Corporale suthor)

U. S. Army Engineer Waterways Experiment Station

Vicksburg, Mississippi

2a. REPORT SECURITY CLASSIFICATION

Unclassifled

3. REPORT TITLE

A SIMPLE ELASTIC CONSTITUTIVE EQUATION FOR GRANULAR MATERIAL

A. DESCRIPTIVE NOTES (TYPe of report and Inclualve datee)

Final report

5. AU THOR(S) (Firat name, middlo inltiel, last namo)

Mosaid M. Al-Hussaini

\begin{tabular}{|c|c|c|}
\hline $\begin{array}{l}\text { 6. REPORT DATE } \\
\text { Jure } 1974\end{array}$ & $\begin{array}{l}\text { 7a. TOTAL NO. OF PAGES } \\
100\end{array}$ & $\begin{array}{r}\text { 7b. NO. OF REFS } \\
45\end{array}$ \\
\hline $\begin{array}{l}\text { Q0. CONTRACT OA GRANT NO. } \\
\text { B. PROJECT NO. 4A061101A9ID }\end{array}$ & $\begin{array}{l}\text { Oa. ORIGINATOR'S REPORT } \\
\text { Miscellaneous Pape }\end{array}$ & $4-18$ \\
\hline $\begin{array}{l}\text { c. } \\
\text { d. }\end{array}$ & $\begin{array}{l}\text { OD. OTHER REPORT NO(S) } \\
\text { thie repORt) }\end{array}$ & her nuenbere that may be eeeloned \\
\hline
\end{tabular}

Approved for public release; distribution unlimited.

\begin{tabular}{|l|l}
\hline 11. SUPPLEMENTARY NOTES & $\begin{array}{l}\text { 12. SPONSORING MILITARY ACTIVITY } \\
\text { Assistant Secretary Of the Army (RED) } \\
\text { Washington, D. C. }\end{array}$
\end{tabular}

In the past or until recently the majority of stress-deformation and stability analyses have been restricted to ideal material behavior. Such idealizations in material properties and geometrical conditions may lead to divergence between observed and predicted behavior. Realistic stress and deformation analyses of homogeneous earth masses or soil-structure interaction problems using numerical techniques such as the finite element and finite difference methods require the formulation of a constitutive model for the soll and structural materials. A literature review made in this study indicated that most procedures used in modeling soils are based on the theory of elasticity and curve fitting. (This study is limited to constitutive models which are based on theory of elasticity.) Iinear, bilinear, trilinear, and hyperbollc models provide, under special conditions, good agreement between observed and predicted soil behavior. Unfortunately, these models lack sufficient experimental and theoretical verification to be qualified as constitutive models. A general constitutive model should predict or reproduce soll behavior under any state of stress and not be restricted to the state of stress from which it is derived. Constitutive models based on higher order elastic continuum are probably the only hope for generating truly representative material models. However, the procedure used in obtaining the needed parameters for such models is very difficult if not impossible unless some simplified assumptions are made. A nonlinear elastic constitutive relationship was developed for two granular materials: crushed Napa basalt and Painted Rock Dam-material. The behavior of the material was assumed to conform with Cauchy elastic material (i.e., the state of stress is only a function of the state of strain); also, the tensorial dilatancy, which contributes to volume expansion of the material, was ignored. Previous laboratory data obtained from hydrostatic compression, triaxial compression, and plane strain shear tests on both crushed Napa basalt and Painted Rock Dam material were used to obtain the needed parameters. The resulting constitutive model was used to predict the stress-strain relations for the uniaxial state of strain (1.e., $K_{0}$ tests), and the predicted curves were compared with laboratory $K_{0}$ data. The results showed that there is a qualitative agreement between the data predicted by the model and those observed in the laboratory. However, the quantitative agreement between the predicted and observed data needs to be improved. The proposed constitutive relationship accounts for nonlinear pressure-volumetric strain behavior, nonlinear shearing stress-strain behavior, and the effect of superimposed hydrostatic pressure on the behavior of soils. The constitutive relationship, however, does not account for shear-dilatancy phenomena often observed during laboratory testing of solls. Therefore, this constitutive model should not be expected to predict (Continued) $D D$, FORM 1473 REPLACES DD FORM 1473, I JAN 64, WHICH IS 


$$
\pi
$$

